Mittheilung aus der Berner chirurgischen Klinik.

(Director: Professor K ocher.)

\title{
Ueber die Enderfolge der operativen Behandlung bei Coxitis tuberculosa.
}

\author{
Von \\ Dr. Wilhelm Manninger, Budapest.
}

(Mit 'Tafel I-II.)

Wenn man die Richtung betrachtet, die die Therapie der tuberculösen Gelenkerkrankungen in den letzten 50 Jahren genommen, kommt man unwillkürlich zu dem Vergleiche zweier entgegengesetzter Wellenbewegungen. Von den 50er bis zu den 80er Jahren war die ultraoperative Therapie, wie man sie später nannte, die Resectionswuth im Schwunge, von da ab kam letztere so arg in Misscredit, dass die Reaction in das andere Extrem überschlug, und wir befinden uns jetzt auf der Spitze der conservativen Welle. Abgesehen von einigen Forschern, die auf dem Gebiete der Gelenktuberculose unser Wissen am meisten bereichert haben, und die auch heute eine vermittelnde Rolle einnehmen, - ich nenne u. a. nur König, Kocher, Krause - kann man die Therapie der Gelenktuberculose, wie sie heute an den meisten Kliniken geübt wird, eine rein conservativ-orthopädische nennen. Die Erfolge der conservativen Therapie haben sich unstreitig gebessert, besonders was die functionellen Erfolge betrifft. Die Hilfsmittel derselben haben sich mit der Zeit bereichert. Man hat gelernt, durch entsprechende Maassnahmen die Gelenke in einer für die Function günstigen Stellung zu immobilisiren und vom Druck zu entlasten. Injectionen von Jodoform, Carbol, Formalin, Camphernaphtol, Zimmtsäure (wohl die verbreitetsten 'der in Legion empfohlenen Mitteln) sollen den localen tuberculösen Process beeinflussen; man hat, um den localen Helungsprocess nachzuahmen, zum Chlorzink gegriffen (Lannelonge's Méthode sclérogène). Zu diesen Maassnahmen kommt noch die von Bier empfohlene Stauungsbe- 
handlung als Adjuvans hinzu. Zweifellos gelingt es in vielen Fällen, durch systematiseh fortgesetzte conservative Therapie, dem Fortschreiten des Localleidens Einhalt zu bieten.

Das Hauptargument der Verfechter der ultraconservativen Therapie ist die vergleichende Statistik. Nun sind aber bei dem Aufstellen derselben eine ganze Reihe von Fehlerquellen ausser Acht gelassen worden, auf die hinzuweisen ich in den folgenden Zeilen bestrebt bin. Es ist dies erstens der Umstand, dass das Material, welches zur Resection kommt, ein ungleich schwereres und ungünstigeres ist, als das mit conservativen Methoden behandelte. Dieses Argument fällt weg, wenn man gleichwerthiges Material - nur conservativ behandeltes und nur operativ behandeltes - zum Vergleich heranziehen könnte. Es giebt aber keine solchen Statistiken.

Zweitens werden immer noch die Operationsstatistiken der septischen Aera zum Vergleiche verwendet. Liest man die erschreckend hohen Mortalitätsziffern derselben, so scheint der Kampf, den der Conservatismus gegen die operative Therapie geführt, leicht begründet. Ich werde versuchen, bei dem Zusammenstellen der Enderfolge den Fortschritt, den die aseptische Aera gezeitigt, gegenüber den früheren Ergebnissen festzustellen.

Ein drittes Moment liegt in der Schwierigkeit, vollständige Statistiken, dic auf grösseres Material gegründet sind, aufzubringen. Von den neueren Statistiken weist besonders Wagner auf diesen Umstand hin; in den Statistiken von Billroth, Rosmanit und Thausing ist in 19,25 und $30 \%$ der Fälle die Erkrankung nicht abgelaufen, bei Caumont $9 \%$, Albrecht $6 \%$, Schmidt $42 \%$, Huisman's $19 \%$. In der ausgezeichneten Arbeit II enle's konnte von 52 Coxitiskranken nur von 37 ein Endresultat aufgebracht werden, also kein Endresultat in 28,8\% der Erkrankten. Von allen Gelenktuberculosen zeigt sich dieser Umstand am prägnantesten bei den Coxitikern; es ist schwer, bei einer Krankheit, die nach Bruns' und Wagner's sehr ausgedehnten Untersuchungen $3^{1 / 2-4,7}$ Jahre bis zum Ablaufe dauert, von allen Kranken Nachricht zu bekommen, geschweige sie nachuntersuchen zu können.

Zum Schlusse kommt noch ein Umstand hinzu, der gegen den Werth der Statistiken überhaupt schwer in die Wage fällt, die Verschiedenheit des Krankenmaterials. Ich meine besonders die socialen und hygienischen Verhältnisse, in welchen die Kranken leben. Wie lassen sich anders die Mortalitätsziffern denten, die die Zahlenreibe von 0 Mortalität (Mesnard), $5 \%$ (Lorenz) und 40\% der Brunsschen Statistik aufweist? 
Ueber die Enderfolge der operativen Behandlung bei Coxitis tuberculosa. 3

Die Resectionsstatistiken sind in den letzten 10 Jahren recht spärlich geworden. Es giebt immerhin eine enorme Fülle casuistischen Materials, das aber für die Frage belanglos ist. Wir besitzen eine ausgezeichnete Bearbeitung der Frage für das Kniegelenk (König), die anderen Gelenke, besonders die Hüfte, wurden sebr stiefmütterlich behandelt ${ }^{1}$ ). Mein Plan war, das in dieser Beziehung sebr reichhaltige Material der Berner Klinik in dieser Richtung zu bearbeiten, und zwar indem ich meine statistischen Untersuchungen auf die 6 grossen Gelenke des Körpers ausdehnte. Leider musste ich von diesem Plane abkommen, da ein grosser Theil der Krankengeschichten bis in die letzten Jahre in Dissertationen verarbeitet war.

Ich musste mich also auf das Hüftgelenk beschränken. Das Hüftgelenk ist insofern am werthvollsten, weil es als das grösste Gelenk des Körpers, einen Prüfstein für die Erfolge der operativen Therapie bietet. Die eventuellen Nachtheile einer operativen Therapie zeigen sich hier am prägnantesten.

Das Material der Berner Klinik ist in vieler Beziehung werthvoll und ist besonders zu Nachuntersuchungen günstig. Erstens durch die einheitliche Bearbeitung der Krankengeschichten, die Professor K ocher seit dem Jahre 1872 immer selbst controlirt und zum grossen Theil selbst dictirt hat; besonders werthvoll sind die, meist eigenhändig geschriebenen Befunde der pathologischen Veränderungen am Gelenk. Zweitens entspricht das Material ganz besonders den von Bruns postulirten Bedingungen, dass man nämlich - mit ganz vereinzelten Ausnahmen - genauen Bescheid über den weiteren Verlauf der operirten Fälle bekommen kann. Die Kranken der Klinik stammen fast ausnahmslos aus der Schweiz und sind ziemlich sässig; man bekommt meist Bescheid über den genauen Wohnort. Ich sandte Fragebogen an die operirten Kranken (1. Allgemeinbefinden? 2. Hustet der Patient? Schwitzt er bei Nacht stark? Hat er viel Auswurf?

1) Sach Niederschrift meiner Arbeit erschien als zweites Heft der, Speciellen Tuberculose der Knochen und Gelenke ${ }^{u}$ die Arbeit König's über das Hüftgelenk. Ich kann leider auf diese vorzügliche Bearbeitung nicht näher eingehen, da ich den ganzen statistischen Theil meiner Arbeit ganz nmarbeiten müsste. König's Statistik bezieht sich auf 758 Fälle von Hüftgelenkserkrankungen, darunter 568 Fälle von Coxitis tuberculosa. Von diesen Fällen wurden 274 , also ca. die Hälfte, der Resection unterworfen. Es gereicht mir zur grossen Freude, dass K önig auf Grund dieses grossen, ausgezeichneten Nlaterials zu ähnlichen Resultaten und Schlussfolgerungen gelangt, wie ich dies an den Fällen der Kocherschen Klinik gefunden habe. Auf Einzelheiten der Arbeit kann ich bei der verschiedenartigen Bearbeitung und der differenten Fragestellung leider nicht eingehen. 
3. Kann der Patient das kranke Bein nach allen Richtungen bewegen? 4. Kann der Patient ohne Lnterstützung gehen?' 5. Oder muss er Krücken, Stock, Apparat zu Hilfe nehmen? 6. Hinkt er beim Gehen? 7. Wie lange kann Patient ohne Ermüdung oder Schmerzen gehen? 8. Kann Patient seiner Beschäftigung nachkommen? 9. Ist der kranke Fuss oder Hüfte schmerzhaft? 10. Sind eiternde Fisteln vorhanden? 11. Besondere Notizen). Ausserdem forderte ich sie auf, zur Nachuntersuchung nach Bern zu kommen. Letzterer Bitte kamen nur wenige nach. Ich musste also einen Theil der Kranken zu Hause aufsuchen, was bei den nicht zu entfernt wohnenden Kranken ohne grossen Zeitverlust möglich war. Die Fragebogen wurden zum Theil von den Kranken, zum Theil von den Hausärzten ausgefüllt, und ich konnte mich aus den Nachuntersuchungen von der Verlässlichkeit der Antworten überzeugen. Nur über einen Punkt giebt diese Art der Erkundigung ungenügend Auskunft. Es ist dies Punkt 3. Die Beurtbeilung der Beweglichkeit in der Hüfte ist dem Kranken ganz unmöglich. Auch verzichtete ich über Verkürzung nảchzufragen, weil diese Angaben unzuverlässig sind.

Die Arbeit ist hauptsächlich auf Constatirung der Endresultate bei operativer Therapie abgesehen. Doch glaubte ich mich nicht nur auf diesen Punkt beschränken zu dürfen; ich verarbeitete das Material auch von anderen, statistisch wichtigeren Gesichtspunkten, obwohl ich mir wohl bewusst bin, dass das Material viel zu klein ist, um auch nur einigermaassen auf Allgemeingültigkeit Anspruch zu machen; ist doch die Statistik die Wissenschaft der grossen Zahl. Um einigermaassen grösseres Material aufzubieten, habe ich das Material zweier aus der Berner Klinik erschienenen Dissertationen mitverarbeitet. Ich habe auch an die Kranken jener Statistiken, soweit sie auffindbar waren, dieselben Fragebogen versandt und werde die entsprechenden Daten bei Besprechung der Enderfolge mittheilen. Das Miteinbezieben dieser Dissertationen scbien mir auch darum gerathen, weil die daselbst gefundenen Ergebnisse in keiner mir bekannten Arbeit über Coxitistherapie angeführt, und weil die zweite derselben, die Arbeit von Guinand, die 40 Fälle von Resectionen betriff, aus der aseptischen Zeit stammt, somit die Resultate mit den meinigen zusammen verwerthet werden können.

Mein Material bezieht sich auf 44 Fälle tuberculöser Coxitis. Die Diagnose ist aus den klinischen Symptomen und dem anatomischen Befunde bei der Operation gestellt. Bakteriologisch sichergestellt sind nur einige Fälle. Doch dürfte an der ätiologischen Sicherstellung der tuberculösen Natur kein Zweifel bestehen, sind doch alle Fäll 
Ueber die Enderfolge der operativen Behandlung bei Coxitis tuberculosa. $\mathbf{5}$

von Professor Kocher als tuberculöse Coxitis nach dem pathologisch-anatomischen Befunde bezeichnet.

Dazu kommen von 54 Fällen der Zehnder'schen Statistik 23 Resectionen und 40 Resectionen aus der ( $x$ u in and'schen Dissertation, zusammen 107 Resectionsfälle. Ich habe die Ergebnisse aus den Tabellen der genannten Dissertationen einheitlich den meinigen umgerechnet, um einen leichteren Ueberblick zu gestatten. Die Zahlen stimmen also nicht überall mit den Originalarbeiten, da sie von zum Theil anderen Gesichtspunkten gruppirt sind. - Wo ich mich auf die oben erwähnten Arbeiten berufe, will ich der Kürze wegen die Zehnder'schen Daten mit I, die Guinand'schen mit II, meine mit III bezeichnen. Ebenso will ich schon hier bemerken, dass die Zahlen aus der Literatur nach einheitlicliem Princip umgerechnet, überall in Procenten ausgedrückt sind, da nur so ein unmittelbarer Vergleich müglich ist.

\section{Allgemein statistische Data.}

A. Alter.

Alterstabelle.

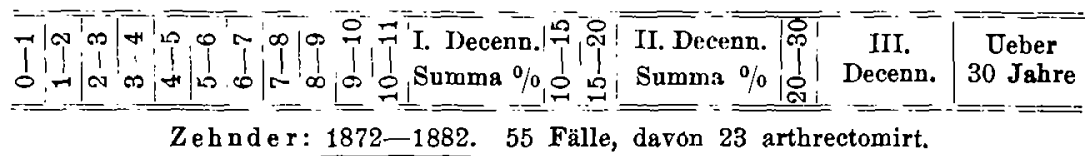
$2|1| 3|4| 6|2| 4|4| 6|2| 2|36-65.4| 7|7| 14=25.4 \%|3| 3=5.5 \% \mid 2=3.7 \%$ Guinand: $1881-1889.40$ Fälle.

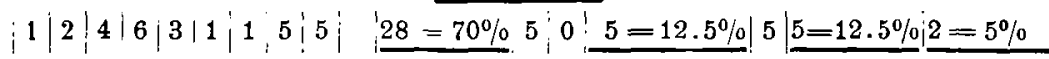
1887-1900. 44 Fälle, davon fehlt bei 7 das Alter; bleibt 37.

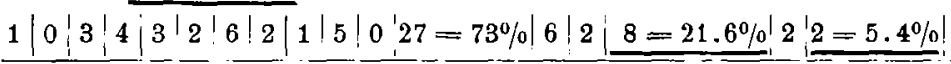
Sämmtliche Fälle I. Dec. 69.4\%. II. Dec. 19.83\%. III. Dec. $7.8 \%$. Ueber 30 Jahre $2.9 \%$.

7 Fälle keine $\Lambda$ ngabe, wann die Krankheit begonnen.

Die 132 Fälle vertheilen sich, wenn man die procentuarischen Berechnungen für jedes Decennium betrachtet, so, dass auf das 1. Decennium 69,4 Proc. (I.65,4 Proc., II. 70 Proc., III. 73 Proc.) "2. $" 19,83$ " (I.25,4 " II. 12,5 " III. 21,6 ") , 3. $\quad 7,8$ (I. 5,5 " II. 12,5 " III. 5,4 ") nach dem 3. Dec. 3,0 , entfallen.

Nach unserem statistischen Material tritt also die Erkrankung in 89,23 Proc. vor dem 20. Lebensjahre auf. 
Betrachten wir nun die Ergebnisse, die andere Statistiken in Bezug auf das Alter ergeben, so bekommen wir folgende Zusammenstellung:

\begin{tabular}{|c|c|c|c|c|}
\hline & I. Dec. & II. Dec. & Unter 20 Jahren & Ueber 20 Jahren \\
\hline Albrecht & 46 & 43,7 & 89,7 & 16,3 \\
\hline Bähr & 74,4 & 23,3 & 97,6 & 2,3 \\
\hline Haas & 49 & 35,5 & 84,5 & 15,4 \\
\hline Marsch & 62 & 27 & 90 & 10 \\
\hline Bruns-Wagner & 48,57 & 37,71 & 85,28 & 13,42 \\
\hline Im Durchschnitt & 55,99 & 33,71 & 89,6 Proc. & 10,4 Pro \\
\hline
\end{tabular}

Die Statistiken der Kinderspitäler sind nicht miteingerechnet. Durch dieselben dürfte sich die Erkrankungsziffer nach dem 20. Lebensjahre noch verringern.

B. Geschlecht.

$\begin{array}{lcccl} & \text { Männlich } & \text { Proc. } & \text { Weiblich } & \text { Proc. } \\ \text { I. } & \mathbf{3 3} & 61,2 & \mathbf{2 1} & \mathbf{3 8 , 8} \\ \text { II. } & 20 & 50 & 20 & 50 \\ \text { III. } & 27 & 61,5 & 17 & 38,5 \\ \text { Im Durchschnitt } & 80 & 58 & 58 & 42\end{array}$

Alfer fand in seiner sehr ausführlichen Statistik das männliche Geschlecht mit 60 Proc., Bruns mit 60,3 Proc. vertreten. Wagner stellt aus der Literatur 60,5 Proc. für das männliche Geschlecht fest.

\begin{tabular}{|c|c|c|c|c|}
\hline \multicolumn{5}{|c|}{ C. Seite. } \\
\hline & I & II & III & Im Durchschnitt \\
\hline Link & 56,37 & 45 & 63,2 & 45,14 Proc. \\
\hline Rechts & 43,63 & 55 & 36,8 & 54,86 \\
\hline
\end{tabular}

D. Gelegenheitsursachen.

Von diesen werden hauptsächlich drei als wichtig in allen Arbeiten angeführt, Heredität, Trauma und Infectionskrankheiten.

a) Heredität:

I. 14,8 Proc. II. 27,5 Proc. III. 38,6 Proc.

Wagner fand 40 Proc. hereditär belastet, Haas 26 Proc., Bähr 31 Proc.

Die Zahlen, die die Statistik aufweist, sind also sehr schwankend. Dies hängt zum Theil nebst dem Zufall, der bei so kleinen Zahlen (ca. 500 Fälle im Ganzen) mitspielt, von der Genauigkeit der Nachforschung, zum Theil davon ab, wie weit man den Begriff Heredität ausdehnt. Man sieht, dass in Serie III die Zahl auf mehr als das 
Ueber die Enderfolge der operativen Behandlung bei Coxitistubereulosa. 7

Doppelte gegenüber der Serie I angewachsen ist, wohl auf Grund exacter aufgenommener Anamnese.

b) Trauma.

I. 21,43 Proc. II. 14,5 Proc. III. 29,5 Proc.

Das ist im Durchschnitt bei 21,8 Proc. der Fälle nachgewiesen. Aus der Literatur fand ich nur bei $\mathrm{H}$ aas und $B$ ähr Daten, 22 resp. 40 Proc.

c) Infectionskrankheiten

waren in den ersten zwei Dissertationen nicht berücksichtigt. An meinem Material fand ich sie in 16 Proc. der Fälle notirt und zwar Masern in 11,35 Proc., dann je einen Fall von Scarlatina und Rötheln (2,27 Proc.). Fall 5, der nach Scarlatina auftrat, ist der einzige Fall, der ätiologisch nicht ganz klar ist. Der pathologisch-anatomische Befund sprach für Tuberculose.

E. Symptome.

1. Sebmerz.

Im Anfangsstadium der Krankheit finden wir in 13 Fällen der Serie III (d. i. 29 Proc.) Schmerzen im Knie vermerkt.

Ich versuchte aus den sehr genau geführten Krankengeschichten, mit Vergleich des anatomischen Befundes eine Relation zwischen der Localisation des Schmerzes und dem Charakter des Leidens (Knochenprocess) herauszufinden. Spontane Schmerzhaftigkeit scheint nach den Fällen bei der synovialen Form ebenso häufig zu sein, als bei der ossalen. Bei letzterer ist einige Mal ein acuter Schmerzanfall, auch mit Schüttelfrost, vermerkt. Es dürfte dies wohl mit dem Durchbruch des Knochenherdes in's Gelenk zusammenfallen.

Bei Pfannenerkrankung ist meist Stossschmerz (Schlag in der Richtung der Femurachse) mit Pressschmerz (Druck in der Richtung des Halses, am Trochanter major) zusammen angegeben, während bei primärer Erkrankung des Kopfes Stossschmerz fehlt und meist exquisiter Pressschmerz verzeichnet ist.

2. Schwellung.

Abgesehen von der durch paraarticuläre $\Lambda$ bscesse bedingten Schwellung finden wir circumscripte Anschwellung, besonders vorn an der Halsgegend und hinter dem Trochanter major in 26 Fällen (von 44) verzeichnet, davon 17 bei Kapselerkrankung, 9 bei primären Knochenherden. Bei 6 Fällen von primären Knochenherden ist das Fehlen der Schwellung ausdrücklich erwälınt. 
3. Contracturstellung.

Flexion, Abduction Flexion, Adduction Fl., Abd. od. Add. mit $\begin{array}{lll}\text { Aus. Rotation } & \text { E. R. } & \text { E. u. A } R \text { gemischt }\end{array}$

I. Zahl der Fälle $11=4 \overline{7}$ Proc. $6=26$ Proc. $6=26$ Proc.

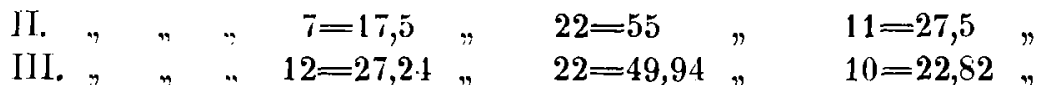

Bei sämmtlichen Kranken war eine mehr oder weniger ausgeprägte Flexionscontractur nachweisbar. Ich habe die Dauer der Erkrankung mit den Contracturformen, welche das kranke Bein angenommen, verglichen und bin zu dem Ergebniss gekommen, dass die Hüter'sche Eintheilung der 3 Stadien mit ziemlicher Regelmässigkeit zu constatiren ist, sofern man sich nur an das Symptom der Abduction und Adduction hält; die Rotationsstellung ist oft abweichend (s. 3. Columne unter "Gemischt").

Bei allen Fällen mit Abduction war die Dauer der Erkrankung weniger als ein Jahr (Ausnahme Fall 6). Bei den Fällen mit Adduction bestand die Krankheit länger als ein Jahr (Ausnahme Fall 5; der einzige nicht ganz einwandsfreie Fall in puncto Aetiologie s. Bemerkung bei "Gelegenheitsursachen" c.).

Es kommen natürlich Ausnahmen vor; besonders ist hier die consequent durchgeführte orthopädische Behandlung zu nennen, der es gelingt, das Eintreten der functionell so lästigen Adductionscontractur vorzubengen. Die Fälle waren, mit Ausnahme eines Falles, bei welchem Gypsverbände gemacht wurden, alle mittelst Extension behandelt, die vor Aufnahme in die Klinik meist für längere Zeit weggelassen wurde und so das Ausbilden der Adductionscontractur bei den älteren Fällen ermöglichte. Bei nichtbehandelten Fällen kann man aber aus der Contracturstellung mit ziemlicher Sicherheit auf die Dauer des Leidens schliessen; die Grenze zwischen den zwei Stadien wăre nach unseren Fällen ein Jahr. Wo die Erkrankung gleich mit Adductionsstellung einsetzt, soll nach König der Schluss auf schwere Ostalerkrankung gerechtfertigt sein.

Function.

In 35 Făllen der Serie III finden sich detaillirte Angaben über die Functionseinschränkung. Dieselben sind so vielgestaltig, dass eine statistische Berechnung keinen Zweck hat.

Ich will nur kurz auf eine Beobachtung hinweisen. Das Becken war in 20 Fâllen ganz fixirt, bei Untersuchung ohne Narkose. In Narkose geprüft konnte man nur bei jenen Fällen Beweglichkeit nachweisen, bei welchen primäre Synovialtuberculose rorlag. Die ostalen 
Ueber die Enderfolge der operativen Behandlung bei Coxitistuberculosa. 9

Falle zeigten selbst in Narkose keine oder nur minimale Beweglichkeit. Die Erklärung dieser Beobachtung liegt wohl darin, dass bei den Formen ostalen Ursprungs frühzeitig ausgedehnte Schrumpfungsprocesse der Kapsel sich einstellten. Ein Analogon wăre in der sog. Caries sicca des Schultergelenkes zu finden. Dieses Symptom ist in keinem Zusammenhang mit dem Alter der Erkrankung; auch war keine Secundärluxation nachzuweisen, für die König auf ähnliche Verhältnisse hinwies. Ob nicht der Zufall bei diesen - auf spärliche Fălle sich beziehenden Beobachtungen - eine Rolle spielt, oder ob man das Symptom zur Diagnose der primăren Knochenerkrankung heranziehen darf, müssen weitere Beobachtungen lehren. Die Zahl der Narkosenuntersuchungen ist zu gering, um das Spiel des Zufalles auszuschliessen.

Gang in allen Fällen hinkend. Reelle Verkürzung meist mit Hochstand des Trochanters, ist in 13 Fällen vermerkt. Die Verkïrzung betrug im Durchschnitt $2,9 \mathrm{~cm}$; das Maximum $7 \mathrm{~cm}$.

Anderweitige tuberculöse Organerkrankungen.

An der Lunge liessen sich in 3 Fällen Symptome von Tuberculose nachweisen: Dammpfung mit entsprechenden auscultatorischen Erscheinungen (Fall 17, 33, 42).

Drüsenschwellung ist. in 24 Fällen angegeben und zwar Drüsen in der Leiste $11 \mathrm{mal}$, Iliacaldrüsen $7 \mathrm{mal}$ und Halsdrüsen $6 \mathrm{mal}$.

Im Urin war bei keinem der Fälle Eiweiss nachweisbar.

Bevor ich zur Besprechung der Operation und Endresultate gehe, möchte ich versuchen, die gefundenen Daten in Einklang zu bringen mit den Kenntnissen, die wir bezüglich der Pathogenese der tuberculösen Gelenkserkrankungen besitzen. So einheitlich wir heute in puncto Aetiologie bei Tuberculose denken, so lückenhaft sind unsere Kenntnisse in Bezug der Gründe, warum sich bei stattgefundener Infection das Leiden so verschiedenartig localisirt. Wir wissen zwar, dass die Localisation der primären Tuberculose abhängig ist zum Theil vom Alter, in dem die Infection stattfindet; je durchgängiger Haut und Schleimhaut sind - und dies ist der Fall bei jugendlichen Individuen - um so weniger setzt der Tubercelbacillus Veränderungen an Ort und Stelle. Es erkranken die Lymphdrüsen, während bei älteren Individuen die Schleimhäute, Lunge, Darmwand erkrankt. Es scheint nun, dass der kindliche Organismus auch für das Weiterwandern aus dem primär erkrankten Organ, meist den Drüsen, grössere Chancen bietet. Dies würde das häufige Entstehen von Miliartuberculose und ebenfalls meist am Wege der Blutbahn, die Häufigkeit 
der Knochen- und Gelenkmetastasen erklären. Es giebt nun aber sicher Fälle, bei denen der Knochen oder das Gelenk der einzige erkrankte Theil ist. König fand bei Sectionen 1/5 der Fälle primär. Nach seiner Anschauung sind aber die primären Fälle noch wesentlich häufiger, da sie bessere Aussichten bieten auf definitive Ausheilung und daher seltener zur Section kommen.

Wenn wir aber fragen, welche Ursachen mitspielen, um den im Blutstrom kreisenden Virus seine Etablirung eben im Knochen oder den Gelenken zu ermöglichen, so sind wir über Aufstellen von Hypothesen nicht hinausgekommen. Die schönen Experimente Krause's und Schüller's über den Einfluss des Traumas schienen Licht in die Frage zu bringen. Lannelongue und Achard, Friedrich, Honsell sind aber zu negativen Ergebnissen gekommen, was gegen die Anschauungen Krause's zu sprechen scheint. Es lassen sich aber diese Ergebnisse aus der Verschiedenheit der Versuchsanordnung, der Zahl, Virulenz des inficirenden Materials, Widerstandskraft der Versuchsobjecte, Art des verwendeten Traumas erklären. Wenn wir die klinischen Statistiken durchsehen, kommen wir auch zu sehr ungleichwerthigen Resultaten. Die Zahlen bei Coxitis schwanken zwischen 14,5 Proc. und 40 Proc. - Es lässt sich vielleicht am leichtesten eine pathogenetische Erklärung der Localisation geben, wenn man die ziemlich fixen Daten von Alter; Geschlecht und die Häufigkeit der Localisation an den verschiedenen Gelenken mit einander und den anatomischen Aufbau und der physiologischen Function der einzelnen Gelenke vergleicht.

Bezüglich des Alters sahen wir, dass die Coxitis tuberculosa in ca. 90 Proc. der Fälle vor dem 20. Lebensjahre auftritt, also zu einer Zeit, in der sich die Knochenbildung in der Epiphyse abspielt. Das männliche Geschlecht ist mit ca. 60 Proc. an der Erkrankung betheiligt. Dazu kommt nach den grossen Statistiken Alf er's und Cheyne's die Vertheilung nach Gelenken folgendermaassen:

Cheyne: Proc. Alfer:

\begin{tabular}{lrrr} 
Wirbelsäule & 23,2 & 239 \\
Kniegelenk & 16,5 & 281 \\
Hüftgelenk & 14,6 & 241 \\
Tarsus u. Sprunggelenk & 14,4 & 43 (184 Knochen) \\
Ellbogengelenk & \multicolumn{2}{c}{ (227 i. Ganzen) } \\
Handgelenk & 6,3 & 114 \\
& 6,0 & $20 \quad$ (109 Knochen) \\
Schultergelenk & \multicolumn{2}{c}{ (129 i. Ganzen) }
\end{tabular}


Ueber die Enderfolge der operativen Behandlung bei Coxitistuberculosa. 11

Als letztes Moment muss man noch hinzunehmen, wie sich die verschiedenen Gelenkerkrankungen bezüglich des Alters verhalten. Für Hüft- und Kniegelenk ist das Maximum der Erkrankung das erste Jahrzehnt, Fussgelenk 5-15 Jahre, Ellbogen 15-20 Jahre, Schultergelenk 15-30 Jahre, IIandgelenk 20-25 Jahre.

Da nun bei weitaus den meisten Gelenkerkrankungen die Uebertragung des tuberculösen Virus der Blutbahn zuzuschreiben ist, abgesehen von den wenigen Fällen, wo eine directe Verschleppung von einer Verletzung aus angenommen werden darf - so darf man die Chancen der Localisation an den verschiedenen Gelenken als ziemlich gleich anrechnen.

Es müssen also locale Ursachen gesucht werden, um die Localisation an den verschiedenen Knochen und Gelenken zu erklären. Nach den oben gegebenen Zahlen scheint mir ein Heranziehen der functionellen Belastnng am nächsten zu liegen. Es wäre dies eine Ausdehnung des Begriffes der traumatischen Entstehung der Knochentuberculose. Es liesse sich dies gut vereinbaren mit Krause's Experimentaluntersuchungen, nach welchen "nur leichte Traumen Anlass zu Gelenk- und Knochentuberculose geben". - Für diese Auffassung spricht, dass die Localisation in den ersten 10 Jahren die untere Extremität (nebst der Wirbelsäule) betrifft. Functionelle Belastung und Traumen treffen in dem ersten Decennium hauptsächlich die untere Extremität. - Dafür spricht die Betheiligung des männlichen Geschlechts (60 Proc. gegen 40 Proc. weiblicher Kranken). Man könnte vielleicht das häufigere Vorkommen der Caries sicca humeri an der rechten Seite damit erklären. Die Erklärung Krause's ist nur ein Umschreiben unserer klinischen Kenntniss in Bezug auf Localisation in Knochen und Synovialis. „In der Jugend sind die primären Ilerde in den Epiphysen das gewöhnliche, während im Alter eher einmal primäre Synovialtuberculose vorkommen kann. Nun neigen manche Gelenke vorwiegend zu letzterer Erkrankungsform, daher werden sie auch öfters im höheren Alter ergriffen." Wenn man den Satz umkehrt und ausgeht von der Erfahrung, dass die Gelenke der oberen Extremität meist in einer späteren Zeit erkranken (und zwar als Folge der stärkeren functionellen Inanspruchnahme im höheren Alter) und dass die Gelenke in späterem Alter mehr zu Synovialerkrankung neigen, so dürfte dies eine präcisere Erklärung sein.

Dazu kommt noch, besonders für die Frage der genaueren Localisation der Herde in den einzelnen Gelenken, der differente Aufbau derselben in den verschiedenen Altersperioden. Dass in einer 
Epiplyse, die noch keinen Knochenkern aufweist, kein Knochenherd enstehen kann, ist klar; König wies des Oefteren darauf hin, dass bei ganz kleinen Kindern bäufig Knochenberde schaftwärts von der Epiphysenlinie entständen, während die noch knorpelige Epiphyse von Herden verschont bleibt. Von äusserster Wichtigkeit für das Verständniss der Localisation scheint mir die Entwickelung des Gefässnetzes in den verknöchernden Epiphysen, die Vertheilung, Weite, Richtung der in den Knochenkern eindringenden Arterien zu sein. Sowohl die Pathogenese als die pathologische Anatomie der Knochentuberculose weisen unzweideutig auf die embolische Entstehung der Knochenherde hin, obwohl dies die experimentellen Untersuchungen noch nicht klar bewiesen haben. Trotz eifrigen Nachsuchens konnte ich nirgends genauen Aufschluss über die Entwickelung des Gefässnetzes in den verknöchernden Epiphysen und die Veränderungen derselben mit zunehmendem Alter bekommen. Durch Zufall sah ich bei Herrn Lexer (Berlin) eine Reihe Bilder, die mich in der Annahme der Wichtigkeit der differenten Gefässversorgung für die Frage der Localisation noch bestärkten. Er hatte die glückliche Idee, die Gefässe der Knochen von verschieden alten Individuen mittelst Quecksilber zu injiciren und nun zu röntgographiren. Durch dies einfache Mittel bekam er eine Reihe sehr übersichtlicher Bilder. Bei weiterer Ausdehnung dieser Untersuchungen dürfte die Frage der Localisation ihrer Lösung um ein Beträchtliches nähier gebracht werden.

Pathologisch-anatomischer Befund bei der Operation. P'rimärer Knochenherd.

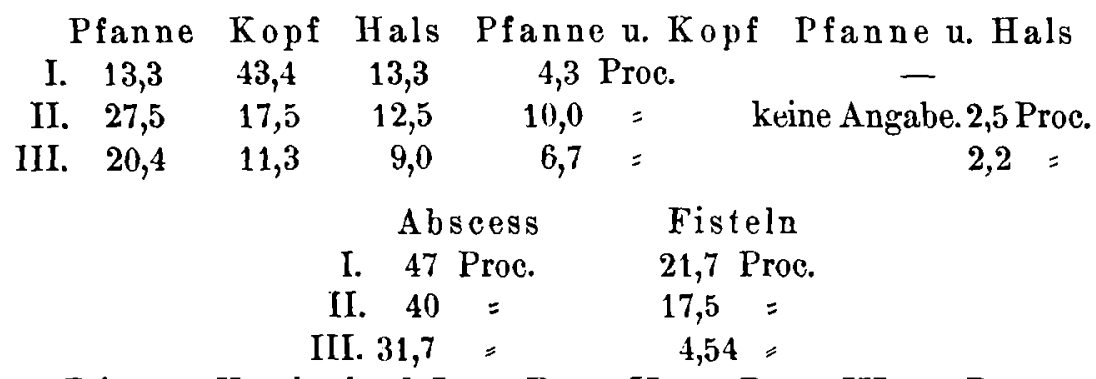

Primärer Knochenherd I. 74 Proc., II. 70 Proc., III. 50 Proc.

Zur Erklärung dieser differenten Ergebnisse muss folgende Erwägung herangezogen werden. Durch die exquisite Besserung der operativen Resultate (s. Endergebnisse) wurde die Indicationsstellung im Laufe der Jahre verschoben zu Gunsten der Resection. Dies zeigt am exquisitesten die Zahl der fistulösen Fälle (4,54 Proc. gegen 
Leber die Enderfolge der operativen Behandlung bei Coxitistuberculosa. 13

21,7 Proc.). Die Verminderung um 20 Proc. zu Gunsten der primär synovialen Fälle liesse sich aber damit allein nicht erklären. Ich habe die von Professor Kocher meist eigenbändig geschriebenen Befunde genau geordnet, je nachdem dabei ein primärer, ostaler Herd anzunehmen war oder nicht. In den Tabellen von Guinand und Zehnder ist diesbezüglich zu wenig Gewicht gelegt worden. Die Originalkrankengeschichten standen mir leider nicht zur Verfugung, ich musste also die Berechnung auf Grund der Tabellen anfertigen. Wie schwer es ist, bei einigermaassen fortgeschrittenen Processen den Ausgangspunkt des Leidens zu bestimmen, weiss Jeder, der eine grössere Anzahl von Gelenkeröffnungen gemacht hat. Ich bestrebte mich, die Fälle, wo ausdrücklich primäre Knochenherde angegeben waren, von denen zu trennen, wo die Beschreibung auf secundäre Knochenveränderung (im Sinne der König'schen secundären Caries) zu beziehen war. Solche secundäre Knochenveränderungen fand ich in 61,72 Proc. der Fälle angegeben. Es stimmt diese Zahl besser mit den oben gefundenen Ziffern von Serie I und II. Die Zahl 50 Proc. von primär Synovialtuberculosen ist vielleicht etwas zu hoch gegriffen, sie entspricht aber eher der Wirklichkeit, als die bisher angenommenen Zahlen von 20-30 Proc., was mit König's Auffassung über die relative Häufigkeit der Synovialtuberculose in guten Einklang zu bringen ist.

Ich muss noch auf einen wichtigen Umstand hinweisen, der in grellem Widerspruch steht mit dem, was wir über die Häufigkeit der Sequesterbildung bei Coxitis bisher wussten. Ich fand Sequesterbildung verzeichnet in I. 26 Proc., II. 27,5 Proc., III. 22,7 Proc. der Fälle. Man nahm seit den Untersuchungen von Riedel an, dass sich in ca. 70 Proc. tuberculöse Sequester bilden. Wie lässt sich dieser Unterschied erklären? Dass bei der Operation kleine Sequester übersehen worden sind, ist bei der genauen Untersuchung und dem grossen Gewicht, das auf die pathologischen Veränderungen und deren Beschreibungen gelegt wurde, nicht gut anzunehmen. Wenn wir in Betracht ziehen, dass die Krankheit bei unseren Fällen im Durchschnitte $2^{3 / 4}$ Jahre dauerte, bis die Kranken zur Operation kamen, so kann man wohl annehmen, dass die Sequester zum Theil aufgezehrt waren zur Zeit der Operation. Riedel leugnet zwar diesen Vorgang a priori, doch wies schon $\mathbf{K o ̈ n i g}$ auf den fundamentalen Unterschied zwischen Sequestern nach acuter Osteomyelitis und den tuberculösen Sequestern hin. Es wäre also anzunehmen, dass ein Theil des Sequester durch die Granulationen aufgezehrt. würden. Dabei ist es wahrscheinlich, dass die Zahl 70 Proc. der 
Riedel'schen Statistik zu hoch gegriffen ist und dass Sequester in kleinerer Zahl vorkommen, als bisher angenommen wurde. Es liesse sich dieses gut vereinbaren mit unserem Befunde der relativen Häufigkeit (ca. 50 Proc. der primär-synovialen Form der Coxitis).

Von den Veränderungen, die die Synovialmembran zeigte, ist zu erwähnen, dass sich in 50 Proc. die granulöse, in 24 Proc. die fungöseitrige Form vorfand. In 15 Proc. war die Erkrankung der Synovialis geringgradig, oder es fehlte die genaue Beschreibung.

In zwei Fällen wurde ausgesprochene Frühluxation bemerkt, in einem Falle finden wir Epiphyseolysis angegeben. In einem einzigen Falle finden wir den von König beschriebenen Fibrinniederschlag im Gelenk verzeichnet. Ueber die Rolle, die derselbe bei der Ausbildung des Destructionsprocesses spielt, lässt sich also kein Urtheil abgeben.

Die Besprechung der Röntgenaufnahmen lässt sich am besten hier einreihen. Leider sind von den operirten Fällen nur bei den letzten dreien (Fall 41, 42, 44) Photograpbien gemacht worden. Erst die Vervollkommnung der Röntgenographie machte es möglich, brauchbare und verlässliche Aufnahmen des Beckens herzustellen, die Aufschluss über Knochenstructur und Knochenherde geben können. Von den neueren Autoren war es besonders $\mathrm{K} \ddot{o n i} \mathrm{~g}$, der die Aufmerksamkeit der Chirurgen auf die Wichtigkeit des Röntgenbildes zur Stellung der genaueren Diagnose bei Coxitis lenkte. Er konnte in zwei exquisiten Fällen Knochenherde in der Pfanne nachweisen.

Um die Verlässlichkeit des Röntgenbildes zu prüfen, sollten nur Fälle herangezogen werden, bei welchen man durch Eröffnen des Gelenks den Befund verificiren kann. Ich verzichte also darauf, aus der reichbaltigen Sammlung des Berner Röntgeninstitutes die typischen Fälle zu reproduciren, da bei den meisten der Operationsbefund fehlt. Durch die Zuvorkommenheit des Leiters des Röntgeninstitutes, Dr. Pasche, war ich in der Lage, sämmtliche Coxitisaufnahmen durchzusehen und so einen Ueberblick zu gewinnen über das Bild der Coxitis in Röntgenbilde. Die 4 Aufnahmen der obigen Fälle (41, 42, 2 Aufnahmen des Falles 44) habe ich mit 2 im Februar 1902 von Professor Koch er operirter Coxitiden ergänzt, bei denen also durch Autopsie die feinere Diagnose verificirt war. Beide Fälle zeigten bei der Operation genau die durch das Röntgenbild vermuthete Veränderung. Ich glaube, dieselben als typische Fälle den meinigen beischliessen zu dürfen.

Ich will versuchen, die Veränderungen, die man am Röntgenbilde im Verlaufe der Coxitis beobachten kann, mit Hilfe der bei- 
Ceber die Enderfolge der operativen Behandlung bei Coxitistuberculosa. 15

gelegten Photogramme zu beschreiben. - Als Ergänzung nehme ich die Notizen, die ich bei Durchmusterung der Berner Sammlung gemacht habe.

Bei den Fällen, wo die krankhafte Veränderung in erster Linie die Synovialis betrifft, ist schon früh eine hochgradige Rareficirung: des Knochens - bis unter den Trochanter major - auffällig. Sie zeichnet sich durch grössere Durchlässigkeit, Verwischtsein der Knochenstructur, besonders aber durch das Verschwinden der Epiphysenlinie aus. Letzteres habe ich bei allen Fällen - ca. 35 Aufnahmen - gefunden. Das Verschwinden betrifft niclit immer die ganze Epiphysenlinie, ein Theil derselben kann auch sichtbar bleiben. Ein exquisites Bild dieser Veränderung bietet Fall E. Wittwer, Figur 1.

Treten zu dieser, auf die Synovialis beschränkten Form, bei der die Contouren des Kopfes und der Pfanne scharf und glatt sind, secundäre Veränderungen am Knochen und Knorpel hinzu, werden die Ränder verschwommen. In den Knochentheilen, besonders am Kopf, sieht man Schatten und lichtere Stellen angedeutet. Ziemlich regelmässig findet sich ein lichter Kegel an der Stelle des Ansatzes des Ligamentum teres. Ob es sich hier um ein Auffasern des Knochens durch Granulationen handelt, die meistens das Ligamentum teres umwachsen, kann ich nicht angeben. Diese Details dürften durch die Reproduction verloren gehen, sie sind schon an den Originalabzügen undeutlich. - Die Platten zeigen aber die Veränderungen ausgezeichnet. In diesem Stadium steht Fall 44, Figur 2 und 3.

Die weiteren Veränderungen sind bei Fällen ostalen Ursprungs gleich mit denen synovialen Ursprungs. Sie beziehen sich auf fortschreitende Destructionsprocesse. Bevor ich aber auf deren Beschreibung eingehe, will ich die Fälle besprechen, bei denen Knochenherde den Ausgangspunkt der Krankheit bilden. Die Knochenatrophie tritt bei diesen Fällen weniger schnell auf und ist nicht so intensiv. Im Kopf oder dem Pfannentheil sieht man isolirte lichte Flecken, meist durch eine dunklere Zone umgeben, theils ohne scharfe Grenze in die Umgebung übergehend. Das Bild verwischt sich aber, sobald starke Synovialprocesse oder Destructionen in den Vordergrund treten. Ein exquisit schönes Bild dieses Stadiums bietet Fall E. Schäfli, bei welchem die Operation einen tiefen Herd am oberen Theil der Pfanne aufdeckte, mit geringer Betheiligung der Synovialis und ganz intactem ¡Kopfknorpel. - Nur um die Ansatzstelle des Ligamentum teres befand sich ein Kranz von Granulationen und ein ebensolcher an der_Umschlagstelle der Kapsel, neben dem freien 
Knorpelrand. An beiden Stellen ist Knochenatrophie im Röntgenbilde sichtbar. Die Krankheit bestand seit 2 Jahren, ohne die Beweglichkeit des Gelenkes wesentlich zu beeinträchtigen. Es war nach den klinisehen Symptomen ein isolirter Herd am oberen, hinteren Pfannenrande anzunehmen (klinische Vorstellung vom 10. Februar 1902), welchen sowohl das Röntgenbild, als auch die Arthrotomie bestätigten. Auffällig ist die geringgradige Atrophie am Knochen.

Bei weiterem Verlaufe finden wir dann die Bilder der Pfannenausweitung und Knochendestruction sowohl bei synovialen als ostalen Fällen. Es lassen sich immerhin in einigen Fällen isolirte Knochenherde, die als Ausgangspunkt der Krankheit anzusehen sind, erkennen. - Meist verwischt sich aber das Bild in ganz typischer Weise. Entsprechend der Pfannenausweitung stellt sich der Kopf an dem hinteren oberen Pfannenrand, um immer höher zu kommen. Die ursprüngliche Form geht verloren, er plattet ab, ebenso gehen die scharfen Contouren der Pfanne und der Beckenschaufel in unregelmässig aufgefressene, von lichten Stellen und Schatten durchsetzte Massen über. Zur Illustration mögen Fall 41 und 42 (Fig. 5 und 6) dienen. In der Berner Sammlung befinden sich noch viel ausgeprägtere Bilder dieses Destructionsprocesses, deren Reproduction ich aber aus den oben angeführten Gründen weglasse.

Ich glaubte, auf die Beschreibung der Röntgenbilder näher eingehen zu müsșen, da dieselben für die feinere Diagnose der Coxitis von eminenter Wichtigkeit sind. Ich fand in der Literatur auch wenig gute Coxitisbilder reproducirt. Ludloff beschreibt die Veränderungen, die die Coxitis in den Röntgenbildern zeigt, aus der Eiselsberg'schen Klinik; in dem von Prof. Eiselsberg und ihm herausgegebenen Atlas sind jedoch bloss zwei Photogramme wiedergegeben; beide betreffen ziemlich weit vorgeschrittene Stadien der Krankheit. Die Beschreibung, die er giebt, stimmt im Ganzen mit der oben gegebenen überein. Nur sind die Differenzen der Bilder bei ostalem und synovialem Ursprung nicht gewtirdigt, da die Behandlung rein conservativ durchgeführt und so eine Verificirung der Befunde nicht möglich war. Vier gute Bilder, aber ganz Anfangsstadien betreffend, ohne Knochenherde, giebt Alban Köhler in seinem Atlas „Knochenkrankheiten im Röntgenbilde“.

II. Die operative Behandlung der Coxitis.

A. Technik.

In allen Fällen wurde die Resection mittelst des $\mathrm{K}$ o ch e r'schen hinteren Winkelschnittes gemacht (Ausnahme Fall 5, bei welchem 
wegen vorne bestchendem $\Lambda$ bscess und Knochenherde der Huetersche Lüngsschnitt verwendet wurde). Ich gebe die Beschreibung nach der 4. Auflage von Koeher's "Operationslehre".

"Winkelschnitt resp. Bogenschnitt an der Basis der Hinterfläche des Trochanter major beginnend, von da zur hinteren Trochanterspitze aufwärts und winklig abbiegend in der Richtung der Faserung des Glutaeus maximus schräg auf und medianwärts durch Haut und oft reichliches Fettgewebe. An der Basis des Trochanter major werden gelegentlich grössere Aeste der Arteria circumflexa externa verletzt und gefasst. Auf der Aussenfläche glatte Fascie des M. glutaeus maximus gespalten, wodurch das Periost und der die Trochanterspitze in ganzer Breite deckende Ansatz des M. glutaeus medius freigelegt und das Abheben des M. glutaeus maximus erleichtert wird. Auf- und rückwärts trennt der Schnitt die Fasern des Glutaeus maximus in Längsrichtung, wobei gewöhnlich im oberen Theil einige grössere Gefässäste durchschnitten und unterbunden werden müssen. Besser ist es noch, womöglich den oberen Rand dieses Muskels freizulegen und abwärts zu ziehen. Es tritt eine dünne Fettschicht zu Tage, welche'getrennt wird, um am unteren Rande des Glutacus medius in das Interstitium zwischen diesem ,Muskel nebst Glutaeus minimus oben und der Sehne des Muskels pyriformis unten zu gelangen. Hier wird eingegangen und zunächst die breite an der Aussenfläche der Trochanterspitze sich ansetzende Sehne des Glutaeus medius und darunter die am vorderen Rande sich anheftende Sehne des Glutaeus minimus sammt dem Periost mit Längsschnitten bis zur Linea intertrochanterica nach vorn abgehoben. An letzterer Stelle löst man den Ansatz des Lig. iliofemorale los unter Beugestellung des Oberschenkels mit Auswärtsrotation. Nunmehr wird entlang dem unteren Rande der Sehne des M. pyriformis die Kapsel gespalten und bei gebeugtem und einwärtsrotirtem Oberschenkel der Ansatz der schlanken Pyriformissehne in der Fossa trochanterica sammt Periost dicht am Knochen losgelöst, danach die sämmtlichen Auswärtsrotatoren in Zusammenhang mit dem Periost oder einer dünnen oberflächlichen Knochenschicht rückwärts abgehoben, nämlich von vorn beginnend, die Sehne des Obturator internus mit Gemelli und des Obturator externus. So wird die periostale Bedeckung der inneren Fläche des Trochanter und der Rückfläche dieses Knochentheiles nach linten abgehoben. Auf diese Weise hat man die vom Nervus glutaeus superior versorgten Muskeln, nämlich die glutaeii medius und minimus nach vorn oben geschoben gegen den M. tensor fasciae hin, welcher dieselbe Nervenversorgung hat und mit den Glutaei für die 
spätere Abduction des Schenkels von besonderer Wichtigkeit ist, während die übrigen Muskeln, Glutaeus maximus und Obturatorii, welche vom $X$. glutaeus inferior wesentlich versorgt sind, nach hinten im Zusammenhang bleiben. Der M. pyriformis ist von einem Nervenzweig des Glutaeus superior oder inferior versorgt, aber dieser Ast geht so boch oben ah, dass dessen Verletzung nicht in Betracht kommt. So wird die ganze Rück-, Aussen- und Vorderfläche von Femurkopf, Femurhals und, soweit nöthig, Trochanter freigelegt, und man hat bloss einige Aeste der Arteria femoris circumflexa interna, welche quer über die Kapsel des Schenkelhalses verläuft und event. die Arteria circumflexa externa da, wo sie sich an der Basis des Trochanter major unter dem Vastus externus durchdrängt und um das Femur herumschlägt, zu unterbinden. Meistens genügt es, die wenigen Arterienäste mit Arterienzangen zu fassen und nachber abzudrehen. Es ist leicht die Synovialis, wenn dieselbe fungös entartet ist und excidirt werden soll, vor der Eröffnung der Kapsel auf eine grosse Strecke hin von hinten exact zu präpariren und von ihrem Ansatze an Pfanne und Schenkelhals loszulösen und so die hintere obere, und zum Theil vordere Wand in toto zu entfernen. Nach Trennung des Lig. teres durch Schnitt von hinten unten auf den Schenkelkopf bei stark adducirtem, einwärts rotirtem und flectirtem Schenkel wird der Kopf nach hinten luxirt, und in dieser Stellung wird die Pfanne der Inspection zugänglich."

Nach Inspection des Gelenkes wurde das Entfernen des krankhaften Theiles mittelst Scheere, Messer und Meissel, je nach Grösse der Erkrankung vorgenommen; soweit man mit dem scharfen Löffel das Krankhafte entfernen konnte, wurde derselbe benützt. Was die Entfernung des Knochens betrifft, wurde auf die Epiphysenlinie möglichst Rücksicht genommen. War die Erkrankung weitergeschritten, so wurde auch vom Halse unter mögliehster Schonung eines Theiles der Epiphyse, ein entsprechendes Stück entfernt. War dabei der Hals so kurz geworden, dass der vorstehende Trochanter durch Aufstossen an dem oberen Pfannenrand die Abduction behinderte, wurde derselbe theilweise mit entfernt. Ebenso wurde bei Entfernung der Pfannenerkrankung das Princip der möglichsten Schonung des Knochens vor Augen gehalten. Die Operation entspricht also der atypischen Artbrectomie. Der Kürze halber will ich immer von Resection sprechen.

Nach beendigter Resection wurde die Wundhöhle mit warmer physiologischer Kochsalzlösung ausgewaschen, die kleineren Gefässe torquirt, an die grösseren Ligaturen mit Juniperussublimat Catgut ge- 
Ueber die Enderfolge der operativen Behandlung bei Coxitis tuberculosa. 19

legt, die Wunde mit Jodoformbrei ausgerieben und je nach dem Grad der Erkrankung primär genäht, oder auch mit Jodoformgaze - bei luxirtem Kopfe - tamponirt und nach 3-7 Tagen secundär geschlossen (s. Wundheilung). Waren periarticuläre Abscesse vorhanden, so wurden dieselben - falls sie nicht in die Schnittrichtung fielen - von einem besonderen Schnitte eröffnet, die Abscesswand mit Scheere und Pincette oder dem scharfen Löffel entfernt, ausgewaschen, mit Jodoform eingerieben und drainirt. Bei den Fällen, wo die Verkürzung der Flectoren und Adductoren so hohe Grade angenommen hatte, dass man die Redressirung nicht vornehmen konnte, wurde unmittelbar nach der Resection die Durchschneidung der entsprechenden Muskeln vorgenommen. Es sind dies die Fälle 28, 34, $35,37$.

Ich will hier auf zwei Operationsmethoden hinweisen, die in neuerer Zeit empfohlen wurden und sich für manche Fälle gut eignen dürften. Die eine ist die von Bardenheuer empfollene Totalexcision der Pfanne, die er bei Pfannenprocessen als Normalverfahren angiebt. Das Verfahren giebt nun sicher die besten Aussichten auf Radicalheilung, muss aber für die allgemeine Resectionspraxis als zu eingreifend bezeichnet werden. Verlor doch Bardenheuer an directer Folge der Operation (Shock und Nachblutung) 2 von 47 Kranken, d. i. 4,3\% directe Mortalität. Dabei ist die Zahl der Recidive nicht kleiner als bei Meisseloperationen. Es muss zwar zugegeben werden, dass die publicirten Fälle Barden h e u er's schwerer scheinen, als die der K ocher'schen Statistik. Was aber bei der Methode von grossem Vortheile erscheint, ist die Betonung der Nachbehandlung, die das zwar nicht ideale, aber praktisch bedeutende Streben nach Ankylose in den Vordergrund stellt. Für Fälle, bei denen man einer lange genug controllirbaren Nachbehandlung nicht sicher ist, scheint es empfehlenswerther als das Erstreben eines beweglichen Gelenkes. Sprengel und König verwerfen auch die primäre Resection der Pfanne als zu eingreifend. Auch sie haben mit der Meisselresection zufriedenstellende Resultate erhalten.

In allen Fällen verwendete Prof. Kocher den von ihm angegebenen Winkelschnitt. Er gab genügenden Raum, um die Pfanne gut übersehen zu können. Es nuss aber zugegeben werden, dass die Fälle relativ leichterer Natur waren und dass schwere Beckenprocesse zu den Ausnahmen gehörten. Für diese Fälle, besonders wenn sie mit multiplen Fisteln complicirt sind, scheint das von Sprengel angegebene Verfahren gute Dienste zu leisten. Die Schnittführung entspricht der von Prof. Ko cher im Jahre 1884 zur Entfernung der 
einen Beckenlıälfte verwendeten. Ausgiebiger Schnitt entlang dem Beckenrande von der Spina post. suj. zur Spina ant. sup. Der Schnitt durchtrennt Muskeln und Periost. An der Grenze des M. glutaeus medius und Tensor fasciae wendet sich derselbe nach unten bis zum Trochanter. So kann ein grosser dreieckiger Lappen subperiostal abgelöst werden. Die Muskeln bleiben im Zusammenhang mit ihren Nerven und Blutgefässen. Die Blutung soll sehr gering sein. Für Fälle, die weit vorne sitzen, muss man den Schnitt nach vorn verlängern bis zum Nervus cruralis, den man im Voraus freilegt. Man durchtrennt dann die $\mathrm{Mm}$. tensor fasciae, rectus cruris und sartorius, event. auch ileopsoas. Es ist dies insbesondere für Fälle mit starker Flexionscontractur empfehlenswerth, da es das beste Mittel ist zur Vermeidung nachträglicher Contracturen. Nach Beendigung der Resection wird der Iappen zurückgenäht, ein Theil der Wunde tamponirt und offen behandelt. Der Schnitt giebt nach den beigefügten Zeichnungen ausgezeichneten Einblick in die Pfanne.

\section{B. Nachbehandlung.}

Dieselbe bestand in einer durch Wochen fortgesetzten Extension in abducirter Stellung. - Bei den späteren Fällen wurde nebst der Extension ein bis zum Knie reichender Gypsverband für die ersten Wochen angelegt. Je nach dem Heilungsverlauf wurde nach durchschnittlich drei Wochen mit den Bewegungsübungen angefangen und zwar Gewicht gelegt darauf, nur active Bewegungen zu gestatten. Es ist dies wichtig wegen der richtigen Formation der Gelenksflächen und der Vermeidung von Schlottergelenken. Leider besitzen wir für das Hüftgelenk keinen geeigneten Apparat, der die Bewegungen desselben so einfach beeinflussen könnte, wie dies der von Kocher zur Nachbehandlung der Ellenbogengelenkresection benützte Charnierhiilsenapparat thut. Den besten Dienst leistet noch ein Hessingapparat mit Charniergelenk, der Flexion und Extension crlaubt. Man kann dann noch nach II offa eine Abductionsvorrichtung anbringen, um der Adductionscontractur vorzubeugen. Der Apparat ist aber zu kostspielig, um allgemeine $\Lambda$ nwendung zu ermöglichen. Man muss daher mit lange Zeit dauernder Extensionsbehandlung gegen die häufig auftretende Flexions- und Adductionscontractur ankämpfen, um ein gutes functionelles Resultat zu erzielen, will man nicht im Voraus auf ein bewegliches Hüftgelenk verzichten.

\section{Wundheilung.}

Je nach der Schwere des Falles wurde die Wunde, nach Auswaschen mit körperwarmer physiologischer Kochsalzlösung und Ein- 
Ueber die Enderfolge der operativen Behandlung bei Coxitis tubereulosa. 21

reiben einer mit $1 / 2$ "oiger Sublimatlösung verriebenen Jodoformpaste primär genäht oder aber mit Jodoformgaze tamponirt, um dann nach 2-7 Tagen secundär genäht, oder auch ganz offen behandelt zu werden. Die Fälle vertheilen sich folgendermaassen:

Primäre Naht ohne Drain: 4 Fälle $(11,12,13,16)$ alle p. prim. geheilt.

Primäre Naht mit Drainage: 20 Fälle $(6,10,15,17,18,19,23$, $24,25,26,27,28,30,31,32,35,37,40,41,43)$ davon 16 p. prim. geheilt, 1 p. sec., 3 fraglich. Primäre Naht, Jodoformegazemêche und Drain: 7 Fälle $(20,21,22,29,34,36,42)$ davon 3 p. prim., 3 p. sec. greheilt, 1 fraglich.

Tamponade bei Iuxirtem Kopfe, offene Wundbehandlung oder Secundïrnalıt und Reposition des Kopfes nach 2 bis 7 mal 24 Stunden: 13 Fälle $(1,2,3,4,5,7,8,9,14,33,38,39,44)$ davon p. prim. gebeilt 4 , p. sec. 6 , fraglich 3 .

Alle Fälle zusammen genommen, sind per primam geheilt 27 also $61,3 \%$, per secundam gehéilt $10=22,7 \%$, fraglich $7=16 \%$.

Wie ich bei der Nachbehandlung erwähnte, wurde mit den Bewegungsübungen, glatten Wundverlauf vorausgesetzt, nach ca. 3 bis 4 Wochen begonnen. Die ersten Gehversuche wurden, je nach Geschicklichkeit des Kranken und dem Heilungsverlauf, zwischen dem 28. und dem 50. Tage, im Durchschnitt nach 48 Tagen vorgenommen. Die Kranken verblieben im Spitale (auch die Recidivoperationen mitgerechnet, mit Abrechnung der im Spitale und unmittelbar nach der Entlassung Gestorbenen) zusammen 3583 Tage, es entfallen also auf einen Kranken im Mittel 102 Tage, von der Operation bis zur Entlassung gerechnet. Die Kranken waren bei der Entlassung im Stande, mit. Stock oder Krücken zu gehen. Bei einigen findet man die Bemerkung, dass sie ohne Unterstiitzung gehen konnten. I eider fehlt bei 14 Fällen der Entlassungsstatus. Bei den Uebrigen war die Wunde vollkommen geheilt, das Gelenk nicht mehr schmerzhaft.

\section{Endresultate.}

Bevor ich zur Besprechung der Endresultate gebe, muss ich bemerken, dass ich von den 44 Fällen meiner Statistik von 41 brauchbare Erejgnisse habe. Fall 29 ist am Leben. Ich konnte aber keine brauchbare Nachricht erhalten, noch den Kranken aufsuchen. Nicht auffindbar sind Fall 17 und 26; die meisten Kranken konnte ich selbst nachuntersuchen, zum Theil in der Klinik, zum Theil zu Hause. Von den nach Bern gekommenen Kranken liess ich Röntgenaufnahmen machen, um über den Zustand des neugebildeten Gelenkes Aufschluss 
zu bekommen. Sämmtliche Nachuntersuchungen sind in den Monaten Januar und Februar 1902 gemacht, der jüngste Fall also 11/2 Jahre nach der Operation. In der Tabelle sind die Resultate der Fragebogen mit $1902 \mathrm{I}$. eingetragen, die nachuntersuchten Fälle mit N. U. und Datum bezeichnet.

Von den 41 Fällen sind gut ohne Fisteln geheilt: $16=41,02 \%$ (Fall 3, 11, 13, 14, 16, 18, 20, 23, 25, 34, 35, 38, 40, 41, 42, 43).

Geheilt nach Fisteleiterung oder Nachoperation $7=17,07 \% \quad(1$, $4,5,6,7,30,31$ ).

Gutes Allgemeinbefinden, ab und zu leichte Fisteleiterung 4 Fälle $=9,75 \%(12,21,24,27)$.

Gutes Resultat $67,84 \%$.

Es besteht profuse Eiterung oder schlechtes Allgemeinbefinden $5=11,195 \%(15,32,33,36,37)$. Gestorben sind $9=21,95 \%(2$, $8,9,10,19,22,28,39,44)$.

Schlechtes Resultat $33,145 \%$.

Von den Todesfällen ist einer direct der Operation zuzuschreiben. Es ist dies Fall 39. 16 Tage nach der Operation erfolgte der Tod. Die Section ergab Fettembolie der Lungen, fettige Degeneration des Herzens und Tuberculose der Lungen. Die Operationswunde zeigte glatten Wundverlauf. Die Erklärung dieses Falles kann man vielleicht in der Analogie mit einigen Fällen suchen, die Payr aus der Grazer Klinik beschrieben hat. Nach unblutigem Redressement von Contracturen trat in 3 Fällen Exitus ein. Die Section ergab, nebst Fettembolie der Lungen, Status thymicus; zur Erkläruug zieht Payr die Beobachtung heran, dass bei Status thymicus eine Hypoplasie des arteriellen Gefässsystems, Verengerung der Lungengefässe und mangelhafte Oxydationsprocesse im Blute den Eintritt des Exitus bei statthabender Fettembolie bedingen. Wenn auch der Status thymicus bei unserem Falle fehlt, so finden wir, zwar durch andere Ursachen bedingt, ähnliche Verhältnisse: starke Abschwächung des Herzens (fettige Degeneration, Atrophie besonders des rechten Ventrikels), dabei die durch lange Rïckenlage, ungenügende Lüftung und Tuberculose der Lungen bedingte Hypoplasie der Lungengefässe, die den deletären Einfluss der Fettembolie erklären mag.

Die restirenden Fälle lassen sich am besten in 2 Gruppen scheiden: Fall 28: Tod nach 1 Monat post operationem

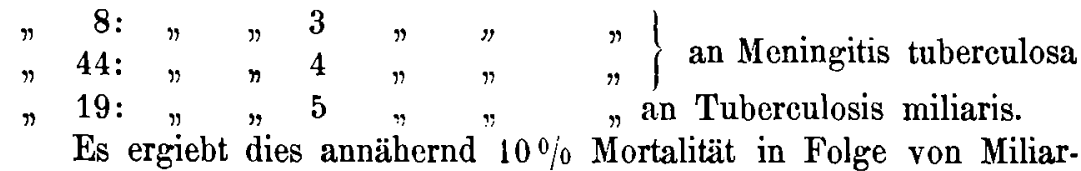


tuberculose, resp. Meningitis tuberculosa, welche nach 1-5 Monaten nach der Operation zum Tode geführt hat. Warum ich die ersten 3 Fälle auch als Miliartuberculose anführe, hat seine Erklärung darin, dass ich eine einheitliche Genese derselben annehmen $\mathrm{zu}$ müssen glaube. Bei den ersten 3 Fällen war keine Section gemacht. Im Vordergrunde des klinischen Bildes stand die Meningitis. Es dürfte aber wohl anzunehmen sein, dass während oder nach der Operation in die Wundfläche aufgenommene Tuberkelbacillen die Generalisation der Tuberculose bewirkten. Dèr Beweis, den Bergmann für diese Auffassung am Chirurgeneongress 1891 verlangte (cit. nach Wahlländer) ist zwar in keinem der Fälle erbracht. Bergmann verlangt die Coincidenz folgender Factoren:

1) Sollen sich die Symptome dẹ Miliartuberculose an die Operation unmittelbar anschliessen, also nach den ersten Wochen auftreten.

2) Muss das Obductionsergebniss - also das Alter der miliaren Knötchen - mit den klinischen Symptomen übereinstimmen.

3) Darf kein anderer tuberculöser Herd, als der operirte im Körper vorhanden sein.

An der logischen Richtigkeit dieser Postulate lässt sich nicht zweifeln. Man geht aber zu weit, wenn man sich an diese Punkte hält; der wichtigste der 3 Punkte ist sicher der erste. Man mag ja manchmal einen Fehlschluss nach der Formel post hoc, ergo propter hoc begehen, das Auftreten unmittelbar nach der Operation wird aber immer den Verdacht an einen causalen Zusammenhang rechtfertigen. Bei Fall 19 fanden sich 2 tuberculöse Geschwüre im Darm; gleichzeitig bestand aber ein grosser, mit tuberculösem Eiter gefüllter Sack an der Operationsstelle. Von welehem der Herde die Propagation erfolgte, lässt sich also auch in diesem Falle nicht sicher sagen, trotz Section.

Bei der zweiten Gruppe der Fälle erfolgte der Tod an Tuberculose innerer Organe und zwar in Fall 22: $1 \mathrm{Jahr}$ post operationem

Section war in keinem der Fälle vorgenommen worden. Nach den Berichten. der behandelnden Aerzte war bei Fall 2 Pneumonia caseosa, bei Fall 9 Meningitis tuberculosa, bei Fall 10 Nierentuberculose anzunehmen. Ueber Fall 22 konnte ich keinen näheren Aufschluss erlangen. Das Hüftleiden war in Fall 9 und 10 ausgeheilt. 
Fall 2 bekam ein Recidiv 4 Monate nach der Operation, welches weiter nicht belandelt wurde.

Von den noch lebenden Kranken war mit Ausnahme der 5 als schlecht bezeichneten Fälle, bei denen noch Fisteln bestehen, die Coxitis ausgeheilt. Eine Beobachtung, die besonders Bruns und Wagner hervorheben, ist auch bei unseren Kranken aufgefallen. Die meisten derselben sehen blühend aus, zeigen keine weiteren tuberculösen Erscheinungen; so ist namentlich in allen Fällen der Lungenbefund normal; vergrösserte Drïsen sind nur vereinzelt zu finden. Es ist dies in guten Einklang zu bringen mit einer Beobachtung, auf die Sprengel aufmerksam gemacht hat, dass bei Coxitis multiple Herderscheinungen selten sind. Er fand, dass je grösser das Gelenk, umso seltener multiple Caries sich findet. Von unseren Fällen sind nur 2 zu nennen, bei denen sich nach der Coxitis tuberculöse Erkrankungen in anderen Gelenken zeigten. Es sind dies Fall 11 und 27. Bei Ersterem trat eine Reibe tuberculöser Gelenkentzündungen auf, bei Letzterem Olenitis tuberculosa.

Weniger günstig sind die Resultate in Bezug auf die functionellen Resultate. Um eine leichtere Uebersicht zu gestatten, will ich die Fälle, bei denen genaue Messungen möglich waren, in Tabellenform zusammenstellen, um auf die Ursachen der schlechten Function später eingehen zu können.

Wie man aus nebenstehender tabellarischen Uebersicht ersehen kann, sind die erzielten functionellen Resultate keine glänzenden zu nennen; man darf natürlich den Vergleich nieht mit normalen Hüftgelenken machen. Die Krankheit bei unseren operirten Fällen dauerte bis zur Operation im Durchschnitt $2^{3 / 4}$ Jahre. Abgesehen von den Veränderungen am Knochen hat man mit Weichtheilprocessen, besonders Verkürzungen und Atrophie der Musculatur zu rechnen, die viel dazu beitragen, dass die Function der operirten Hüfte trotz möglichster Schonung von Musculatur und Innervation eine ungenügende wird.

Wenn man die Gründe der unvollständigen Restitution analysirt, so muss man folgende Momente auseinanderbalten.

A) den grössten Einfluss spielt bei der schlechten Function ohne Zweifel die nicht unbeträchtliche Verkürzung der Extremität. Dieselbe setzt sich aus 2 Factoren zusanmen: Aus einer Verkürzung der Knochen und der Verschiebung des Femurs gegen das Becken. Die Erstere ist in unseren Fällen im Durchschnitt auf 4- $-8 \mathrm{~cm}$ anzusetzen. Da bei den meisten der Fälle die Epiphysenlinie des Femurkopfes geschont werden konnte und diese Epiphyse auch auf das Längenwachsthum des Femurs einen kaum nennenswerthen Einfluss hat, so 
Ueber die Enderfolge der operativen Behandlung bei Coxitis tuberculosa. 25

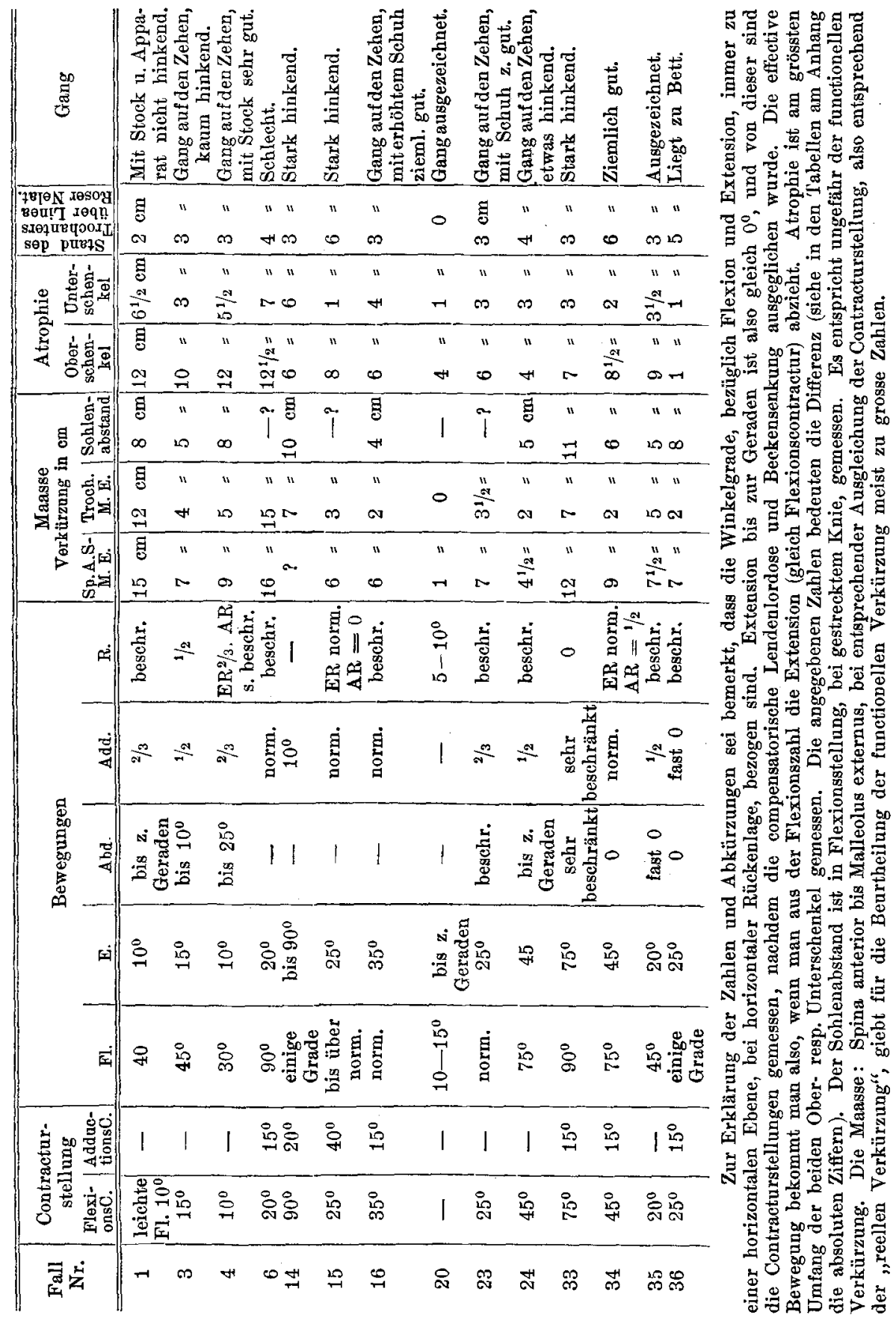


ist die Verkürzung - wie auch die weiter unten geschilderte Atrophie auf den Ausfall der functionellen Reize zurückzufübren; sie gehört also zum grössten Theil in das Capitel der Inactivitätsatrophie. In gleichem Sinne atrophirt die ganze Beckenhälfte. (Siehe Röntgenbilder.)

In zweiter Linie kommt in Betracht das Hinaufrutschen des Femurkopfes am Becken, welche man am Hochstande des Trochanters messen kann. Der Trochanter stand in unseren Fällen im Durchschnitte $2-3 \mathrm{~cm}$ uber der Roser-Nélat on'schen Linie. Es ist dies wohl bedingt durch die Ausweitung der Pfanne, an deren obersten Punkt sich der resecirte Kopf ansetzt. In einigen Fällen (so Fall 15 und 34), bei welchen der Trochanter $6 \mathrm{~cm}$ über der Linie stand, kann man wohl von einer Luxation auf die Darmbeinschaufel sprechen. Es gelang trotz Extension nicht, den Kopf an guter Stelle zu behalten.

B) Von den Contracturstellungen findet sich - mit Ausnahme eines Falles (Fall 20) Flexionscontractur verzeichnet. Dieselbe beträgt im Durchschnitt 300 . Dazu kommt Adductionscontractur bei der Hälfte der Fälle, im Durchschnitt von $20^{\circ}$. Beide Contracturen tragen dazu bei, die bestehende Verkürzung noch zu vermehren. Die Adduction stärkeren Grades bedingt einen Hochstand der kranken Beckenhälfte; bei geringeren Graden ist dies meist nicht der Fall; der Oberschenkel steht in leichter Adduction, und es entwickelt sich ein compensatorisches Genu valgum; durch diese veränderten statistischen Verhältnisse wird das Gehen ermöglicht. Ich konnte diesen Typus bei den meisten der mit leichter Adductionscontractur Behafteten beobachten.

C) Als letztes Moment kommt die Atrophie der Musculatur in Betracht. Die Verkttrzung lässt sich in den meisten Fällen durch erhöhte Sohle oder, wenn zu hochgradig, mittelst einer Prothese ausgleichen; dieses Hilfsmittel verwenden die meisten Kranken. Trotz dieser Ausgleichung knicken die Kranken bei jedem Schritt ein. Am exquisitesten sah ich dies Einknicken bei Fall 1. Die Kranke trägt einen Schienenhülsenapparat mit $8 \mathrm{~cm}$ Erhöhung. 'Irotz Ausgleichung der Verkürzung ist der Gang binkend. Sobald sich die Kranke aber auf einen Stock stützt, merkt man nicht das geringste Hinken. Dieselbe Wabrnebmung konnte ich bei vielen Kranken machen. Die Erklärung liegt wohl im selben Moment, welchem das Hinken bei congenitaler Luxation und manchen Fällen yon Coxa vara zuzuschreiben ist. Zum Theil durch Hochstand des Trochanters, zum Theil Atrophie der Musculatur sind die Glutealmuskeln nicht im Stande, das Becken zu fixiren, es kippt bei jedem Schritte über. In Bezug auf die Bewegungen lässt sich bei fast allen Fällen feststellen, dass die 
Flexion, Adduction und Einwärtsrotation ziemlich gut erhalten sind; die Extension ist im Sinne der angegebenen Flexionscontractur vermindert, Abduction und Auswärtsrotation sehr beschränkt, meist fast Null.

Zur Ergänzung muss ich hier auf die Ergebnisse eingehen, die die Roentgographie zu der Frage der Function geliefert hat. Ich muss gleich vorausschicken, dass sie nicht viel Aufschlüsse über diesen Punkt gegeben hat. Der Zufall wollte es, dass die Aufnahmen Fälle betreffen, die alle Stadien von bester bis schlechtester Function aufweisen. Die Plotogramme wurden bei allen Kranken, die in die Klinik zur Nachuntersuchung kamen, ohne Auswahl aufgenommen. Sie dürften daher ein ziemlich treues Bild der Knochenveränderungen geben, wie sie nach Resection zu Stande kommen. Auffallend ist bei allen Fällen eine stark ausgesprochene Assymetrie des Beckens. Dieselbe ist bedingt durch ein Zurückbleiben im Wachstum der afficirten Beckenhälfte. Ihr Grad entspricht der Atrophie, welche der Femur aufweist. Sie scheint noch auffälliger durch den meist vorhandenen Schiefstand, den das Becken einnimmt. Ich will die einzelnen Bilder in der Reihenfolge besprechen, die die Function ergiebt, und zwar nicht die Bewegungen als Richtschnur genommen, sondern den Gang, besonders aber das Hinken; es ist zwar einzuwenden, dass Letzteres in erhöhtem Maasse bedingt sind durch die Verkürzung; dieselbe gewinnt aber Ausdruck theils in der Atrophie, theils in der Stellung des Femurs zum Becken, kann also mit einbezogen werden.

Die beste Function zeigte Fall 20. Das Bein steht in normaler Stellung. Bewegungen sind sehr beschränkt. Flexion von $15^{\circ}$, Rotation ca. $10^{0}$, sonst keine Bewegungen. Am Halse und der Pfanne zeigen sich unregelmässige Schatten. Der Hals erscheint durch periostale Auflagerungen stark verdickt; Gelenkspalt ist nicht zu erkennen, doch ist die doppelte Contour der Pfanne gut sichtbar.

Analog diesem Falle, nur durch eine reelle Verkürzung von $5 \mathrm{~cm}$ versehieden, ist Fall 35. Der Gang ist kaum hinkend, trotz der Verkürzung. Alle Bewegungen in ca. 20-25 Graden möglich; nur die Rotation ist sehr beschränkt. Diesem Befunde entspricht, dass der Hals fast ganz verschwunden ist. Bei der Operation wurde der Kopf bis zum Haistheil, ferner der Trochanter major entfernt; der zurückgebliebene Stumpf ist verdickt. Am äusseren Umfang des Femurs, der Höhe des Trochanter minor entsprechend, eine Exostose, wohl dureh Knochenbildung in einem abgelösten Periostlappen entstanden.

Starke Atrophie des Femurs, bei sonst gut erhaltenen Knochen- 
verhältnissen charakterisiren Fall 23. Bei normaler Flexion und Adduction ist leichte Flexionscontractur vorhanden. Abduction und Rotation sind selır beschränkt. Das Bein ist um $3 \frac{1}{2} \mathrm{~cm}$ kürzer. Trotz ausgeglichener Verkürzung ist der Gang nicht gut. Bei jedem Schritte knickt das Becken um.

Bei Fall 34 ist am auffallendsten das Missverhältniss zwischen Function und anatomischem Befund. Hals und Kopf sind ganz verschwunden. Es scheint, als ob der Trochanter minor in die Pfanne getreten wäre; dadurch stẹt der Trochanter beträchtlich über der normalen $(6 \mathrm{~cm})$. Die Bewegungen sind ziemlich gut erhalten, nur Abduction unmöglich. Trotz Flexionscontractur ist der Gang gut bei entsprechend erhöhter Sohle. Endlich sind 2 Fälle (Fall 15 und 33) durch sehr hochgradige Atrophie ausgezeichnet. Bei ersteren steht der Kopf auf der Beckenschaufel, nahe dem oberen Pfannenrande, bei letzterem auf derselben. Bei beiden ist gut erhaltene Flexion und Adduction, bei sehr starker Beschränkung der übrigen Bewegungen vorbanden.

Wie ersichtlich, steht die Function in verkehrtem Verbältnisse mit der Atrophie. Je hochgradiger letatere, um so schlechter die Function. Man muss aber die Atrophie als secundär ansehen. Bei den 2 letzteren Fällen bestanden durch längere Zeit Fisteln, die zu einem Schonen der erkrankten Extremität führten, daher die so hochgradige Atrophie; letztere beeinflusst natürlich die Function in schlechter Weise, da sie zu vermindertem Längenwachsthum führi. Es entsteht so ein Circulus vitiosus, bei welchem man zum Schlusse nicht mehr den primären Factor erkennen kann.

Auffallend ist, dass den besten Gang die 2 Fälle zeigten, bei welchen durch periostale Wucherungen eine starke Beschränkung der Beweglichkeit entstanden war, dass ferner bei anatomisch sehr ungünstigen Verbältnissen, wie sie Fall 34 zeigt, der Gang recht gut zu nennen ist.

Jedenfalls weisen die Verhältnisse der Röntgenuntersuchung darauf hin, dass das Hauptgewicht bei der Nachbehandlung auf dauernd zu erbaltende gute Stellung gerichtet sein muss, dass das Forciren von ausgiebigen Bewegungen, sobald es auf Kosten der guten Stellung geschieht, zu vermeiden sei, dass man ferner, sobald als möglich, eine functionelle Belastung der Extremität erstrebe, die den besten physiologischen Reiz bietet, der das Ausbilden der Atrophie hintanbält und welche die Atrophie der Muskeln verhütet, durch Uebung derselben behufs Fixation des Gelenks.

Die Ursache, warum die Function nach den Resectionen eine 
ungenügende ist, liegt meist in der ungenügenden Nachbehandlung. Die Kranken wurden mit eingetretener Heilung, nach Wiederkehr der Function, im Durchschnitte 100 Tage nach der Operation entlassen. Es wurde aber empfohlen, durch Monate über Nachts Extension anzulegen und den weiteren Verlauf controlliren zu lassen. Nur einzelne konnten sich einen Hessingapparat zu den Gelübungen anschaffen. Bei den Nachfragen, wie lange die sachgemässe Nachbehandlung gedauert, bekam ich sehr betrübende Nachrichten. Die meisten Kranken lagen einige Wochen nach Entlassung zu Bett, ohne Extension, ohne Controlle, fingen dann an zu laufen, so gut es eben ging, und bei der exquisiten Neigung zur Verkürzung bildete sich dann eine Contractur der Flexoren und Adductoren aus, die durch die compensatorische Lendenlordose maskirt, keinen Anlass gab, den Arzt um Rath zu fragen. Gerade das schnelle Schwinden der Schmerzen nach der Operation, das subjective Wohlbefinden der Kranken ist der Hauptgrund, warum die Nachbehandlung so vernachlässigt wird. Die Indolenz der Kranken zeigt sich am prägnantesten bei den Fisteleiterungen; in 36 Proc. trat solche kürzere oder längere Zeit nach der Operation auf. Da dieselbe meist nicht hochgradig ist und ohne stärkere Schmerzen verläuft, kam nur ein kleiner Theil derselben (15,9 Proc.) zur Nachbehandlung derselben in die Klinik. Die anderen heilten zum Theil spontan aus, zum Theil bestehen jetzt noch Fisteln.

Viel günstiger sind die Resultate, wenn man nur vor Augen hält, inwiefern man durch die Operation ein gebrauchsfähiges Bein erbalten konnte. Fast alle Kranken können ihrer Arbeit nachkommen. Im Hause gehen sie meist ohne Unterstützung, um zu längeren Ausgängen einen Stock zu IIülfe zu nehmen. Zu den schlechteren Resultaten gehören diejenigen, die eine viertel bis eine halbe Stunde obne Ermüdung gehen können, einige machen Stunden lang dauernde Bergtouren, ohne Schmerzen oder Ermüdung zu spüren, und dies trotz der nicht unbeträchtlichen Verkürzung und Contracturen. Es stehen dem Organismus eben mannigfache Factoren zur Verfügung, um diese Nachtheile auszugleichen, die compensatorische Lordose, Beckensenkung, Gang auf den Zehen.

Es erübrigt noch, über die Ergebnisse zu berichten, die ich von den Kranken der Serie $I$ und II erhielt. Da dieselben bei der Abfassung der betreffenden Dissertationen nachuntersucht waren, glaubte ich auf eine neuere Untersuchung verzichten zu dürfen, schon der nicht unbeträchtlichen Kosten und des Zeitaufwandes halber. Ich sandte die Fragebogen an die Gemeindeschreiber und erhielt, mit 
Ausnahme zweier Kranker, Auskunft. Es war mir besonders darum zu thun, festzustellen, wie viel von den Kranken im Verlaufe des 2. und 3. Decenniums nach der Operation gestorben sind.

Von den Ueberlebenden der Zehnder'schen Fälle starb Fall 18, Karl Blatti, am 21. Februar 1882, 81/2 Jahre nach der Operation. Die Nachuntersuchung im Jabre 188.1 ergab starke Eiterung, sehr schlechten Algemeinzustand. Todesursache konnte ich nicht feststellen.

Von den Ueberlebenden der Guinand'schen Statistik starben im weiteren Verlaufe 3; und zwar Fall 4, Anna Porter, am 2. April 1890,8 Jahre post operationem, Todesursache unbekannt. Im Januar 1890 war folgender Befund erhoben: „Patientin ist anämisch, sonst gesund, Hüfte geheilt".

Fall 5. Alfred Trachsel, gestorben am 15. November 1898, 16 Jahre nach der Operation; Todesursache: Lungentuberculose. Befund vom Januar 1890: „Patient hat noch eine Fistel und befindet sich schwach, geht mit Krücke und Stock".

Fall 20. Louis Schallenberg, starb am 15. März 1899 an Lungentuberculose, 14 Jahre nach der Operation. Befund vom Februar 1890: "Gesund und sieht kräftig aus, geht den ganzen Tag herum".

Leider sind die Zahlen, trotz den fast ausnahmslos eingetroffenen Antworten (es fehlen nur 2 von 30 Kranken) statistisch nicht zu verwerthen, da ich die Adressen der Privatkranken nicht bekommen konnte. In den Dissertationen fehlen die Namen, und die entsprechenden Controllbücher sind nicht mehr aufzufinden.

Wenn ich die Angaben der Kranken trotzdem verarbeite, geschieht dies in der Ueberzeugung, dass die Frgebnisse bei den Privatkranken diejenigen der Spitalkranken keineswegs versehlechtern dürften; bei den Kranken meiner Zusammenstellung konnte ich im Gegentheil finden, dass die Endresultate bei den Privatkranken wesentlich besser waren als diejenigen der Spitalkranken. Es ist dies ja selbstverständlich, können doch die Bessersituirten mehr Sorgfalt auf die Nachbehandlung verwenden und die Kranken in bessere hygienische Verhältnisse bringen.

Da aus dem eben gesagten Grund keine lückenlose Zusammenstellung möglich ist, verzichte ich auf die tabellarische Wiedergabe der Endresultate und will dieselben nach den Punkten der Fragebogen zusammenfassen.

1. Das Allgemeinbefinden ist bei der Iälfte der Fälle als "gut ${ }^{4}$, bei der anderen Hälfte als "sehr gut" bezeichnet.

2. Mit Ausnahme von Fall 8/I., bei welchem multiple Caries 
besteht, ist in keinem der Fälle Verdacht auf anderweitige tuberculöse Erkrankung vorhanden; kein Husten, Auswurf oder Nachtschweiss.

3. In ca. der Hälfte der Fälle ist angeblich gute Beweglichkeit vorhanden; in den übrigen Fällen keine, oder nur beschränkte Beweglichkeit. Dass dieser Nachweis nicht stichhaltig ist, habe ich in den einleitenden Zeilen erwähnt, da das Mitgehen des Beckens von den Kranken meist nicht beachtet wird.

4. Die IIälfte der Kranken benützt Stock zum Gehen, zum Theil Schuhe mit erhöhter Sohle, keine Krücken.

5. Mit Ausnahme eines Kranken hinken alle mehr oder weniger stark.

6. Die meisten Kranken geben an, 2-4 Stunden lang ohne Schmerzen und Ermüdung gehen zu können; nur in 2 Fällen ist angegeben, dass das Gehen anstrengt und nach $1 / 2$ Stunde starke Ermüdung eintritt.

7. Alle Kranken können ihrer Beschäftigung gut nachkommen. Die meisten haben wohl sitzende Beschäftigung (Schneider, Medailleur, Schuhmacher). Doch finden sich auch Beschäftigungen, die grosse Ansprüche an den Mann stellen (Schmied, Fabrikarbeiter, Plätterin).

8. Schmerzen in der Hüte sind in 3 Fällen verzeichnet.

9. In zwei Fällen sind Fisteln vorhanden.

Ich glaubte, diese Daten doch anführen zu müssen, um zu zeigen, dass die Operation in Bezug auf Recidive gute Erfolge ergiebt; die Todesfälle betreffen meist Kranke, die bei der ersten Nachuntersuchung Verdacht auf Lungentuberculose erwecken mussten oder deren Hüftleiden nicht ausgeheilt war. Von besonderer Wichtigkeit ist, dass die Kranken alle erwerbsfäbig geworden sind. Alle haben gutes und sehr gutes Allgemeinbefinden. - Es sind dies ja allbekannte Punkte, sie müssen aber immer wieder betont werden, da von Seite Cltraconservativer immer wieder Stimmen laut werden, die das allgemeine Urtheil über die operative Behandlung trüben. So will ich hier eine Aeusserung Calot's anführen, die sich auf die Resultate der operativen Therapie bezieht (nach dem Referat im Centralblatt für Chirurgie, 1900). Das Bild der Resection, das Calot entwirft ist, folgendes: „Es besteht ein Abscess; man öfnet ihn und einige Zeit darauf macht man die Resection. 6 Monate nachher Nephritis, 1 Jahr später Degeneration der Fingeweide und $11_{z}-2$ Jahre nach der Resection Tod. Dies der Verlauf von wenigstens $3 / 4$ der Fälle; die tubrigen bleiben verstümmelt und meist siech. Durch secundüres Hinzutreten septischer Entzündungsprocesse über kurz 
oder lang Tod des Individuums. Jedes Kind mit Pott'schem Buckel, dem man breit seinen Knochenherd und seine Abscesse eröffnet, ist ein Kind des Todes."

Ich habe diesen Auszug nur gebracht, um die Uebertreibung des Ultraconservatismus zu zeigen. Einer Widerlegung sind derartige Meinungen nicht bedürftig. Ich will nur kurz einige Sätze aus Briefen der Kranken mittheilen, die den Zustand der Kranken besser schildern, als es Zahlen und Berechnungen thun können.

Fall I, 2. "Ich habe geheirathet und habe 4 Kinder, welche alle gesund sind".

Fall II, 35 (Brief einer Verwandten). "Sie ist ein Bild blühender Gesundheit, so recht der Typus einer urkräftigen, blonden Luzernerin. Sie hat keine Schmerzen, hinkt unmerklich, kann bergsteigen, 3-4 Stunden ohne Mühe gehen und tanzt wie ein Vogel “.

Wenn auch Fälle wie letzterer zu den Ausnahmen gehören, sind die Enderfolge, bei entsprechender Nachbehandlung durchweg gut zu nennen.

Bevor ich zur Besprechung der Indicationen zur Operation gehe will ich noch eine kurze Zusammenstellung der operativen Statistik geben, um die Eingangs erwähnten Fehlerquellen und die Verbesserung der operativen Resultate zu demonstriren. Leider stand mir nur ein kleiner Theil der enormen Coxitisliteratur zur Verfügung. Ich benutzte das vorhandene Material der Universitätsbibliotheken Bern, Zürich und Strassburg. Trotz des relativ kleinen Materials lässt sich aber eine ziemliche Regelmässigkeit in den gefundenen Zahlen zeigen und deren Ursachen angeben.

Ich theile die Statistiken in 2 grosse Gruppen, sofern sie der vorantiseptischen und antiseptischen - anderntheils der aseptischen Aera angehören. Der Uebergang fällt ungefähr in die zweite IIälfte der 80er Jahre.

Statistiken der vorantiseptischen und antiseptischen Aera. 
Leber die Enderfolge der operativen Behandlung bei Coxitis tuberculosa. 33




I. Manninger

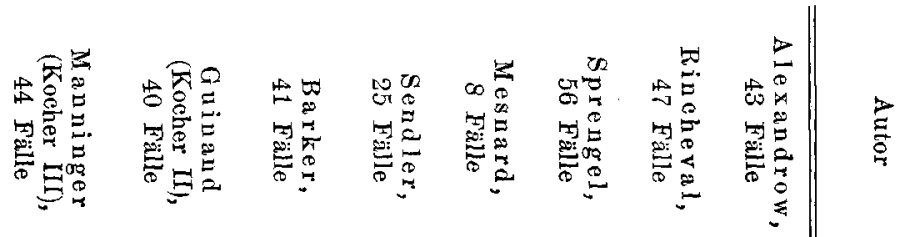

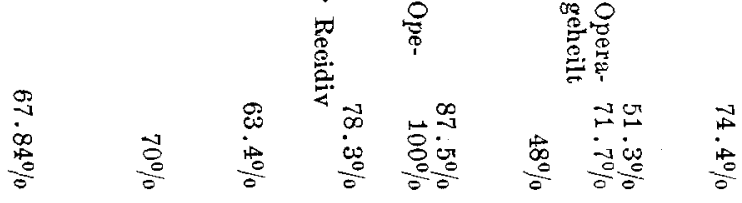

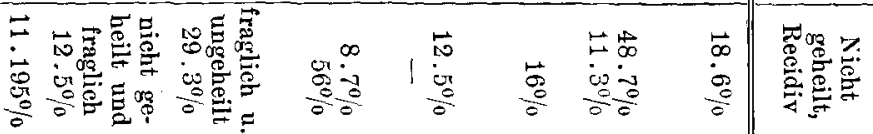

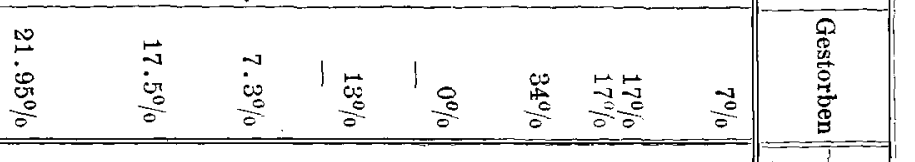

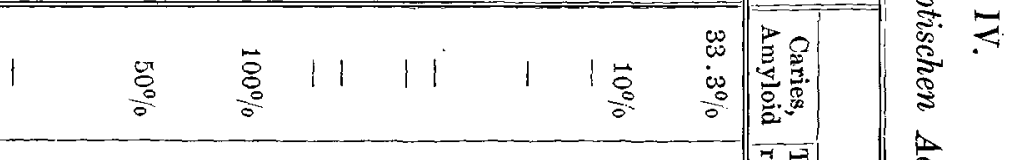

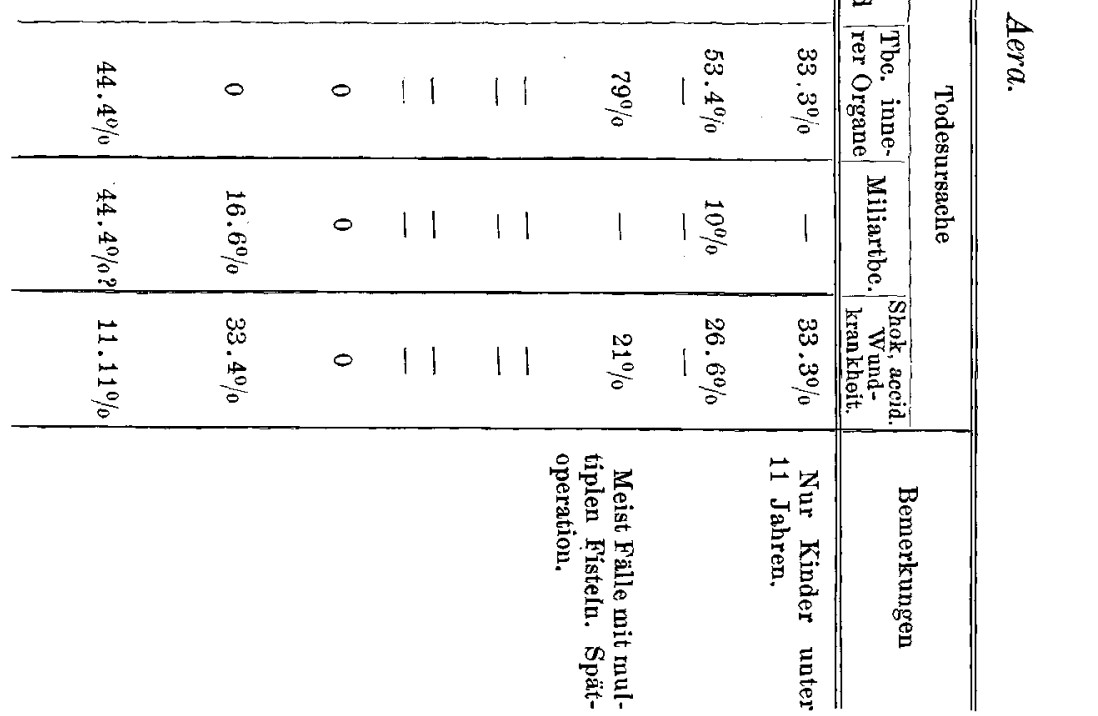


Leber die Enderfolge der operativen Behandlung bei Coxitis tuberculosa. 35

Vergleicht man nun die beiden Tabellen, so ist ein immenser Fortschritt in den Erfolgen der operativen Therapie in die Augen springend. Will man Durchschnittszahlen nehmen (unter Weglassung derjenigen Statistiken, die keine Endresultate bringen, aus der ersten Tabelle die Zahlen Riedel's, aus der zweiten die Mesnard's und Sendler's), so kommt man zu folgenden Zahlen:

Dauerheilung in der vorantiseptischen und antiseptischen Zeit: 34,4 Proc. gegen 65,8 Proc. in der aseptischen Aera. Gesammtmortalität 54,31 * $\quad 17,4=$

Und doch findet man in allen Handbüchern und für die conservative Methode plaidirenden Artikel immer noch die obigen Zahlen der septischen Zeit. Es muss nun noch hinzugefügt werden, dass in fast allen Kliniken die Resection im Sinne der Spätresection gemacht wird, gegen die früheren Jahre. Man versucht eben immer das ganze Arsenal der conservativen Behandlung, ehe man zum Messer greift. Die Besserung der Resultate ist nicht allein der peinlicheren Fernhaltung der Eitererreger zuzuschreiben. Es kommt dazu die feiner und rationeller ausgebildete Technik. So wurde bei den meisten Operationen der ersten Tabelle bloss der Knochen entfernt und die Kapsel, wohl auch mancher Pfannenherd unberücksichtigt gelassen.

Ich habe, soweit es aus den verschiedenen Arbeiten, die von ganz abweichenden Gesichtspunkten eingetheilt sind, die Todesursachen berechnet und zwar so, dass immer das Verhältniss zu 100 berechnet ist. Die Tabelle ist also folgendermaassen zu lesen:

Albrecht: Von sämmtlichen Todesfällen erfolgte der Tod an fortschreitender Caries, Eiterung und Anyloid in 47,1 Proc., an Tuberculose innerer Organe 47,1 Proc., an accidentellen Wundkrankheiten 5,8 Proc.

Während bei der ersten Serie die locale Erkrankung, Eiterung, fortschreitende Caries den grössten Theil der Todesfälle bedingt, wozu noch die accidentellen Wundkrankheiten kommen (die 2 Factoren machen ungefähr zwei Drittel der Todesfälle aus), ist in neueren Statistiken meist allgemeine Tuberculose und Tuberculose innerer Organe die Todesursache, während der räthselhafte Shock, die Sepsis, fast ganz verschwunden sind.

Wie verhält es sich nun mit den Frgebnissen der conservativen Statistik? Da die conservative Behandlung der Coxitis seit Billr oth nicht viel Wandlungen durchgemacht bat, kann ich wohl auch die Statistiken Billroth's mit heranziehen. 
Tabelle V.

Conservative Statistik.

\begin{tabular}{|c|c|c|c|c|c|c|}
\hline \multirow{2}{*}{ Autor } & \multicolumn{2}{|c|}{ Geheilt } & \multicolumn{2}{|c|}{ Nicht geheilt } & \multicolumn{2}{|c|}{ Gestorben } \\
\hline & eitrig & nicht eitrig & eitrig & nicht eitrig & eitrig & nicht eitrig \\
\hline $\begin{array}{l}\text { Billroth, } \\
\qquad 1860-1876\end{array}$ & 13.5 & 80 & 30.5 & 8.3 & 56 & 11.7 \\
\hline $\begin{array}{l}\text { Rosmanit, } \\
\qquad 1877-1880\end{array}$ & 22.7 & 84.6 & 31.8 & - & 45.4 & 15.4 \\
\hline $\begin{array}{l}\text { Thausing, } \\
\qquad 1881-1891\end{array}$ & 34.9 & 70.8 & 39.5 & 17.2 & 26.6 & 12 \\
\hline Bruns-Wagner, & 42 & 77.5 & - & - & 52 & 22.5 \\
\hline Caumont. & 26.3 & 70 & 10.5 & 5.0 & 63 & 25 \\
\hline Marsch... & 37.5 & 62.5 & 12.5 & 25 & 50 & 12.5 \\
\hline Henle $\cdot \cdot$. & & 4.1 & $\begin{array}{r}\text { ge } \\
\text { nich }\end{array}$ & $\begin{array}{l}\text { essert } \\
.8 \\
\text { geheilt } \\
.2\end{array}$ & & 6.7 \\
\hline Albrecht. . & & 68 & & .4 & & 2.6 \\
\hline Pedolin... & & 62 & & .7 & & 3.7 \\
\hline
\end{tabular}

Macht man die Durchschnittsberechnung, so kommen für eitrige Fälle 27,1 Proc. Heilung $48,8=$ Mortalität,

für nicht eitrige Fälle $74,2=$ Heilung $16,5=$ Mortalität.

Die Statistiken, wo keine Scheidung in diese zwei Kategorien vorhanden war, sind nicht mitberechnet; die fehlenden Fälle sind noch ungeheilte Fälle. Ich habe einige Statistiken, so die von Lorenz und M esnard absichtlich nicht mitgerechnet, da sie ganz besonders günstiges Material unter günstigen äusseren Verhältnissen zur Verfügung hatten. Das angeführte Material stammt meist aus den grösseren deutschen Kliniken, ist ziemlich gleichwerthig und kann also $\mathrm{zu}$ Schlüssen herangezogen werden.

Die Consequenz, die man aus obigen Zahlen ziehen kann (die Heilungsziffer für eitrige Fälle ist entschieden zu niedrig, da ein Theil der Fälle noch nicht ausgeheilt war), ist die, dass die operative Statistik für eitrige Fälle - und solche sind zum grossen Theil die in den letzten zehn Jahren resecirten - entschieden bessere Resultate giebt, als die conservative. Die Heilungsziffern stehen nicht viel hinter 
den der nichteitrigen, conservativ behandelten zurïck (65,8 Proc. gegen 74,2 Proc.), die Mortalität ist nicht viel höher, als die bei conservativ behandelten nicht eitrigen Fällen (16,5 Proc. gegen 17,4 Proc.).

Wenn man nun den Kernpunkt der Frage ins Auge fasst und die Frage aufwirft: wann soll operirt werden, so lässt sich die Antwort nicht so leicht geben, auf keinen Fall schematisch lösen.

Man muss zwei Gruppen von Kranken unterscheiden; jene der social besser Situirten, die die lange dauernde conservative Therapie bis zum Ende rationell durchführen und durch entsprechende hygienische Maassregeln unterstïtzen können, und jene grosse Zahl der weniger gut Situirten, für die es eine Lebensfrage ist, bald auf die Füsse zu kommen, bald gesund zu werden. Diese Kastenindication schmeckt stark mittelalterlich und scheint durchaus nicht wissenschaftlich genug zu sein, und doch glaube ich, dass sie praktische Wichtigkeit hat. Ich erinnere nochmals an die Erfolge, die Lorenz, Mesnard, $\mathrm{H}_{0}$ f fa an ihren Privatpatienten aufweisen konnten. Für beide Klassen jedoch, glaube ich, besteht beute noch die Indication, die II ueter in seiner Klinik der Gelenkkrankheiten dahin formulirt hat: "Ich halte die Resection bei Coxitis für indicirt, sobald eine ausgedehnte Eiterung des Gelenkes sich manifestirt, oder sobald der Verlauf lehrt, dass der Ausgang in Eiterung nicht mehr verhütet werden kann."

Die Eiterung so in den Vordergrund der Frage zu stellen, scheint bei den Erfolgen, die die Jodoforminjection bei Abscessen aufweist, etwas incorrect. Es ist aber bekannt, dass die Eiterung als solche das Ausheilen des Grundprocesses sehr schlecht beeinflusst. Sie verhindert die rasche Bildung von schwieligen, abkapselnden Processen, die wir als den Heilungsvorgang der Tuberculose kennen gelernt haben, sie führt häufig zur Bildung von fistulösen Processen, deren wir gerade an der Ilüfte so schwer Herr werden können. Sie verschlechtert die Prognose quoad vitam (ich verweise nur auf die oben gegebenen Statistiken Billroth's, Brun's) und quoad functionem. Man kann von einem vereiterten Hüftgelenk sicher sein, dass es in Ankylose ausheilen wird.

Was den zweiten Punkt anbelangt, haben wir in der Röntgenphotographie eine sehr werthvolle Hilfe bekommen. Man kann mit Hilfe derselben Knochenherde mit ziemlicher Sicherheit nachweisen. Der Schluss wird durch die klinische Untersuchung bestätigt. Die $\Lambda$ usheilung derselben ist meist verzögert, sie bieten den grössten Procentsatz der Recidive.

Wenn man nun bei der obigen Indicationsstellung die Scheidung 
in die zwei Classen - besser situirte und arme Bevölkerung - beibehält, so ist dies auch wichtig für die Art der Operation.

Bei den Kranken, von denen man sicher sein kann, dass sie einer lauf Jahre hinausgehenden Behandlung nichts in den Weg stellen, die einer consequent durchzuführenden mechanischen und Injectionstherapie zugänglich sind, kommt es bekanntlich weniger häufig zur Eiterung. Hs giebt aber auch bei diesen schwere Knochenerkrankungen, da man am besten so früh als möglich operirt. Gerade hier, wo man auf ein bewegliches Hüftgelenk rechnen kann, kommt es darauf an, die Resection zu einer Zeit auszufübren, wo die Atrophie der Beckenmuskeln keinen hohen Grad erreicht hat, also Aussicht bietet auf gutes functionelles Resultat. Nur bei den Fällen, die einer genauen, auf lange Zeit sich erstreckenden orthopädischen Nachbehandlung zugänglich sind, soll man auf bewegliches Gelenk hinarbeiten.

Bei den Fällen zweiter Kategorie ist eine consequente conservative Therapie oft undurchführbar. Trotz dem Einführen der Gypsverbände, deren Wohlthat auch den ärmeren Kreisen zugänglich ist, kann jeder Arzt, der längere Zeit an einer chirurgischen Poliklinik thätig war, die Beobachtung machen, wie viele Kranke sich der Behandlung entziehen. Nach 1-2 Verbänden bleibt der Patient aus. Der Verband wird abgenommen, der Kranke bleibt ohne Verband im Bett, läuft auch wohl auf seinem kranken Bein herum, bis sich wieder eine Contractur bildet oder das Leiden sich verschlimmert. Man sucht eine andere Ambulanz auf, bekommt wieder einige Injectionen oder Gypsverband und so geht das Monate, oft Jahre hin, bis früher oder später ein Abscess oder eine Fistel zum Vorschein kommt, die bei consequenter Behandlung vielleicht nicht entstanden wäre. Dies mag wohl mit ein Grund sein, abgesehen davon, dass oft überhaupt lange Zeit bis zum Einholen ärztlichen Rathes verstreicht, warum in der Armenpraxis die Abscedirungen um so vieles häufiger sind, als in der Privatpraxis. Die Operation dürfte daher öfter ihre Indication finden, als bei der ersten Kategorie, sich also nicht bloss auf eitrige und schwer ostale Fälle beschränken.

Was nun die Differenz der Operation betrifft, so sollte hier immer die Heilung in Ankylose erstrebt werden. Hält man an der obigen Indication fest - Knochenerkrankung und Eiterungen -, so ist bei conservativer Behandlung auch Ankylose zu erwarten. Dazu kommt noch, dass gute Function nur bei systematischen, lange fortgeleiteten, orthopädischen Maassnahmen zu erwarten wäre, denen sich, schon der damit verbundenen Kosten und Zeit wegen, diese Kranken regelmässig ent- 
ziehen. Ob man mit Bardenheuer Becken und Femur vernagelt, oder die Ankylose mit Gehgypsverband, in dem die Patienten herumlaufen können und der möglichst lange, bis zur vollständigen Ankylose liegen soll, erreicht, hängt vom individuellen Geschmack des Operateurs ab; jedenfalls kann man sie in einer grossen Zahl der Fälle erreichen und entgeht damit den lästigen secundären Contracturen, wenn man auch nicht vergessen darf, dass sich secundär noch eine Verbiegung des Knochens ähnlich der von König für das Kniegelenk geschilderten Femurschaftverbiegung einstellen kann. Es beruht dieses Verbiegen wohl auf der durch das Röntgenbild nachweisbaren und bei der Operation so oft gefundenen Knochenatrophie, gehört aber jedenfalls $\mathrm{zu}$ den seltenen Vorkommnissen, trotzdem sein allfälliges Vorkommen von ausgezeichneten Beobachtern constatirt ist.

Die Indicationsstellung entspricht im Grossen der von König gegebenen. Die guten Resultate bei den anderen Gelenken, die immer fortschreitende Verbesserung der operativen Technik dürfte wohl dazu beitragen, diese Indicationen noch etwas weiter zu stecken. Ich liess absichtlich einen Punkt unberührt, weil er ganz incommensurabel und von den Anschauungen des Operateurs abhängig ist. Es ist dies die Indication, die man öfter folgendermaassen definirt: die operative Therapie tritt in ihr Recht, wenn bei conservativer Therapie kein Erfolg zu verzeichnen ist. Wann können wir nun bei einer so langwierigen Krankheit, wie die Coxitis - und wohl die meisten Gelenktuberculosen - von Erfolg sprechen? Die meisten Fälle kommen nach Monaten, oft nach Jahren in die chirurgischen Kliniken. Nur eine genaue Untersuchung, eine möglichst in's Detail gehende Diagnose kann uns Aufschluss geben über unser Verhalten. Kann man starke destructive Processe ausschliessen, soll man die conservative Therapie einleiten oder fortsetzen; nur eine möglichst genaue anatomische Diagnose soll uns das Messer in die Hand drücken. Auf keinen Fall soll man warten, bis fistulöse Processe, die doch meist - wenn nicht immer - mit Mischinfection einhergehen, die Prognose um so vieles verschlechtern. Aus demselben Grund ist die einfache Incision der Abscesse zu verwerfen. Selbst bei peinlichster Sorgfalt gelingt es uns selten, eine secundäre Infection ferne zu halten. Prof. Kocher betont oft in seiner Klinik, dass man einen tuberculösen Abscess nur öffnen darf, wenn man die Hoffnung hat, den primären Knochenprocess oder zu Grunde liegenden tuberculösen Herd überhaupt mit zu entfernen. Die Abscesse communiciren meist mit dem Gelenk, und so bedeutet die Infection des Abscesses meist gleichzeitig die des Gelenkes. Hat man es nur auf Heilung des Ab- 
scesses abgesehen, so leistet die Punction mit Jodoforminjection entschieden Besseres, als die Incision. Heilt auch der Abscess nicht, hat man wenigstens nicht geschadet.

Zum Schlusse noch eine Indication. Hat sich im Verlaufe der Coxitis, eine sogenannte secundäre Luxation - oder besser Pfannenwanderung - eingestellt, so bietet die Operation auch die besten Aussichten auf eine gute Function. Ganz zwingend drängt sich uns die Operation auf bei fistulösen Processen. Hält man aber

Ta b ellen.

\begin{tabular}{|c|c|c|c|c|c|c|c|c|c|}
\hline Name, Alter & 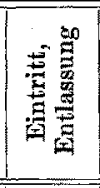 & 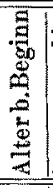 & 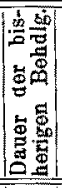 & 要 & 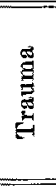 & $\frac{0}{\square .0}$ & $\begin{array}{l}\text { Anamnesti- } \\
\text { sche Daten }\end{array}$ & $\begin{array}{c}\text { Statas beim } \\
\text { Eintritt }\end{array}$ & Therapie \\
\hline $\begin{array}{c}\text { 1. R...t, } \\
\text { Marthe, } \\
\text { Montaudon- } \\
\text { Chauxdefonds } \\
6 \text { Jahre. }\end{array}$ & $\begin{array}{c}\text { 9. Jan. } \\
1887 . \\
5 . \\
\text { April } \\
1887 .\end{array}$ & $5 \mathrm{~J}$. & $\begin{array}{c}7 \\
\mathrm{M} .\end{array}$ & $\begin{array}{c}\text { Gross- } \\
\text { mutter } \\
\text { t an } \\
\text { Phty- } \\
\text { se. }\end{array}$ & - & L. & $\begin{array}{c}\text { Vor 2 Jahren } \\
\text { Masern, An- } \\
\text { fangmit Frost, } \\
\text { Delirium; } \\
\text { hinkt seit } 4 \\
\text { Monaten. Ab- } \\
\text { duction vor } 3 \\
\text { Monaten be- } \\
\text { merkt. }\end{array}$ & $\begin{array}{l}\text { Rechtswinklige } \\
\text { Fl. und A. R., Be- } \\
\text { wegungen sehr } \\
\text { schmerzhaft, Bec- } \\
\text { ken fixirt. Im Urin } \\
\text { nichts d bnormes, } \\
\text { Lungen normal. }\end{array}$ & $\begin{array}{l}\text { 18. Jan. } 1887 \\
\text { Hinterer Winkel- } \\
\text { schnitt, Entfer- } \\
\text { nung der fungösen } \\
\text { Kapsel sammt } \\
\text { oberf. Knochen- } \\
\text { schicht an Kopf } \\
\text { und Pfanne, Jodo- } \\
\text { formtamponade } \\
\text { nach Spülung mit } \\
\text { Salzwasser. }\end{array}$ \\
\hline $\begin{array}{c}\text { 2. F } \ldots . . . x \\
\text { Otto, Beip, } \\
11 \text { Jahre. }\end{array}$ & $\begin{array}{c}\text { 10. Mai } \\
1887 . \\
3 . \text { Nov. } \\
1887 .\end{array}$ & - & - & - & 一 &.-- & 一 & $\begin{array}{l}\text { Starke Adduc- } \\
\text { tion u. A. R. Re- } \\
\text { elle Verkürzung } \\
2 \mathrm{~cm} \text {. Schwellung } \\
\text { der Trochanter- } \\
\text { gegend. Elastische } \\
\text { tiefgelegene } \\
\text { Schwrellung unter } \\
\text { d. äusseren Hälte } \\
\text { des Poupart'schen } \\
\text { Bandes; Becken } \\
\text { Gxirt, jede Be- } \\
\text { wegung sehr } \\
\text { schmerzhaft. Im } \\
\text { Urin kein Eiweis. } \\
\text { Lunge normal, } \\
\text { keine Drüsen. }\end{array}$ & $\begin{array}{l}\text { 1T. Mai } 1887 . \\
\text { Entleerung des } \\
\text { Abscesses v.vorne; } \\
\text { grosser Knochen- } \\
\text { herd. Hinterer } \\
\text { Winkelschnitt. } \\
\text { Bei Reposition } \\
\text { bricht d. Kopf ab; } \\
\text { Entfernung des- } \\
\text { selben. Aeusserer } \\
\text { Theil d. Troehan. } \\
\text { ter major entfernt. } \\
\text { Jodoformgaze- } \\
\text { tamaponade. Ex. } \\
\text { tension beider- } \\
\text { seits. }\end{array}$ \\
\hline
\end{tabular}


Ueber die Enderfolge der operativen Behandlung bei Coxitis tuberculosa. 41

- und sicher zu Gunsten der Patienten - an den obigen Indicationen fest, so dürften diese Spätresectionen mit der Zeit zur Ausnahme werden.

Herrn Prof. Kocher sage ich für das überaus liebenswürdige Entgegenkommen, sowie für die Ueberlassung seines werthvollen Materials hiermit meinen herzlichsten Dank.

Bern, Februar 1902.

Tabellen.

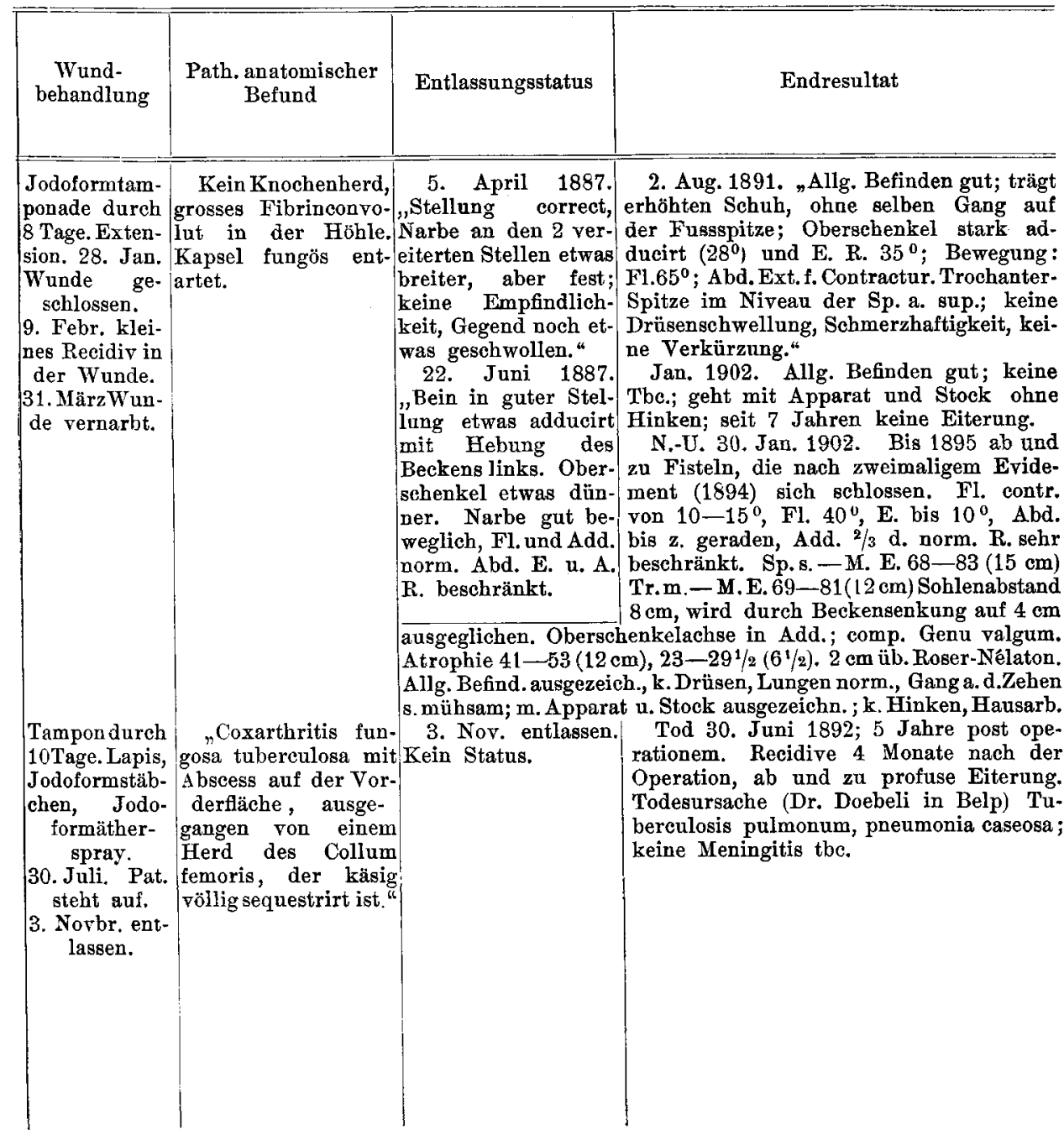




\begin{tabular}{|c|c|c|c|c|c|c|c|c|c|}
\hline Name, Alter & = & 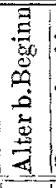 & 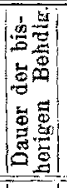 & 戀 & 莺 & $\underset{\mathbb{D}}{\mathbb{5}}$ & $\begin{array}{l}\text { Avamnesti- } \\
\text { sche Daten }\end{array}$ & $\begin{array}{l}\text { Status beim } \\
\text { Eintritt }\end{array}$ & Therapie \\
\hline $\begin{array}{l}\text { 3. G...t, } \\
\text { Elisabeth, } \\
\text { Auvernier, } \\
10 \text { Jahre. }\end{array}$ & $\mid \begin{array}{l}\text { 5.April } \\
\text { 1889. } \\
\text { Mitte } \\
\text { April } \\
1889 .\end{array}$ & $7 \pi$ & $\begin{array}{c}3 \\
\mathrm{M} .\end{array}$ & $\begin{array}{c}\text { Mutter } \\
+ \text { an } \\
\text { chron. } \\
\text { Peri- } \\
\text { tonitis. }\end{array}$ & - & R. & $\begin{array}{l}\text { Anfang plötz- } \\
\text { lieh mit } \\
\text { Schmerzen, } \\
\text { Frost und Fie- } \\
\text { ber, 1/2 Jahr } \\
\text { lag das Kind } \\
\text { in Gouttiere, } \\
\text { dann Bäder- } \\
\text { behandlung; } \\
\text { seit 1 Jahre } \\
\text { keine Schmer- } \\
\text { zen. }\end{array}$ & $\begin{array}{l}\text { FI, contr. 65, } \\
\text { Add. 450. Geringe } \\
\text { A. R. Active be-- } \\
\text { weglichkeit 0; } \\
\text { passiv ebenfall. } \\
\text { Druck nicht } \\
\text { schmerzbaft. Lun- } \\
\text { ge normal, keine } \\
\text { Drüsensehwel- } \\
\text { I ung. KeinEiweiss. } \\
\text { Hinkt sehr stark, } \\
\text { Gang mit Stock } \\
\text { mühsam. }\end{array}$ & $\begin{array}{l}\text { 16. April } 1889 . \\
\text { Hinterer Winkel- } \\
\text { sehnitt; b. Heraus- } \\
\text { Iuxiren Fract in- } \\
\text { tertrochanterica; } \\
\text { Pfanne, Kopf ab- } \\
\text { gehobelt, Granu- } \\
\text { lationen entfernt. } \\
\text { \& pülen mit Snbli- } \\
\text { mat u. Salzwasser. } \\
\text { Jodoformtampo- } \\
\text { nade. Extension. }\end{array}$ \\
\hline $\begin{array}{c}\text { 4. H.......g, } \\
\text { Henri, } \\
\text { Neuchatel, } \\
10 \text { Jahre. }\end{array}$ & $\begin{array}{c}30 . \\
\text { April } \\
1889 . \\
18 . \\
\text { Juni } \\
1889 . \\
28 . \\
\text { Fe- } \\
\text { bruar } \\
1890 . \\
18 . \\
\text { April } \\
1890 .\end{array}$ & $9 \mathrm{~J}$. & $\begin{array}{c}1 \\
\text { M. }\end{array}$ & $\begin{array}{l}\text { Gross- } \\
\text { mutter } \\
\text { päterl. } \\
\text { seits † } \\
\text { Phty. } \\
\text { se. }\end{array}$ & - & L. & $\begin{array}{l}\text { Hatte vor 1 } \\
\text { Jahr Magern, } \\
\text { um Ostern bil- } \\
\text { dete sich ein } \\
\text { Abscess in der } \\
\text { Häftgegend, } \\
\text { ohne Schmer- } \\
\text { zen; Eröff- } \\
\text { nung dessel- } \\
\text { ben. Seit } 8 \text { Mo- } \\
\text { naten Hinken } \\
\text { Extension. Nie } \\
\text { spontane } \\
\text { Schmerzen. }\end{array}$ & $\begin{array}{l}\text { F1. contr. } 30^{\circ} . \\
\text { Starke Abd., } \\
\text { schwach A. R. Gut } \\
\text { entwickeiter,sonst } \\
\text { gesunder Knabe. } \\
\text { Pr. Sehwerz. Urin } \\
\text { viel Phosphate, } \\
\text { kein Eiweiss. } \\
\text { Am 28. Febr. } \\
\text { 1890. Fistel am } \\
\text { oberen Ende der } \\
\text { Narbe. Keine } \\
\text { Schwellung und } \\
\text { Empfindliehkeit. } \\
\text { Add. 8 , A. R., } \\
\text { Patient geht hin- } \\
\text { kend. Urin kein } \\
\text { Eiweiss. }\end{array}$ & $\begin{array}{l}\text { 7. Mai } 18 \$ 9 . \\
\text { Hinterer Bogen- } \\
\text { schnitt ; Abho- } \\
\text { belung von Kopt } \\
\text { und Pfanne. Drai- } \\
\text { nage nach aussen. } \\
\text { Jodoformtampo- } \\
\text { zade. Naht. Ex- } \\
\text { tension. Sublimat. } \\
\text { Saluwasser - Spin- } \\
\text { lung. } \\
\text { 11. Märy 1890. } \\
\text { Fistel wird aus } \\
\text { gekratzt. } 1 \text { cm } \\
\text { vom Kopf entfernt } \\
\text { u. Troohanter ab- } \\
\text { geschrägt, dass des } \\
\text { Adam'sche Bogen } \\
\text { i.d.Pfanne kommt. } \\
\text { Nabt. }\end{array}$ \\
\hline $\begin{array}{l}\text { 5. Chételat, } \\
\text { Angéline, } \\
4 \text { Jahre, } \\
\text { Courcelon. }\end{array}$ & $\begin{array}{c}24 . \text { Fe- } \\
\text { bruar } \\
1890 . \\
29 . \\
\text { April } \\
1890 .\end{array}$ & $4 \mathrm{~J}$. & $\frac{4}{\mathrm{M}}$ & - & - & $\mathbf{R}$. & $\begin{array}{l}\text { Vor 4 Monaten } \\
\text { Scarlatina. } \\
\text { Seitdem will } \\
\text { das Kind nicbt } \\
\text { aufstehez ; erst } \\
\text { in letzter Zeit } \\
\text { istVerkürzung } \\
\text { und E. R. auf- } \\
\text { gefallen. }\end{array}$ & $\begin{array}{l}\text { Add, contractur. } \\
\text { E. R. Becken } \\
\text { rechts gehoben; } \\
\text { Geleakgegend } \\
\text { gtark gesch wollen. } \\
\text { Abscess in der Re- } \\
\text { gio glutealis. Iun- } \\
\text { gen normal. Kein } \\
\text { Eiweiss. Vor der } \\
\text { Operation einige } \\
\text { Mal Fieber bis } \\
\text { 38-39. }\end{array}$ & $\begin{array}{l}\text { Abscess punc- } \\
\text { tirt, eröfnet, in } \\
\text { Eiter Staphylo- } \\
\text { coceen. } \\
\text { 20. Mai. Resec- } \\
\text { tion des Kopfes } \\
\text { 7. vorne. (Hüter's } \\
\text { Längsschnitt.)Ex- } \\
\text { tirpat. d. Kapsel. } \\
\text { Thymolgazetam- } \\
\text { ponade. Exten- } \\
\text { sion. }\end{array}$ \\
\hline
\end{tabular}




\begin{tabular}{|c|c|c|c|}
\hline $\begin{array}{l}\text { Wund- } \\
\text { behandlung }\end{array}$ & $\begin{array}{l}\text { Path. anatomischer } \\
\text { Befund }\end{array}$ & Entlas sungsstatus & Endresultat \\
\hline $\begin{array}{l}\text { Tampon und } \\
\text { Naht nach } 7 \\
\text { Tagen ent- } \\
\text { fernt. } \\
\text { 15. Juni Geh- } \\
\text { versuche. } \\
\text { Gelenk noch } \\
\text { etwas schmerz- } \\
\text { haft. } \\
\text { 18. Juni ent- } \\
\text { lassen. } \\
\text { 16.März Nähte } \\
\text { entfernt, Nar- } \\
\text { be weit er- } \\
\text { offnet. Salicyl- } \\
\text { pulver in die } \\
\text { Wunde. } \\
\text { 18. April ent- } \\
\text { lassen. }\end{array}$ & $\begin{array}{l}\text { "Coxarthritis dif- } \\
\text { fusa fungosa ohne er- } \\
\text { sichtlichen Knochen- } \\
\text { herd; Kopf u. Pfanne } \\
\text { oberflächlich zerstört, } \\
\text { Epiphyse noch er- } \\
\text { halten. Bloss noch } \\
\text { Knorpelreste; viel } \\
\text { fungöse Granulatio- } \\
\text { nen. (Das geimpfte } \\
\text { Meerschweinchen ist } \\
\text { tuberculös ge- } \\
\text { worden.)، }\end{array}$ & 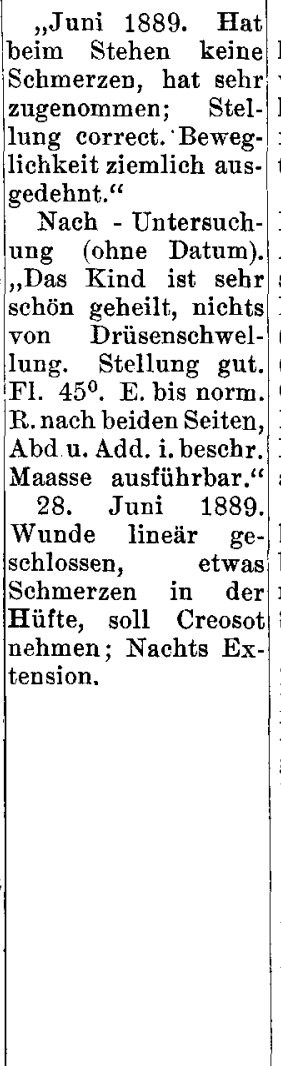 & 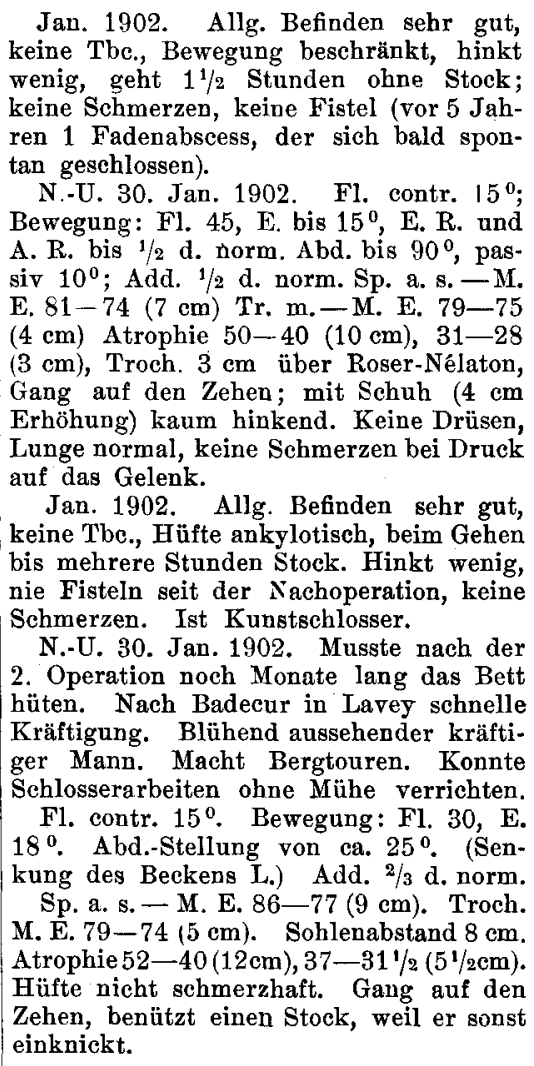 \\
\hline $\begin{array}{l}\text { Offene Wund- } \\
\text { behandlung. } \\
\text { Chlorzink. } \\
\text { 29. Juni Wun- } \\
\text { den geheilt. } \\
\text { Nie Fieber. }\end{array}$ & $\begin{array}{l}\text { "Abscessbildung } \\
\text { hinten und vorne } \\
\text { am Gelenk. Fisteln } \\
\text { führen zum Kopfe,der } \\
\text { ganz verschwunden } \\
\text { ist. In der Gelenk- } \\
\text { höhle mehrere Seque- } \\
\text { ster mit käsig. Granu- } \\
\text { lationen, welche ganz } \\
\text { den Charakter der } \\
\text { tbc. Granulationen } \\
\text { haben." }\end{array}$ & $\begin{array}{l}\text { 29. Juni } 1890 \text {. Hin- } \\
\text { tere Wunde (Abscess) } \\
\text { ganz verheilt. Vorn } \\
\text { kleiner Granulations- } \\
\text { pfropf, der nicht in } \\
\text { die Tiefe führt. Stel- } \\
\text { lung des Beines sehr } \\
\text { gut. } \\
\text { Fl. bis } 130^{\circ}, \text { E. R. } \\
\text { u. Abd. gut. Knie in } \\
\text { geringer Valgusstel- } \\
\text { lung. }\end{array}$ & $\begin{array}{l}\text { Jan. 1902. Allg. Befinden sehr gut, } \\
\text { keine Tbc. Bewegung beschränkt, kann } \\
\text { ohne Stock gehen, leichter mit selbem. } \\
\text { Gang stark hinkend. Haus- und Feldar- } \\
\text { beit. Ab und zu Schmerzen und leichte } \\
\text { Fisteleiterung im Winter Das Bein soll } \\
\text { im Wachsthum zurückgeblieben sein. } \\
\end{array}$ \\
\hline
\end{tabular}




\begin{tabular}{|c|c|c|c|c|c|c|c|c|c|}
\hline Name, Alter & 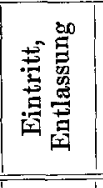 & 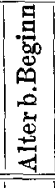 & 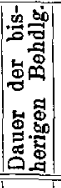 & 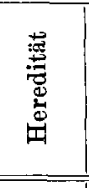 & 苞 & : & $\begin{array}{l}\text { Anamnesti- } \\
\text { sche Daten }\end{array}$ & $\begin{array}{c}\text { Status beim } \\
\text { Eintritt }\end{array}$ & Therapie \\
\hline $\begin{array}{c}\text { 6. A....t, } \\
\text { George, } \\
\text { Savagnier, } \\
6 \text { Jahre. }\end{array}$ & $\mid \begin{array}{c}26 . \\
\text { März } \\
1891 . \\
23 . \text { Mai } \\
1891 .\end{array}$ & $4 \mathbf{J}$ & $2 \mathrm{~J}$. & - & $\begin{array}{c}\text { Trau- } \\
\text { ma. }\end{array}$ & R. & $\begin{array}{l}\text { Schmerzen im } \\
\text { r. Knie vor } 2 \\
\text { Jahren, Hin- } \\
\text { ken, allg. Be- } \\
\text { handlg. Dann } \\
\text { perm. Exten- } \\
\text { sion. Intermit- } \\
\text { tirend Besse- } \\
\text { rung. Seit } 2 \\
\text { Monaten Hin- } \\
\text { ken stärker. }\end{array}$ & $\begin{array}{l}\text { Fl. contr. } 30^{\circ}, \\
\text { leichte A. R.Abd., } \\
\text { Becken rechts ge- } \\
\text { senkt. Atrophie } \\
\text { der Musculatur } \\
\text { bis am Unter- } \\
\text { schenkel. Lungen } \\
\text { normal, in der } \\
\text { Fossa iliaca eine } \\
\text { pflaumengrosse } \\
\text { Drüse. Kein Ei- } \\
\text { weiss. }\end{array}$ & $\begin{array}{r}\text { 1. April } 1891 . \\
\text {,Arthrectomie m. } \\
\text { Kocher's Winkel- } \\
\text { schnitt; dbtragung } \\
\text { des Kopfes z.TTheil } \\
\text { bis zurEpiphysen- } \\
\text { linie." }\end{array}$ \\
\hline $\begin{array}{c}\text { 7. Schärr, } \\
\text { Ernst, } \\
\text { Gondiswyl, } \\
4 \text { Jahre. }\end{array}$ & $\begin{array}{c}30 . \\
\text { Juni } \\
1891 . \\
16 . \\
\text { Aug. } \\
1891 .\end{array}$ & $3 \mathrm{~J}$. & $1 \mathrm{~J}$ & - & - & L. & $\begin{array}{l}\text { Vor 1 Jahre } \\
\text { Schmerzen in } \\
\text { der Hüfte, } \\
\text { Hinken. Vor } \\
4 \text { Monaten } \\
\text { Trauma durch } \\
\text { Repositions- } \\
\text { versuche eines } \\
\text { Wunder- } \\
\text { doctors. Seit- } \\
\text { her starkeVer- } \\
\text { schlimmerg. } \\
\text { Vor } 2 \text { Monaten } \\
\text { Scarlatina. } \\
\text { Seither bett- } \\
\text { lägerig. } \\
\text { Schmerzen im } \\
\text { Knie. }\end{array}$ & $\begin{array}{l}\text { Fl. Add.u.A.R. } \\
\text { Contr. Activ keine } \\
\text { Bewegung, passiv } \\
\text { Fl. von } 65-120^{\circ} \\
\text { Druck und Bewe- } \\
\text { gung sehr } \\
\text { schmerzhaft. In } \\
\text { Narkose: E.R frei, } \\
\text { Bein schnellt je- } \\
\text { doch in Aussen- } \\
\text { rotation zurück, } \\
\text { E. auch möglich. } \\
\text { Gegend d. Schen- } \\
\text { kelhalsesverdickt. } \\
\text { Lungen normal. }\end{array}$ & $\begin{array}{l}\text { 19. Juni 1891. } \\
\text { Hinterer Winkel- } \\
\text { schnitt. Kopf und } \\
\text { Pfanneabgehobelt } \\
\text { Kapseltheile ent- } \\
\text { fernt. Wunde tam- } \\
\text { ponirt, bei luxir- } \\
\text { tem Kopfe. Spülen } \\
\text { mit Salzwasser. }\end{array}$ \\
\hline $\begin{array}{l}\text { 8. Spahr, Ida, } \\
\text { Corcelles, } \\
141 / 2 \mathrm{~J} \text {. }\end{array}$ & $\begin{array}{c}\text { 7. Mai } \\
1891 . \\
18 . \\
\text { Januar } \\
1892 .\end{array}$ & J. & $\begin{array}{c}31 / 2 \\
\mathrm{~J}\end{array} \mid$ & $\begin{array}{c}\text { Vater } \\
\text { hinkt. } \\
?\end{array}$ & $\begin{array}{l}\text { Distor- } \\
\text { sion, }\end{array}$ & $R$. & $\begin{array}{l}\text { Masern. Vor } \\
3 \text { Jahren Dis- } \\
\text { torsion; darauf } \\
\text { Schmerzen im } \\
\text { Knie ohne } \\
\text { Schwellung. } \\
\text { Vor 2 Jahren } \\
\text { nach Anstren- } \\
\text { gung Schmerz. } \\
\text { in der Hüfte. } \\
\text { Hinken. } \\
\text { Leichte } \\
\text { Schmerzen im } \\
\text { Knie. }\end{array}$ & $\begin{array}{l}\text { Add. } 78^{\circ}, \text { FI. } \\
30^{\circ} \text {, R. } 35^{0} \text {. } \\
\text { Gelenk fixirt. In } \\
\text { Narkose Abd. bis } \\
\text { z. Geraden, Fl. bis } \\
90^{\circ} \text {, R. frei. Ge- } \\
\text { gend desSchenkel- } \\
\text { halses verdickt. } \\
\text { Länge der Beine } \\
\text { gleich. R. Bein } \\
\text { atrophisch. Lung. } \\
\text { normal. Am Halse } \\
\text { Drüsen. }\end{array}$ & $\begin{array}{l}\text { 7.Februar 1891. } \\
\text { Hinterer Bogen- } \\
\text { schnitt. Kopf mit } \\
\text { Messer zuge- } \\
\text { schnitten. Pfanne } \\
\text { ausgeräumt, Kap- } \\
\text { sel so viel als mög- } \\
\text { lich erhalten. In } \\
\text { Luxationsstellung } \\
\text { mit Jodoformgaze } \\
\text { tamponirt. }\end{array}$ \\
\hline
\end{tabular}


Ueber die Enderfolge der operativen Behandlung bei Coxitis tuberculosa. 45

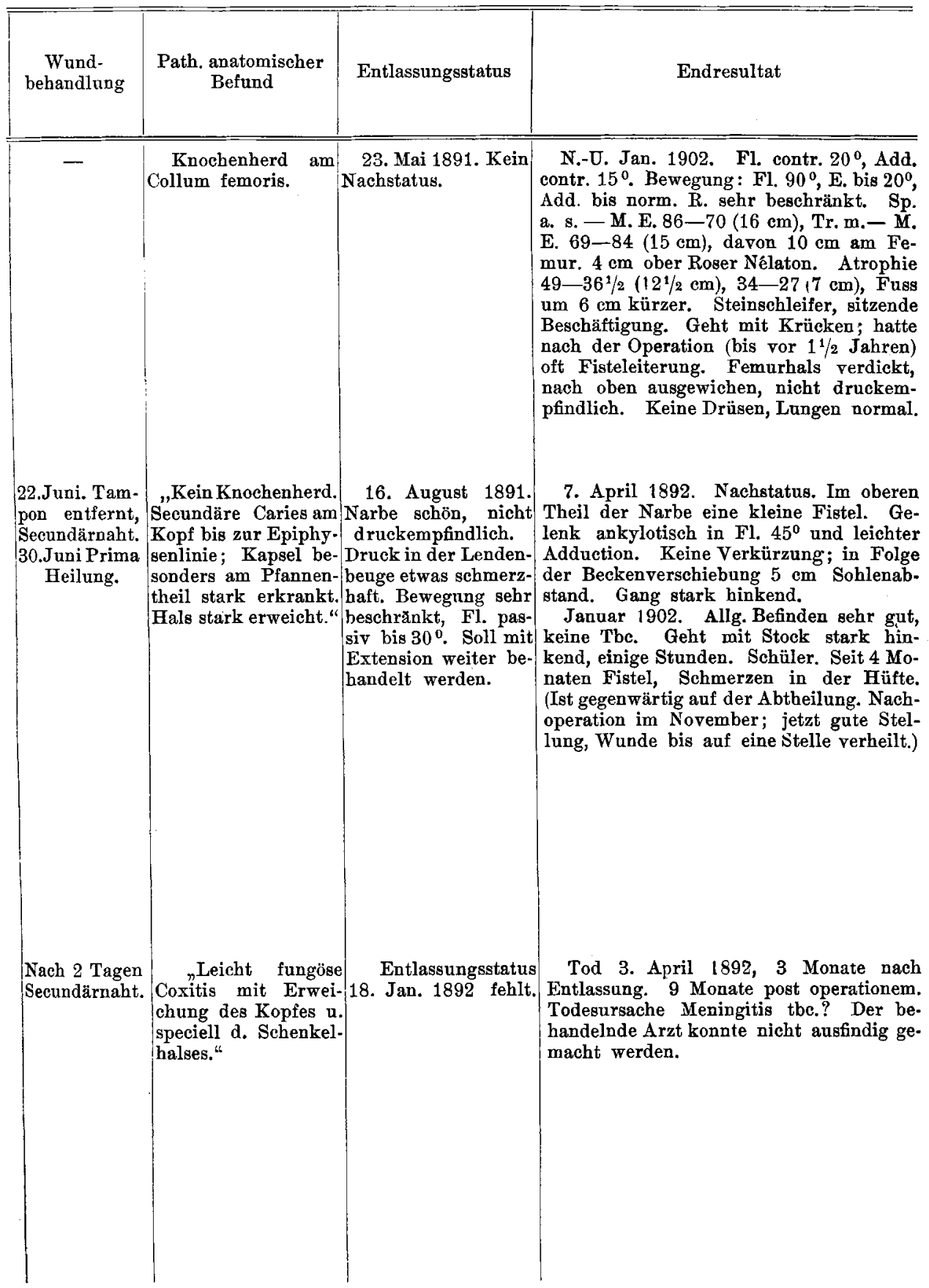




\begin{tabular}{|c|c|c|c|c|c|c|c|c|c|}
\hline Name, Alter & 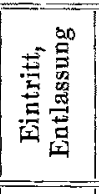 & 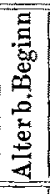 & 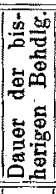 & 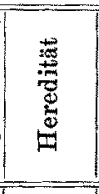 & 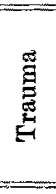 & 总 & $\begin{array}{l}\text { Anamnesti- } \\
\text { sche Daten }\end{array}$ & $\begin{array}{l}\text { Status beim } \\
\text { Eintritt }\end{array}$ & Therapie \\
\hline \multirow[t]{2}{*}{$\begin{array}{l}\text { 9. Delachanx, } \\
\text { Arthur, } \\
\text { Travers, } 6 \mathrm{~J} \text {. }\end{array}$} & $\mid \begin{array}{c}9 . \text { Juni } \\
1891 . \\
14 . \\
\text { August } \\
1891 .\end{array}$ & $4 \mathrm{~J}$. & $2 \mathrm{~J}$. & $\begin{array}{c}\text { Mutter } \\
\text { des } \\
\text { Kran- } \\
\text { ken an } \\
\text { Tbe. } \\
\text { pulm. } \\
\text { gestor- } \\
\text { ben. }\end{array}$ & - & L. & $\begin{array}{l}\text { Hinken seid } 2 \\
\text { Jahren. Seit } \\
\text { 1/2 Jahr Con- } \\
\text { tracturstellg. } \\
\text { Extension } \\
\text { durch } 6 \text { Wo- } \\
\text { chen, nach } \\
\text { Weglassender- } \\
\text { selben starke } \\
\text { Sehmerzen b. } \\
\text { Gehen. }\end{array}$ & $\begin{array}{l}\text { Leicht flectirt, } \\
\text { Add. } 22^{\circ} \text {, E.R. } 25^{\circ} \\
\text { Hochstand der } 1 . \\
\text { Seite. Activ obige } \\
\text { Bewegungen frei, } \\
\text { Abd. und E. nicht } \\
\text { möglich In Nar- } \\
\text { kose Bewegungen } \\
\text { ziemlieh frei.Lun- } \\
\text { gen normal. }\end{array}$ & $\begin{array}{l}\text { 19. April } 1891 . \\
\text { Hinterer Winkel- } \\
\text { schnitt. Kopf und } \\
\text { Pfanne abgeho- } \\
\text { belt, Synovialis } \\
\text { entfernt. Jodo- } \\
\text { formgazetampo- } \\
\text { nade in Luxations- } \\
\text { stellung. }\end{array}$ \\
\hline & & & & & & & $\begin{array}{l}\text { 4. Aug. 1892. } \\
\text { Extension zu } \\
\text { Hause nur } \\
\text { kurze Zeit. } \\
\text { Seit Kurzen. } \\
\text { 2 Fisteln in } \\
\text { der Narbe. }\end{array}$ & $\begin{array}{l}\text { Fl. und Add. } \\
\text { Contr, gegen das } \\
\text { Beeken ziemlich } \\
\text { beweglich. Ver } \\
\text { kürzung } 3 \mathrm{~cm} \text {. Ge } \\
\text { lenk anch beim } \\
\text { Gehen nicht } \\
\text { schmerzhaft. } \\
\text { Starkes Hinken }\end{array}$ & $\begin{array}{l}\text { 10. Aug 1892. } \\
\text { Fisteln ausge- } \\
\text { kratzt. Patient } \\
\text { soll noeh dureb } \\
\text { Monate extendirt } \\
\text { werden. }\end{array}$ \\
\hline $\begin{array}{l}\text { 10. Widmer, } \\
\text { Eduard. }\end{array}$ & $\begin{array}{c}19 . \\
\text { März } \\
1892 . \\
20 . \\
\text { Juni } \\
1892 .\end{array}$ & - & - & - & - & - & - & - & $\begin{array}{l}\text { 19. März } 1892 . \\
\text { Resectio. Prima- } \\
\text { heilung.Sehrlang- } \\
\text { sam eintretende } \\
\text { Function. }\end{array}$ \\
\hline $\begin{array}{l}\text { 11. D ... } \\
\text { Leon, } \\
\text { Cornanx, } \\
181 / 2 \mathrm{~J} .\end{array}$ & $\begin{array}{c}11 . \\
\text { Decbr. } \\
1891 . \\
17 . \\
\text { Januar } \\
1892 .\end{array}$ & $5 \mathrm{~J}$ & - & - & - & - & $\begin{array}{c}1879 \text { wegen } \\
\text { Coxitis in Be- } \\
\text { handlung. Hat } \\
\text { sich } 8 \text { Jahre } \\
\text { lang ausge- } \\
\text { zeichnet be- } \\
\text { funden. Seit } \\
\begin{array}{c}\text { 3 Monaten Re- } \\
\text { cidive. }\end{array}\end{array}$ & $\begin{array}{l}\text { Fl, } 35^{0}, \text { Add. } \\
10^{0} \text {. Kein Stoss. } \\
\text { schmerz. Press. } \\
\text { schmerz. Lungen } \\
\text { normal. }\end{array}$ & $\begin{array}{l}\text {,Typische Ar- } \\
\text { threetomie nach } \\
\text { Kochermit totaler } \\
\text { Entfernung der } \\
\text { Knorpelfläche bis } \\
\text { auf gesundem } \\
\text { Knoehen, Ent- } \\
\text { spreehende Ver- } \\
\text { kleinerung des } \\
\text { Kopfes, aber Er- } \\
\text { haltung der Epi- } \\
\text { physenlinie." }\end{array}$ \\
\hline
\end{tabular}


Ueber die Enderfolge der operativen Behandlung bei Coxitis tuberculosa. 47

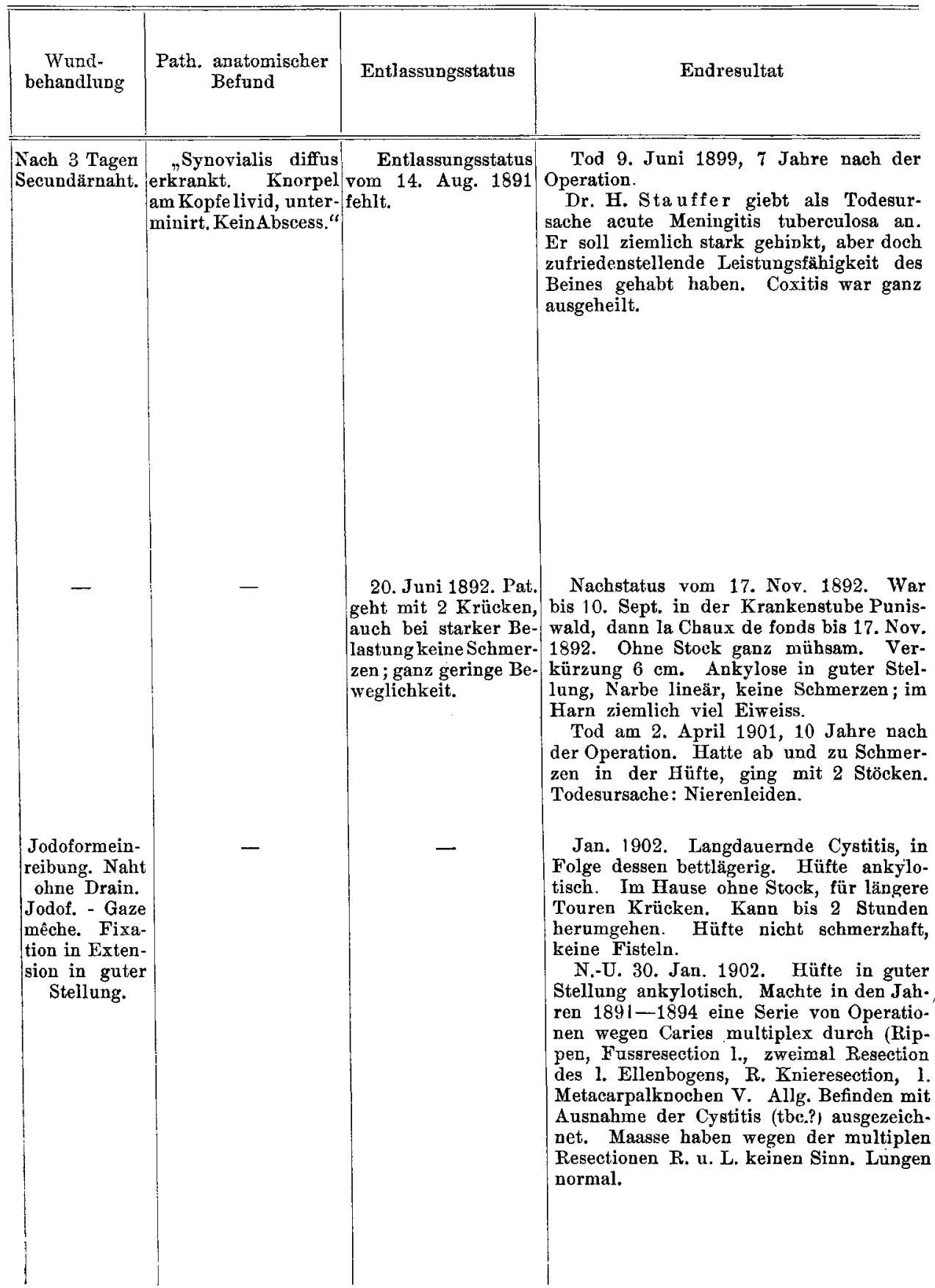




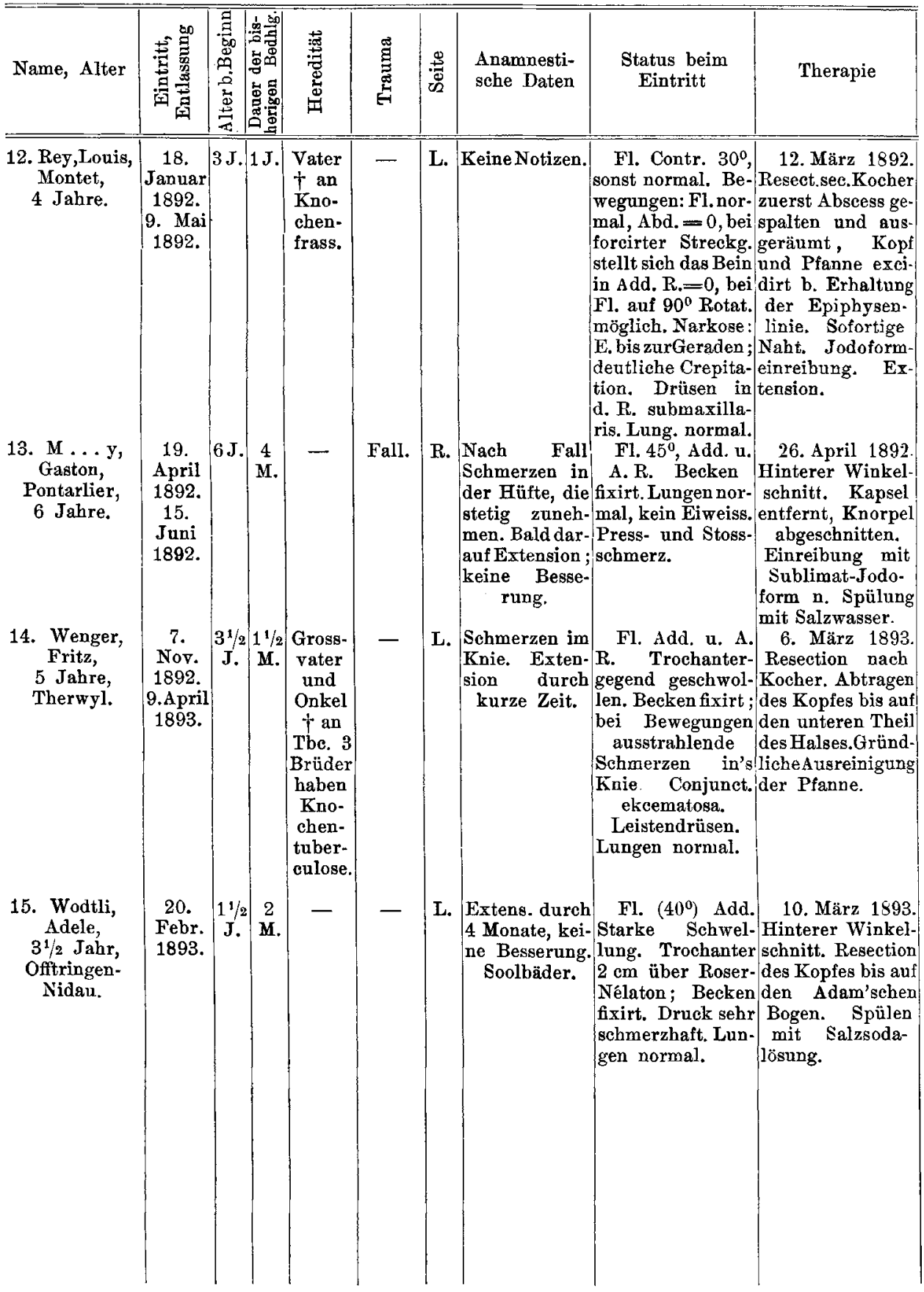


Ueber die Enderfolge der operativen Behandlung bei Coxitis tuberculosa. 49

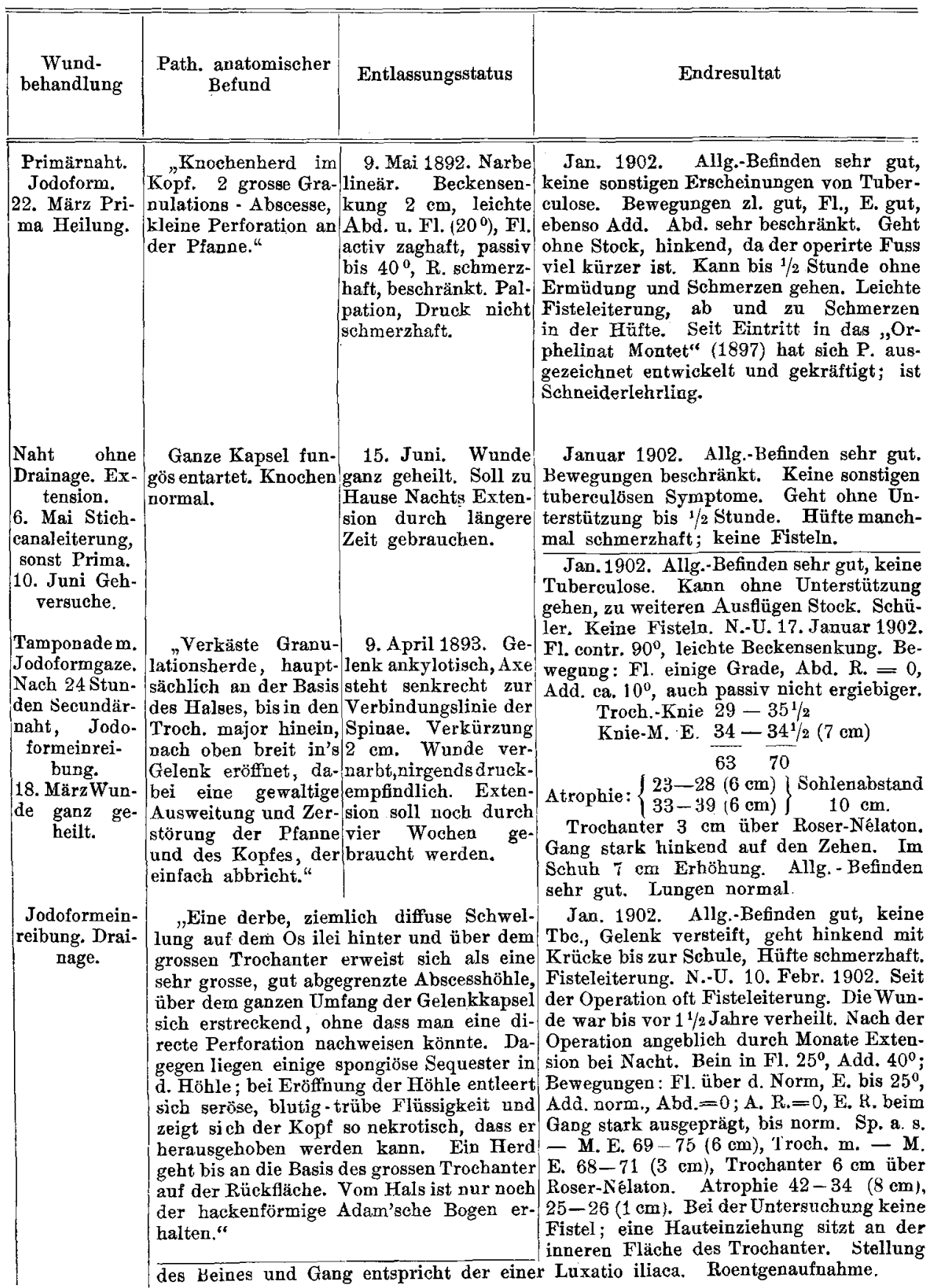

Dentsche Zeitsehrift f. Chirurgie. LXV. Bd. 


\begin{tabular}{|c|c|c|c|c|c|c|c|c|c|}
\hline Name, Alter & 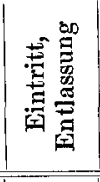 & 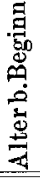 & 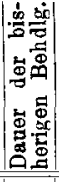 & 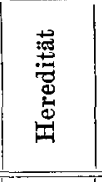 & 莺 & 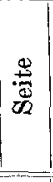 & $\begin{array}{l}\text { Anamnesti- } \\
\text { sche Daten }\end{array}$ & $\begin{array}{c}\text { Status beim } \\
\text { Eintritt }\end{array}$ & Therapie \\
\hline $\begin{array}{l}\text { 16. E ... y, } \\
\text { Henry, } \\
\text { Fribourg, } \\
2^{1 / 2} \mathrm{~J} \text {. }\end{array}$ & \begin{tabular}{|c|}
10. \\
März \\
1893. \\
11. Mai \\
1893. \\
10. \\
Novbr. \\
1893. \\
28. \\
Jan. \\
1894.
\end{tabular} & $\begin{array}{c}9 \\
\text { M. }\end{array}$ & $1^{3 / 4}$ & \begin{tabular}{|c|} 
Gross- \\
mutter \\
Mutter \\
Tante \\
$\dagger$ \\
Phthi- \\
se.
\end{tabular} & - & L. & \begin{tabular}{|c|} 
Vom 9.Monate \\
an bewegte das \\
Kind das linke \\
Bein nicht. \\
Salzbäder \\
durch 1 Jahr. \\
29 März 1892. \\
Abscess am \\
Oberschenkel. \\
Mit dem 20. \\
Monat lernt \\
d. Kind gehen. \\
Seit 4 Monaten \\
starkes Hin- \\
ken; Schmer- \\
zen. Blephara- \\
denitiden, \\
Ekzeme. \\
10. Nov. 1893. \\
V. Mai b. Aug. \\
in Extension, \\
konnte nach- \\
her gut gehen. \\
Von Octbr. an \\
Schmerzen im \\
Knieu.Hinken
\end{tabular} & $\begin{array}{l}\text { Fl. contr. v. 40 } \\
\text { Becken fixirt. Tro- } \\
\text { chanter u. Halsge- } \\
\text { gend stark ver- } \\
\text { dickt. Bewegung. } \\
\text { Druck sehr } \\
\text { schmerzhaft. } \\
10 . \text { Norbr.1893. } \\
\text { ddd. }\left(20^{\circ}\right) \text { Ge- Ge- } \\
\text { streckt, keine R. } \\
\text { Becken fixirt. An } \\
\text { der Vorderfläche } \\
\text { desGelenkes derbe } \\
\text { Schwellung; keine } \\
\text { Fluctuation, keine } \\
\text { Verkürzung. Lun- } \\
\text { ge normal. }\end{array}$ & $\begin{array}{l}\text { 15. März 1893. } \\
\text { Hinterer Winkel- } \\
\text { schnitt. Entfer- } \\
\text { nung des Herdes } \\
\text { am Hals u. Tro- } \\
\text { chanter. Kapsel } \\
\text { am hinteren Um- } \\
\text { fang excidirt. } \\
\text { Pfanne und Kopf } \\
\text { belassen. } \\
16 . \text { November. } \\
\text { Resectionsschnitt } \\
\text { vorne, zwischen } \\
\text { Sartorius und } \\
\text { Tensor fasciae.Ex- } \\
\text { cision der Kapsel. } \\
\text { Kopf, Pfanne und } \\
\text { Hals ausgeräumt. }\end{array}$ \\
\hline $\begin{array}{l}\text { 17. Sch .... r, } \\
\text { Oskar, } \\
\text { Schoindez. }\end{array}$ & \begin{tabular}{|c|}
13. \\
März \\
1893. \\
30. \\
Juni \\
1893. \\
Reci- \\
div. \\
1. Nov. \\
1893. \\
6. Febr. \\
1894.
\end{tabular} & - & - & - & - & L. & \begin{tabular}{|} 
Vor 4 Wochen \\
weg. unsiche- \\
rer Diagnose \\
entlassen.Seit- \\
dem hat sich \\
ein Abscess ge- \\
bildet. \\
1. Sept. 1893. \\
In der Narbe \\
wiederholt \\
Fistelbildung; \\
abendliche \\
Temperatur-
\end{tabular} & $\begin{array}{l}\text { Abd normal, bei } \\
\text { Add. Schmerzen. } \\
\text { Flexion an der } \\
\text { Grenze schmerz- } \\
\text { haft. Ext. ohne } \\
\text { Anstand. } 2 \text { Finger } \\
\text { unter d. Poupart- } \\
\text { schen Band verti- } \\
\text { cale, elastische } \\
\text { Schwellung hinter } \\
\text { dem Sartorius; } \\
\text { Dämpfung über d. } \\
\text { l. Clavicula. Ath- }\end{array}$ & $\begin{array}{l}\text { 15. März } 1893 . \\
\text { Eröffnung u. Aus- } \\
\text { räumung des Ab- } \\
\text { scesses von vorne. } \\
\text { Wunde geschlos- } \\
\text { sen. Resectiou von } \\
\text { hinterem Winkel- } \\
\text { schnitt aus. Ab- } \\
\text { tragen d. hinteren } \\
\text { Theils d. Kopfes. } \\
\text { Kapselexcision. } \\
\text { Drainage v. vorne } \\
\text { und hinten. }\end{array}$ \\
\hline & & & & & & & steigerung. & $\begin{array}{l}\text { mung normal. } \\
\text { 1. Novbr. 1893. } \\
\text { Bein } \text { gestreekt } \\
\text { leicht adducirt. } \\
\text { E. R. Bewegung } \\
\text { sehr gering. Ueber } \\
\text { den Trochanter 2 } \\
\text { Fistelöffnungen ; } \\
\text { Rückfläche d. Ge- } \\
\text { lenkes druck- } \\
\text { empfindlich. Urin } \\
\text { normal. }\end{array}$ & $\begin{array}{l}\text { 8. November. } \\
\text { Cauterisirung der } \\
\text { Fistel.Resections- } \\
\text { schnitt in der } \\
\text { Narbe. Gelenk u. } \\
\text { Knochenfläche ge- } \\
\text { reinigt, mit Ther- } \\
\text { mocauter ver- } \\
\text { schorft. Abtragen } \\
\text { des Kopfes bis zur } \\
\text { Epiphysenlinie. } \\
\text { Jodoformeinrei- } \\
\text { bung. }\end{array}$ \\
\hline
\end{tabular}


Ueber die Enderfolge der operativen Behandlung bei Coxitis tuberculosa. 51

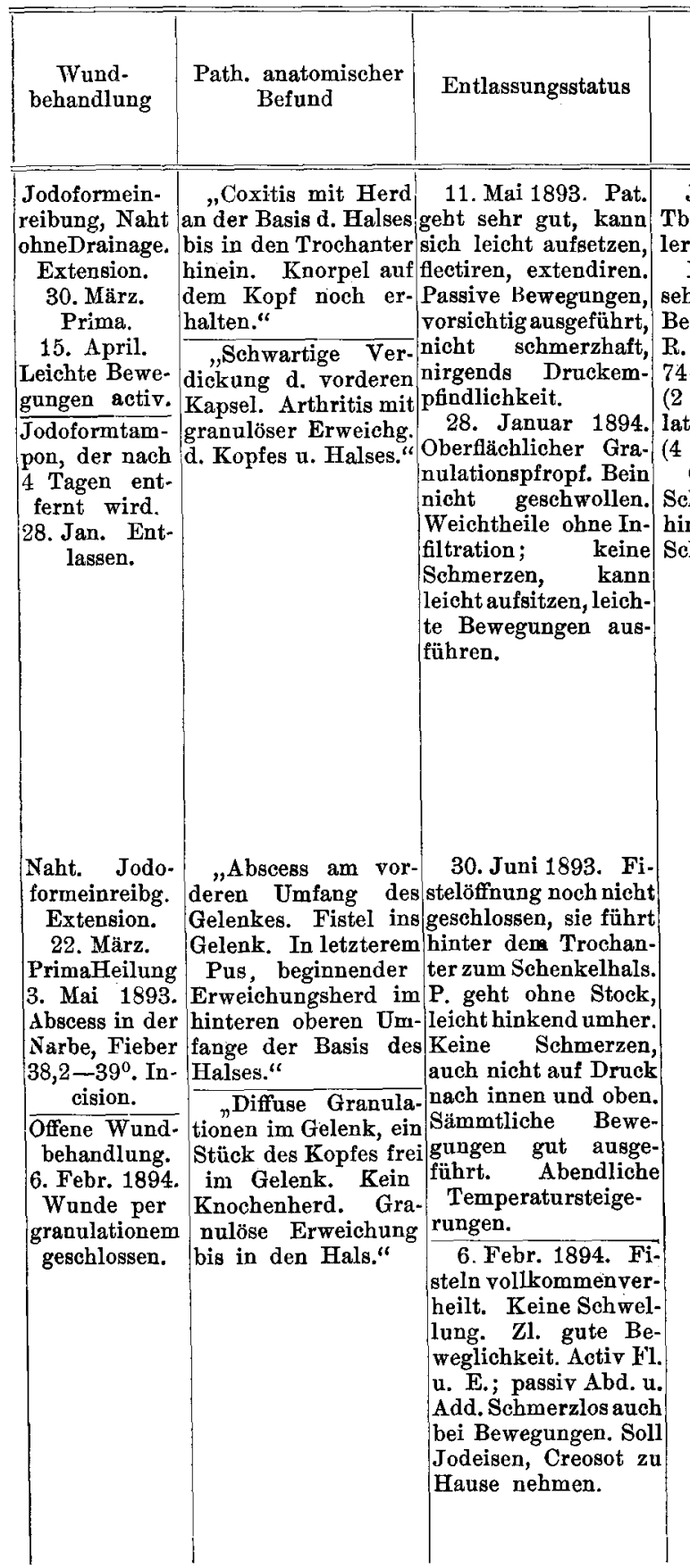

Nicht auffindbar. 


\begin{tabular}{|c|c|c|c|c|c|c|c|c|c|}
\hline Name, Alter & 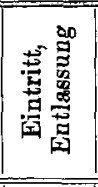 & 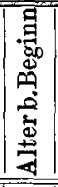 & 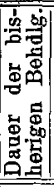 & $\begin{array}{l}\text { 戀 } \\
\text { 总 } \\
\text { 总 } \\
\text { 团 }\end{array}$ & 鸹 & 劳 & $\begin{array}{l}\text { Anamnesti- } \\
\text { sche Daten }\end{array}$ & $\begin{array}{c}\text { Status beim } \\
\text { Eintritt }\end{array}$ & Therapie \\
\hline $\begin{array}{l}\text { 18. Müller, } \\
\text { Jeanne, } \\
\text { Vendlincourt, } \\
7 \text { Jahre. }\end{array}$ & $\begin{array}{c}\text { 6. Nov. } \\
1893 . \\
24 . \\
\text { Juni } \\
1894 .\end{array}$ & $\begin{array}{l}6^{1 / 2} \\
\mathrm{M}\end{array}$ & $\begin{array}{l}1 / 2 \\
J\end{array}$ & - & Fall. & L. & $\begin{array}{l}\text { Nach Fall } \\
\text { gleich Schmer- } \\
\text { zen im Knie, } \\
\text { mit Schwel- } \\
\text { lung daselbst, } \\
\text { welche aber } \\
\text { bald vergeht. } \\
\text { Trotzdem bl. } \\
\text { das Hinken be- } \\
\text { stehen. Seit } \\
\text { August } \\
\text { Schmerzen in } \\
\text { der Hüfte. }\end{array}$ & $\begin{array}{l}\text { FI. Abd. A. R. } \\
\text { Scheinbare Ver- } \\
\text { längerung } 2 \text { cm. } \\
\text { Pressschmerz. } \\
\text { Spontane Schmer- } \\
\text { zen beim Stehen. } \\
\text { Becken fixirt. } \\
\text { Halsgegend ver- } \\
\text { dickt. } 2 \text { Drüsen in } \\
\text { der Fossa iliaca, } \\
\text { leichte Atrophie } \\
\text { links. Kein Ei- } \\
\text { weìss. Lungen } \\
\text { normal. }\end{array}$ & $\begin{array}{l}\text { 12. März 1894. } \\
\text { Hinterer Winkel- } \\
\text { schnitt. Kopf und } \\
\text { Pfanne abgeho- } \\
\text { belt. Kapsel ex- } \\
\text { cidirt. Jodoform- } \\
\text { einreibung. Tiefe } \\
\text { Catgutnähte. Ex- } \\
\text { tension. }\end{array}$ \\
\hline $\begin{array}{l}\text { 19. Nobs, } \\
\text { Alfred, } \\
61 / 2 \text { Jahre, } \\
\text { Seedorf. }\end{array}$ & $\begin{array}{c}\text { 19. Mai } \\
1894 . \\
+229 \\
\text { Nov. } \\
1894\end{array}$ & $\begin{array}{c}5 \\
\mathrm{M}\end{array}$ & $\left|\begin{array}{c}1 / 2 \\
\mathrm{~J}\end{array}\right|$ & - & $\begin{array}{c}\text { Schlag } \\
\text { auf den } \\
\text { Tro- } \\
\text { ehan- } \\
\text { ter. }\end{array}$ & I. & $\begin{array}{l}\text { Beim Reck- } \\
\text { turnen Schlag } \\
\text { auf den Tro- } \\
\text { chanter, von } \\
\text { da ab Hinken; } \\
\text { vor } 3 \text { Monaten } \\
\text { starkeSchmer- } \\
\text { zen u. Schwel- } \\
\text { lung d. Hüfte. } \\
\text { Hatte oft ekze- } \\
\text { matöse Con- } \\
\text { junctivitis. }\end{array}$ & $\begin{array}{l}\text { Fl. contr. } 45^{0}, \\
\text { leichte Abd. und } \\
\text { E.R. Bewegungen: } \\
\text { F1. } 120^{\circ} \text { passiv bis } \\
\text { norm. E. Abd.=0, } \\
\text { E. R. beschränkt. } \\
\text { Abscess unter dem } \\
\text { Trochanter, wel- } \\
\text { cher auf Druck } \\
\text { nichtschmerzhaft. } \\
\text { Exquisiter Press- } \\
\text { schmerz, Drüsen } \\
\text { in inguine. Kein } \\
\text { Eiweiss. Lungen } \\
\text { normal. }\end{array}$ & $\begin{array}{l}\text { 22. Juni 1894. } \\
\text { Eröffnung u. Aus- } \\
\text { räumung des Ab- } \\
\text { scesses; Naht. } \\
\text { Hinterer Winkel- } \\
\text { schnitt. Syno- } \\
\text { vialis excidirt. } \\
\text { Ausräumung von } \\
\text { Pfanne und Kopf. } \\
\text { Jodoformeinrei- } \\
\text { bung. }\end{array}$ \\
\hline $\begin{array}{l}\text { 20. Zi ... r, } \\
\text { Josef, } \\
\text { 43/4 Jahre, } \\
\text { Genf. }\end{array}$ & $\begin{array}{c}22 . \\
\text { Febr. } \\
1895 . \\
29 . \mathrm{Mai} \\
1895\end{array}$ & $\begin{array}{c}2^{3} / 4 \\
M\end{array}$ & $\begin{array}{l}2 \\
\text { J. }\end{array}$ & - & - & L. & $\begin{array}{l}\text { Vor } 2 \text { Jahren } \\
\text { Schmerzen in } \\
\text { der Hüfte. } \\
\text { Das Kind zieht } \\
\text { das Bein nach. } \\
\text { Intermittirend } \\
\text { Besserung. } \\
\text { Seit } 1 \text { Jahr } \\
\text { progressive } \\
\text { Verschlimme- } \\
\text { rung. }\end{array}$ & $\begin{array}{l}\text { Fl. Add. und } \\
\text { E. R. Activ keine } \\
\text { Bewegungen. } \\
\text { Starke Schmerzen } \\
\text { bei passiven Be- } \\
\text { wegungen,Kapsel- } \\
\text { verdickung ander } \\
\text { Vorderseite. Rück- } \\
\text { wärts Sehwellung } \\
\text { mit Fluctuation. } \\
\text { Atrophie d. kran- } \\
\text { ken Seite. Urin } \\
\text { kein Eiweiss. Lun- } \\
\text { gen normal. }\end{array}$ & $\begin{array}{l}\text { 2. März 1895. } \\
\text { Hinterer Winkel- } \\
\text { schnitt; Abscess- } \\
\text { eröffnung u. Aus- } \\
\text { räumung. Abtrag- } \\
\text { ung des Knorpels } \\
\text { am Kopfe, Jodo- } \\
\text { form. Theilweise } \\
\text { Naht. Jodoform- } \\
\text { mêche. Gypsver- } \\
\text { band. }\end{array}$ \\
\hline
\end{tabular}


Ueber die Enderfolge der operativen Behandlung bei Coxitis tuberculosa. $\quad 53$

\begin{tabular}{|c|c|c|c|}
\hline $\begin{array}{l}\text { Wund- } \\
\text { behandlung }\end{array}$ & $\begin{array}{l}\text { Path. anatomischer } \\
\text { Befund }\end{array}$ & Entlassungsstatus & Endresultat \\
\hline \begin{tabular}{|} 
Naht mit Drai- \\
nage. \\
26. März \\
Prima. \\
27. April Ab- \\
scess (Staph. \\
albus). Inci- \\
sion. Drainage. \\
27. Mai Be- \\
wegungen.
\end{tabular} & $\begin{array}{l}\text { "Typische Coxitis } \\
\text { im Anfangsstadium. } \\
\text { Fungös diffuse Arthri- } \\
\text { tis mit Erweichungs- } \\
\text { herd von blass-rötb- } \\
\text { licher Farbe im } \\
\text { Schenkelkopf u.leicht } \\
\text { ablösbarem Knorpel. } \\
\text { Der Hauptherd ent- } \\
\text { puppt sich als braun- } \\
\text { grauer, ganz beweg- } \\
\text { licherSequesterneben } \\
\text { dem Ansatz des Lig. } \\
\text { teres in der Pfanne, } \\
\text { vorragend zu fühlen. } \\
\text { Nach Entfernung des- } \\
\text { selben zeigt sich eine } \\
\text { grosse Höhle, die aus- } \\
\text { gerüumt wird." }\end{array}$ & $\begin{array}{l}\text { 24. Juni 1894. Ent- } \\
\text { lassung. Status fehlt. }\end{array}$ & $\begin{array}{l}\text { Januar 1902. Allg.-Befinden schlecht. } \\
\text { Hustet, hat aber keinen Auswurf, schwitzt } \\
\text { nicht bei Nacht. Bewegungen beschränkt. } \\
\text { Gebraucht Stock, geht hinkend bis eine } \\
\text { Stunde. Keine Beschäftigung. Beide } \\
\text { Beine sehmerzhaft. Hat keine Fisteln, } \\
\text { auch nie solche gehabt. }\end{array}$ \\
\hline $\begin{array}{l}\text { Naht; Abscess } \\
\text { drainirt. Ex- } \\
\text { tension. }\end{array}$ & $\begin{array}{l}\text { „Abscess aussen u. } \\
\text { über dem Tensor fas } \\
\text { vorne ans Gelenk au } \\
\text { nenrand. Der Knorp } \\
\text { am Halse dicke blau } \\
\text { am Knorpelrand aufsi } \\
\text { satz des Lig. teres. } \\
\text { Pfanne } 2 \text { tiefe Eins } \\
\text { nebst käsigen Granul } \\
\text { käsige Sequester lie } \\
\text { forirt." }\end{array}$ & $\begin{array}{l}\text { vorne am Trochanter, } \\
\text { ciae latae, mit einem } \\
\text { fwärts bis zum Pfan- } \\
\text { pel des Kopfes intact; } \\
\text { urothe Granulationen, } \\
\text { itzend, ebenso am An- } \\
\text { Dagegen zeigt die } \\
\text { senkungen, in denen } \\
\text { ationen } 2 \text { harte, gelbe, } \\
\text { gen. Die Pfanne per- }\end{array}$ & $\begin{array}{l}\text { Tod am 29. Nov. 1894, 5 Monate post } \\
\text { operationem. Section am 30. Nov. } 1894 . \\
\text { (Auszug aus dem Sectionsprotokoll Prof. } \\
\text { Langhans.) Tuberculosis miliaris, menin- } \\
\text { gitis tuberculosa. "Hüftgelenk: das obere } \\
\text { Femurende ist nekrotisch, Pfanne nicht } \\
\text { mehr erkenntlich, ganz mit grünen Mas- } \\
\text { sen bedeckt, unterhalb dieser Höhle eine } \\
\text { zweite mit braungelbem Eiter gefüllt. Ge- } \\
\text { hirn: Pia über Pons, Chiasma sulzig ver- } \\
\text { dickt, theilweise getrübt. Gefässe in der } \\
\text { Fossa Silvii trüb, kleine Knötchen. Sei- } \\
\text { tenventrikel stark erweitert, mit klarer } \\
\text { Flüssigkeit gefüllt. Lunge, Milz, Niere, } \\
\text { Leber zeigen miliare Knötchen. Darm : } \\
2 \text { tuberculöse Geschwüre im Coceum." }\end{array}$ \\
\hline $\begin{array}{l}\text { 20. April. Ent- } \\
\text { fernung des } \\
\text { Gypsver- } \\
\text { bandes. Wunde } \\
\text { p. pr. verheilt. } \\
\text { Extension } \\
\text { Nachts. }\end{array}$ & $\begin{array}{l}\text { "Synovitis fungosa; } \\
\text { Gelenk vollkäsigen } \\
\text { Eiters. Abscess in } \\
\text { Communication mit } \\
\text { dem Gelenke. Kein } \\
\text { Käseherd. Knorpel } \\
\text { abgehoben." }\end{array}$ & $\begin{array}{l}\text { 29. Mai. In Ruhe- } \\
\text { lage Bein parallel } \\
\text { nach vorn gerichtet; } \\
\text { geringe Beweglich- } \\
\text { keit im Gelenk. Act. } \\
\text { u.passiv Bewegungen } \\
\text { schmerzlos. Pat. geht } \\
\text { allein, ohne Stock, } \\
\text { ohne Schmerzen; hat } \\
\text { sehr zugenommen. }\end{array}$ & $\begin{array}{l}\text { N.-U. Jan. } 1901 . \text { Allg.-Befinden aus- } \\
\text { gezeichnet. Kann den ganzen Tag laufen. } \\
\text { Schmerzen bei Wetterwechsel. Fuss in } \\
\text { Streckstellung. Flexion ca. 10-150. R. } \\
5-10^{\circ} \text {, sonst keine Bewegung. } \\
\text { Sp.-M. E. } 72-70 \text { (1 cm), Troch. m. } \\
- \text { M. Z. Keine Verkürzung. Atrophie } \\
32-28 \text { (4 cm), 22-20 (1 cm). Keine } \\
\text { Drüsen. Lungen nornal. Verdickung am } \\
\text { Schenkelhals und Trochanter. Gang aus- } \\
\text { gezeichnet. Sitzt mit gekrümmter Wirbel- } \\
\text { sänle sehr gut. } \\
\text { Roentgenaufnahme. }\end{array}$ \\
\hline
\end{tabular}




\begin{tabular}{|c|c|c|c|c|c|c|c|c|c|}
\hline Name, Alter & 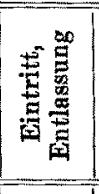 & 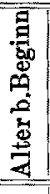 & 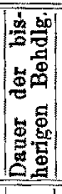 & 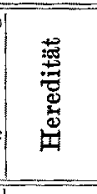 & 恚 & 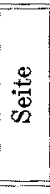 & $\begin{array}{l}\text { Anamnesti- } \\
\text { sehe Daten }\end{array}$ & $\begin{array}{c}\text { Status beim } \\
\text { Eintritt }\end{array}$ & Therapie \\
\hline $\begin{array}{l}\text { 21. Weber, } \\
\text { Elise, } 22 J_{.}, \\
\text {Hubersdorf. }\end{array}$ & $\begin{array}{c}25 . \\
\text { A pril } \\
1895 . \\
6 . \text { Mai } \\
1896 .\end{array}$ & 17 & $5 \mathrm{~J}$. & - & $\begin{array}{c}\text { Tran- } \\
\text { ma. }\end{array} \mid$ & L. & \begin{tabular}{|c|} 
Xach einem \\
Misstritt, bei \\
welchem P.ein \\
Knacken in d. \\
Hïfte spürte, \\
Hinken, das \\
seit 2 Jahren \\
sich ver- \\
schlimmerte. \\
Schmerzen. n. \\
intensiv; Aus- \\
strahlen b. ins \\
Knie. Seit $1 / 2.2$. \\
bettlägerig. \\
Seither heftige \\
Schmerzen.
\end{tabular} & $\begin{array}{l}\text { Leichte Add. u. } \\
\text { E. R. Schwellung } \\
\text { am Schenkelhalse. } \\
\text { Starker Press- u. } \\
\text { Stossschmerz. } \\
\text { Streckung activ u. } \\
\text { passiv bis } 180^{\circ} \\
\text { Fl. activ } 20^{\circ}, \text { pas- } \\
\text { siv bei } 30^{\circ} \text { schon } \\
\text { schmerzhaft. A. R. } \\
5^{0}, \text { E. R. 10 } 15^{\circ} \\
\text { Atrophie d. Ober- } \\
\text { schenkels u. Glu. } \\
\text { teus. Verkürzung } \\
1 \text { cm. Derbe, } \\
\text { grosse Leisten- } \\
\text { drüsen; Urin kein } \\
\text { Eiweiss, Lungen } \\
\text { normal. }\end{array}$ & $\begin{array}{l}\text { 20. Juni 1895. } \\
\text { Hinterer Winkel- } \\
\text { schnitt. Excision } \\
\text { der Kapsel. Ab- } \\
\text { tragungdesKopfes } \\
\text { mit Meissel. Aus. } \\
\text { loffeln der Pfanne. } \\
\text { Tiefe Catgutaühte, } \\
\text { Jodoformmêhe. } \\
\text { Extension. }\end{array}$ \\
\hline $\begin{array}{c}\text { 22. Gertsch, } \\
\text { Adolf, } 23 \text { J., } \\
\text { Gündli- } \\
\text { sehwand. }\end{array}$ & $\begin{array}{c}2 . \text { Mai } \\
1895 . \\
5 . \text { Mai } \\
1896 .\end{array}$ & $\begin{array}{l}21 \\
J\end{array}$ & $2 \mathrm{~J}$. & $\begin{array}{c}2 \\
\text { Brüder } \\
\text { tuber- } \\
\text { culös. }\end{array}$ & $\begin{array}{c}\text { Fall } \\
\text { auf die } \\
\text { Hüfte. }\end{array}$ & R. & $\begin{array}{c}\text { Durch Eisen- } \\
\text { bahn } 20-30 \text {-30m } \\
\text { mitgesehleift, } \\
\text { seitherHinken } \\
\text { u. Schmerzen } \\
\text { im Gelenk. Vor } \\
1 \text { Jahre Ver- } \\
\text { schlimmerung } \\
\text { bettlägerig. } \\
10 \text { Wochen } \\
\text { Extension. } \\
\text { 1. Jodoformin- } \\
\text { jection. }\end{array}$ & $\begin{array}{l}\text { Add. } 10^{\circ}, \text { A. R. } \\
35^{\circ} \text {. Verkürzung } \\
11 / 2 \mathrm{~cm} \text {. Schwel- } \\
\text { lung in d. Gegend } \\
\text { des Kopfes, Stoss- } \\
\text { schmerz. Bewe- } \\
\text { gung: nur A. R. u. } \\
\text { E. R. ca. } 10^{\circ} \text {. Per } \\
\text { rectum Pfanne } \\
\text { stark druckem- } \\
\text { pfindlich. Knie } \\
170^{\circ} \text { fixirt, Va- } \\
\text { russtellung des } \\
\text { Fusses (Bettlage) } \\
\text { kein Eiweiss, Lun- } \\
\text { gen normal. }\end{array}$ & $\begin{array}{l}\text { 13. April 1895. } \\
\text { Hinterer Winkel. } \\
\text { schnitt. Bei der } \\
\text { Luxation bricht } \\
\text { derKopfab; Kopt. } \\
\text { rest abgemeisselt, } \\
\text { ebenso die Pfanne. } \\
\text { Jodoformeinrei- } \\
\text { bung, Jodoform. } \\
\text { mêche. }\end{array}$ \\
\hline $\begin{array}{l}\text { 23. Vermeille, } \\
\text { Albertine, } \\
\text { Bemont, } 6 \mathrm{~J} .\end{array}$ & $\mid \begin{array}{c}\text { 6. Juni } \\
1895 . \\
9 . \text { Nov. } \\
1895 .\end{array}$ & - & - & - & - & $\mathbf{R}$. & - & $\begin{array}{l}\text { Starke Verkür- } \\
\text { zung mitA.R. }\left(30^{\circ}\right) \\
\text { Fl. }\left(30^{\circ}\right) \text {. Troeh. } \\
\text { major } 1 \text { cm über } \\
\text { der Spinalinie. } \\
\text { Abd. sehr be- } \\
\text { schränkt, Add.gut } \\
\text { ausführbar.R. }=0 \text {, } \\
\text { Leistengegend et- } \\
\text { was verdickt. } \\
\text { Pressschmerz. }\end{array}$ & $\begin{array}{l}\text { Bis 30. Juli } \\
\text { Extension. } \\
\text { 30. Juli. Finterer } \\
\text { Winkelschnitt. } \\
\text { Abtragung des } \\
\text { Kopfes. Exten- } \\
\text { sion. }\end{array}$ \\
\hline
\end{tabular}


Ueber die Enderfolge der operativen Behandlung bei Coxitis tuberculosa. 55

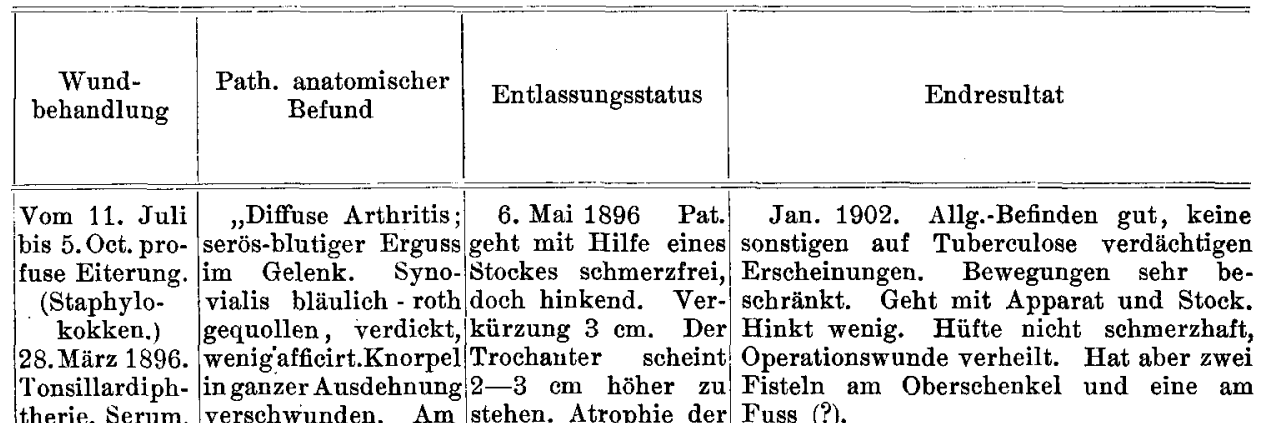

Seit 11. März Kopf, der unregel- Muskeln. Gelenkge-

Hessing. Bis mässige Defecte zeigt, gend diffus wenig ge-

Mai 1896 mäs- an einer Stelle ein schwollen.Flexion ac-

sige Fisteleite- klein. kugelförmiger, tiv 0 , passiv $45^{\circ}, \mathbf{R}$.

rung, ab u. zu flacher Sequester. beschränkt, Abd.,

Fieber Aber die Hauptver-Add. activ unbedeu-

$38-39^{\circ}$. änderung liegt in der tend, passiv $35^{\circ}$.

Pfanne, wo drei ganz Eine Fistel in der

oberflächliche, grosse Narbe bis $6 \mathrm{~cm}$

Sequester sitzen, wohl tief, secernirt wenig.

die Hälfte der Pfanne Man stosst nicht auf ausmachend, $1 \mathrm{~cm}$ Knochen.

dick."

11. Juli Ab- „Gelenkperforation 5. Mai 1896. Im scess in der ohne Verkäsung am oberen Bereich der operationem ,an den Folgen seiner KrankNarbe. Bis 29. inneren Pfannenum- Narbe 2 spaltförmige heit".

Oct. stark ei- fang. Im Bereich der Fisteln, von welchen ternde Fisteln. Bursa iliaca vor dem man bis $6 \mathrm{~cm}$ tief Eröffnung und Schenkelhals eine eindringen kann, ohne Auskratzen weich-elastische Ge-auf Knochen zu stosder Fisteln. schwulst, durch seröse sen. Secretion der Offene Wund- Ansammlung gebild.; Fisteln gering, active behandlung. im Gelenk blutig- Bewegungen im HüftExtension. 9. Nov. Nach- Erweichung d. Schen- derung nicht durch blutung. Lig. kelkopfes u. Halses." Schmerzen bedingt. d.Art.glut.sup. ohne typische Localisation, die sich nicht bessert.

21. August. „Epiphyseolysis in 9. Nov.1895. Narbe

N.-U. 11. Febr. 1902 . FI. contr. $25^{\circ}$, Wunde p. pr. Folge von Coxar- lineär. Local keine leichte Abductionsstellung, maskirt durch \begin{tabular}{l|l|l|l|} 
verbeilt. & thritis tbc." & Druckempfindlich- \\
\hline
\end{tabular}

4. September.

Gehversuche. keit. Extreme Bewegung. nicht sehmerzhaft. Function gleich dem gesunden Bein. Verkürzung von ca. $6 \mathrm{~cm}$. Soll eine erhöhte Sohle bekommen.
Tiefstand der Spinae. Bewegung: Fl. normal. E. bis $25^{\circ}$, R. beschränkt. Add. $2 / 3$ d. Norm. Abd. sehr beschränkt.

Sp. a. s. -M. E. $67-74(7 \mathrm{~cm})$. Tr. m. M. E. $68^{1 / 2}-72\left(3^{1 / 2} \mathrm{~cm}\right)$. Atrophie $27-$ $30(3 \mathrm{~cm}), \quad 40-46(6 \mathrm{~cm})$, Trochanter $3 \mathrm{~cm}$ über Roser-Nélaton.

Gang mit auswärts rotirtem Fuss, auf den Zehen, Einknicken bei jedem Schritt. Mit Schuh (Sohleneinlage von $5 \mathrm{~cm}$ ) Gang gut, etwas hinkend. Hatte nie Fisteln gehabt. 


\begin{tabular}{|c|c|c|c|c|c|c|c|c|c|}
\hline Name, Alter & 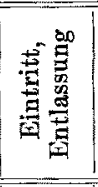 & 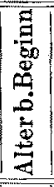 & 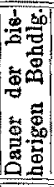 & 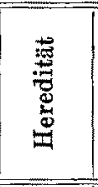 & 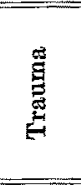 & $\begin{array}{l}9 \\
.9 \\
0 \\
\infty\end{array}$ & $\begin{array}{l}\text { Anamnesti- } \\
\text { sche Daten }\end{array}$ & $\begin{array}{c}\text { Status beim } \\
\text { Eintritt }\end{array}$ & Therapie \\
\hline $\begin{array}{l}\text { 24. Schlatter, } \\
\text { Eduard, } \\
\text { Oberwintrach, } \\
\text { 3\%/2 Jahre. }\end{array}$ & $\mid \begin{array}{c}22 . J u l i \\
1895 . \\
24 . \\
\text { Januar } \\
1896 .\end{array}$ & - & $-\infty$ & - & - & 一 & - & - & $\begin{array}{c}\text { Bis 9. Dec. } 1895 . \\
\text { Extension. } \\
\text { 9. Dec. Opera. } \\
\text { tion. Hinterer } \\
\text { Winkelsehnitt. }\end{array}$ \\
\hline $\begin{array}{c}\text { 25. Siegen- } \\
\text { thaler, } \\
\text { Marie, } \\
\text { Schwarzenegg, } \\
10 \text { Jahre. }\end{array}$ & $\begin{array}{c}25 . \\
\text { Nov. } \\
1895 . \\
10 . \text { Mai } \\
1896 .\end{array}$ & $\begin{array}{c}6 \\
\mathrm{~J}\end{array}$ & $\frac{4}{J}$ & $\mid \begin{array}{c}\text { Sehwe- } \\
\text { ster }+ \\
\text { an } \\
\text { Phty- } \\
\text { se. }\end{array}$ & - & R. & $\begin{array}{c}\text { Vor } 4 \text { Jahren } \\
\text { Masern, seit. } \\
\text { her Hinken. } \\
\text { SeltenSchmer- } \\
\text { zen. Seit 1Jahr } \\
\text { Verschlimme- } \\
\text { rung. }\end{array}$ & $\begin{array}{l}\text { Fl. contr. } 45^{\circ} \\
\text { heeken fixirt. In } \\
\text { Narkose : Fl. } 26^{\circ}, \\
\text { R.gering,Add. } 20^{\circ}, \\
\text { Abd. } 10^{\circ} \text {. In der } \\
\text { Fossa iliacakleine } \\
\text { Drüsen. Hinter } \\
\text { dem Trochanter } \\
\text { derbeSchwellung. } \\
\text { Stoss- und Press- } \\
\text { schmerz. }\end{array}$ & $\begin{array}{l}\text { 10. Febr. } 1896 . \\
\text { Hinterer Winkel- } \\
\text { schnitt. Beim } \\
\text { Luxiren } \text { bricht } \\
\text { der Kopf unter- } \\
\text { halb der Epiphy- } \\
\text { senlinie ab; Ent- } \\
\text { fernungdesselben. } \\
\text { Abrundung des } \\
\text { Halses. Aus- } \\
\text { räumen der } \\
\text { Pfanne. Gyps- } \\
\text { verband. }\end{array}$ \\
\hline $\begin{array}{l}\text { 26. Dolder, } \\
\text { Emma, } \\
\text { Hellsau, } \\
\text { 19 Jabre, }\end{array}$ & $\begin{array}{c}12 . \\
\text { März } \\
1896 . \\
14 . \\
\text { August } \\
1896 .\end{array}$ & $\begin{array}{l}13 \\
\text { bis } \\
18 \\
\text { J. }\end{array}$ & $\begin{array}{c}6 \\
\text { J. } \\
1 \\
\text { J. }\end{array}$ & - & Fall. & $\begin{array}{l}\mathbf{R} . \\
\mathbf{u} . \\
\mathrm{L} .\end{array}$ & $\begin{array}{l}\text { Vor } 5 \text { Jahren } \\
\text { am r. Hüft- } \\
\text { gelenk wegen } \\
\text { Coxitisresecirt } \\
\text { (Niehans). Seit } \\
\text { 1. Jahr Schmer- } \\
\text { zen in der 1. } \\
\text { Hüfte. Exten- } \\
\text { sion; keine } \\
\text { Besserung. } \\
\text { Hatte oft an } \\
\text { Katarrhen zu } \\
\text { leiden. }\end{array}$ & 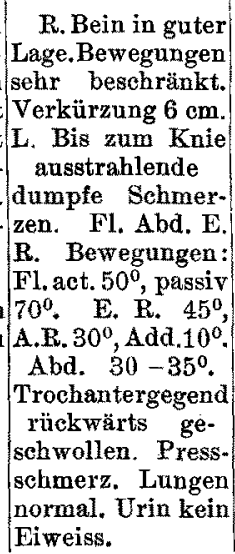 & $\begin{array}{l}\text { 19. Juni } 1896 . \\
\text { Winkelschnitt. } \\
\text { Resection des er- } \\
\text { weichten Trochan- } \\
\text { ters und Kopfes. } \\
\text { Pfanne normal }\end{array}$ \\
\hline
\end{tabular}


Ueber die Enderfolge der operativen Behandlung bei Coxitis tuberculosa. 57

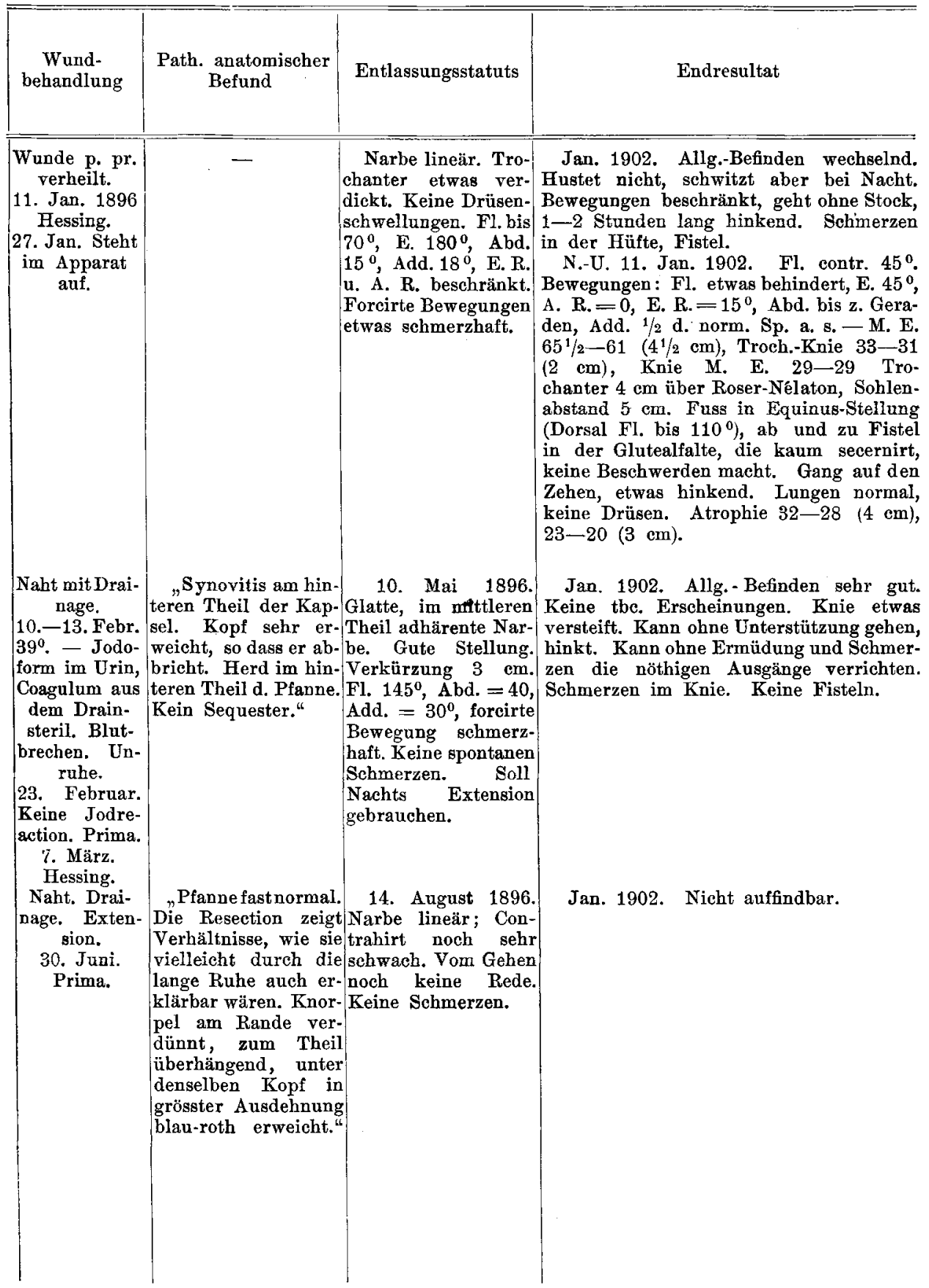




\begin{tabular}{|c|c|c|c|c|c|c|c|c|c|}
\hline Name, Alter & 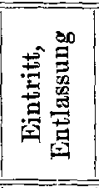 & 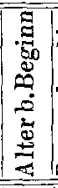 & 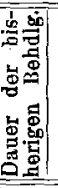 & 薄 & 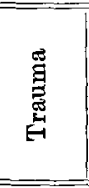 & 萢 & $\begin{array}{l}\text { Anamnesti- } \\
\text { sehe Daten }\end{array}$ & $\begin{array}{l}\text { Status beim } \\
\text { Eintritt }\end{array}$ & Therapie \\
\hline $\begin{array}{c}\text { 27. B ....t, } \\
\text { Hermann, } \\
\text { Brieg, } \\
5 \text { Jahre. }\end{array}$ & $\begin{array}{c}29 . \\
\text { April } \\
1896 . \\
3 . \\
\text { August } \\
1896 .\end{array}$ & $\left|\begin{array}{c}3^{1 / 2} \\
\mathrm{~J}\end{array}\right|$ & $\mid \begin{array}{c}1 \\
1 \\
J\end{array}$ & $\mid \begin{array}{c}2 \text { Ge- } \\
\text { schwi- } \\
\text { ster } \\
\text { Tbe. }\end{array}$ & - & R. & \begin{tabular}{|l|} 
Nach wochen- \\
langen Klagen \\
über Müdig- \\
keit, plötzlich \\
heftige \\
Schmerzen in \\
derHüfte,Hin- \\
ken, Bettruhe, \\
Extension. \\
Später lang- \\
same Besse- \\
rung, keine \\
starken \\
Schmerzen. \\
26.Febr. 1896. \\
Entleerung \\
eines Absces- \\
ses, seither \\
starke Eite- \\
rung.
\end{tabular} & $\begin{array}{l}\text { Fl. contr. } 50^{\circ} \text {, } \\
\text { Add. } 30^{\circ} \text {. Ver- } \\
\text { kürzung } 2^{1} / 2 \mathrm{~cm} . \\
\text { Trochanter in der } \\
\text { Höhe des Spinae. } \\
\text { Stoss- und Press- } \\
\text { schmerz nichtaus- } \\
\text { gesprochen. Bewe- } \\
\text { gungen minimal. } \\
\text { Vorne oben vom } \\
\text { Trochanter stark } \\
\text { eiternde Fistel. In } \\
\text { der Fossa iliaca } \\
\text { fluctuirende Ge- } \\
\text { schwulst. Multi- } \\
\text { ple Drüsen in der } \\
\text { Leiste. }\end{array}$ & $\begin{array}{l}\text { 2. Mai 1896. } \\
\text { Spaltung und Aus- } \\
\text { rüumung des } \\
\text { Beckenabscesses } \\
\text { und der Fistel, } \\
\text { Tamponade. Dann } \\
\text { hinterer Winkel- } \\
\text { schnitt. Kopf } \\
\text { z. Th. entfernt. } \\
\text { Ausräumen des } \\
\text { Gelenkes. Jodo. } \\
\text { formeinreibung. } \\
\text { Gypsverband. }\end{array}$ \\
\hline $\begin{array}{l}\text { 28. D .... r, } \\
\text { Gertrud, } \\
8 \text { Jahre, } \\
\text { Wohlen. }\end{array}$ & $\begin{array}{l}\text { 5. Mai } \\
1896 . \\
16 . \\
\text { Juni } \\
1896 .\end{array}$ & $\begin{array}{l}6 \\
\text { J. }\end{array}$ & 2 & 0 & Fall. & - & $\begin{array}{|cc|}\text { Einige } & \text { Wo- } \\
\text { chen nach Fall } \\
\text { auf die } & \text { Hüfte } \\
\text { Hinken } & \text { und } \\
\text { Schmerzen. } \\
\text { Extension,auf- } \\
\text { fällige } & \text { Besse- } \\
\text { rung. } & \text { Vor } \\
\text { einem } & \text { Jahr } \\
\text { starke } & \text { Ver- } \\
\text { schlimmerg. } \\
\text { Extension } \\
\text { durch Monate, } \\
\text { Apparat, keine } \\
\text { Besserung. }\end{array}$ & $\begin{array}{l}\text { Add. } 30^{\circ} \text {, keine } \\
\text { Fl. Becken fixirt. } \\
\text { Bewegungen pas- } \\
\text { siv sehr schmerz- } \\
\text { haft. Stoss- und } \\
\text { Pressschmerz. } \\
\text { Verkürzung } 2 \mathrm{~cm} \text {. } \\
\text { Verdickung am } \\
\text { Schenkelhals. } \\
\text { Drüsen in inguine } \\
\text { u. am Halse. Lun- } \\
\text { gen normal. }\end{array}$ & $\begin{array}{l}\text { 16. Mai 1896. } \\
\text { Winkelschnitt. } \\
\text { Abtragung des } \\
\text { Kopfes bis zur } \\
\text { Epiphyse. Aus- } \\
\text { räumen d. Pfanne. } \\
\text { Kapselexcision. } \\
\text { Jodoformeinrei- } \\
\text { bung. Drain. } \\
\text { Gypsverband. Ex- } \\
\text { tension. Myotomie } \\
\text { der Adductoren. }\end{array}$ \\
\hline $\begin{array}{l}\text { 29. Fleury, } \\
\text { Marie Louise, } \\
\text { Courroux, } \\
8 \text { Jahre. }\end{array}$ & $\begin{array}{c}\text { 18. Mai } \\
1896 . \\
5 . \text { Nov. } \\
1896 .\end{array}$ & $\begin{array}{l}7 \\
\mathrm{~J}\end{array}$ & 1 & $\mid \begin{array}{c}\text { In der } \\
\text { Fam. } \\
\text { des } \\
\text { Vaters } \\
\text { viel } \\
\text { Fälle } \\
\text { von } \\
\text { Tbe. } \\
\text { Eltern } \\
\text { ge- } \\
\text { sund. }\end{array}$ & Fall. & L. & \begin{tabular}{|lr} 
Schmerzen & u. \\
Hinken 3 Tage \\
nach & Fall auf \\
dem & Eise. \\
Schmerzen u. \\
Hinken. Seit \\
Hnfang & nicht \\
stark & zuge- \\
nommen. War \\
niebettlägerig.
\end{tabular} & $\begin{array}{l}\text { Schmerzen beim } \\
\text { Gehen u. Stehen. } \\
\text { Fl. contr. } 60^{\circ} . \\
\text { Bewegungen: F1. } \\
80^{\circ} \text {, Add. sehr ge- } \\
\text { ring. Sonst Be- } \\
\text { wegungen fast } 0 . \\
\text { Press- und Stoss } \\
\text { schmerz. Harte } \\
\text { Leistendrüsen. } \\
\text { KeinEiweiss. Lun- } \\
\text { gen normal. Ver- } \\
\text { kürzung } 3 \mathrm{~cm} \text {. }\end{array}$ & $\begin{array}{l}\text { Bis 12. Septem- } \\
\text { ber 1896. Exten- } \\
\text { sion. 12. Septbr. } \\
\text { Winkelschnitt } \\
\text { nach Kocher. Ab- } \\
\text { tragung d.Kopfes. } \\
\text { Ausräumen der } \\
\text { Pfanne. Excision } \\
\text { der Synovialis. } \\
\text { Gefensterte Gyps- } \\
\text { hose. }\end{array}$ \\
\hline
\end{tabular}


Ueber die Enderfolge der operativen Behandlung bei Coxitis tubereulosa. 59






\begin{tabular}{|c|c|c|c|c|c|c|c|c|c|}
\hline Name, Alter & 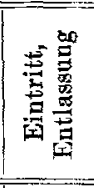 & 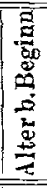 & 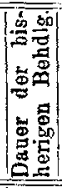 & 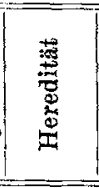 & 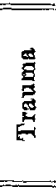 & 焉 & $\begin{array}{l}\text { Anamnesti- } \\
\text { sohe Daten }\end{array}$ & $\begin{array}{l}\text { Status beim } \\
\text { Eintritt }\end{array}$ & Therapie \\
\hline $\begin{array}{l}\text { 30. Egger, } \\
\text { Arthur, } 15 J_{.} \\
\text {Aarwangen, } \\
\text { Solothurn. }\end{array}$ & $\begin{array}{l}\text { 1. Juni } \\
1896 . \\
8 . \text { Aug. } \\
1896 .\end{array}$ & $\begin{array}{l}12 \\
\mathrm{~J}\end{array}$ & $3 \mathrm{~J}$ & $\mid \begin{array}{c}\text { Brüder } \\
+ \text { an } \\
\text { Phthi- } \\
\text { se. }\end{array}$ & - & L. & \begin{tabular}{|} 
Plötzliche \\
Schmerzhaf- \\
keit u. Hin- \\
kan nach Er- \\
kältung. Be- \\
handlg. durch \\
2 Jahre. Bis \\
vor Monaten \\
nicht bettläge- \\
rig. Keine \\
Besserung.
\end{tabular} & $\begin{array}{l}\text { Keine ausgespr. } \\
\text { Contractur. Keine } \\
\text { Verkürzung. } \\
\text { Becken fixirt; ac- } \\
\text { tiv nur geringe } \\
\text { Rotation möglich. } \\
\text { Starker Stoss- u. } \\
\text { Pressschmerz. In } \\
\text { NarkoseBewegun- } \\
\text { gen allseitig gut } \\
\text { ausführbar, obne } \\
\text { Knacken u. Crepi- } \\
\text { tation, Am Hals- } \\
\text { theil nioht hoch- } \\
\text { gradige Schwel- } \\
\text { lung. Lungen } \\
\text { normal. Im Urin } \\
\text { kein Eiweiss. }\end{array}$ & $\begin{array}{l}\text { 9. Juni } 1896 . \\
\text { Hinterer Winkel- } \\
\text { schnitt. Abtra- } \\
\text { gung d. Knorpels. } \\
\text { Ausräumen der } \\
\text { Pfanne. Jodoform- } \\
\text { einreibung. Gyps- } \\
\text { verband. }\end{array}$ \\
\hline $\begin{array}{l}\text { 31. A ....n, } \\
\text { Paul, Chattel } \\
\text { St. Dénis, 8.J. }\end{array}$ & $\begin{array}{c}17 . \\
\text { Juni } \\
1896 . \\
1 . \text { Aug. } \\
1896 .\end{array}$ & $6 \mathrm{~J}$ & $2 J$ & $\begin{array}{c}\text { Vater- } \\
\text { und } \\
\text { müt- } \\
\text { ter- } \\
\text { licher- } \\
\text { seits } \\
\text { belas- } \\
\text { tet. }\end{array}$ & - & $\mathbf{R}$, & $\begin{array}{l}\text { Schmerzen im } \\
\text { Knie, Hinken, } \\
\text { welches sieh } \\
\text { bessert, um } \\
\text { nach 1 Jahr } \\
\text { wiederzukeh- } \\
\text { ren, Interne } \\
\text { Behandlung, } \\
\text { puints de feu. }\end{array}$ & $\begin{array}{l}\text { Leichte Fl. } \\
\text { Contr. Add. Fl } \\
\text { bis } 90^{\circ}, \text { E. R. } \\
\text { normal. Abd. u. } \\
\text { A. R. =0, Keine } \\
\text { Schmerzen beim } \\
\text { Gehen. Hüftkopf } \\
\text { auf Druck nicht } \\
\text { empfindlich, keine } \\
\text { Verdickung, Nach } \\
\text { aussen am Os ilei } \\
\text { derbe Resistenz } \\
\text { Lange normal. }\end{array}$ & $\begin{array}{l}\text { 20. Juni. Hin- } \\
\text { terer } \text { Winkel- } \\
\text { schnitt. Abtra- } \\
\text { gung des Pfannen- } \\
\text { knorpels u. eines } \\
\text { Theiles des Kopf- } \\
\text { knorpels. Exeision } \\
\text { der hinteren Kap- } \\
\text { selwand. Exten- } \\
\text { sion. }\end{array}$ \\
\hline $\begin{array}{l}\text { 32. G.... y, } \\
\text { Laure dlice, } \\
\text { Coffrane, } 13 \mathrm{~J} \text {. }\end{array}$ & $\begin{array}{c}10 . J u l i \\
1898 . \\
16 . \\
\text { August } \\
1896 .\end{array}$ & $\begin{array}{l}12 \\
\text { J. }\end{array}$ & $\{J$. & 0 & 一 & - & $\begin{array}{l}\text { Schmerzen im } \\
\text { Knie n. Fuss. } \\
\text { Später dureh } \\
102 \text { Tage Ex- } \\
\text { tension (bis } \\
\text { Novbr. 1895). } \\
\text { Etwas Besse- } \\
\text { rung, d. nach } \\
\text { Aufstehen } \\
\text { gleich ver- } \\
\text { sch windet. }\end{array}$ & $\begin{array}{l}\text { Abd. u. A. R. } \\
\left(45^{0}\right), \text { Fl. } 30^{\circ} \text {. Ge- } \\
\text { gend d. Schenkel- } \\
\text { halses vorne ver- } \\
\text { dickt. Press- } \\
\text { schmerz. Drüsen } \\
\text { i. d. Leistenbeuge. } \\
\text { Lungen normal. }\end{array}$ & 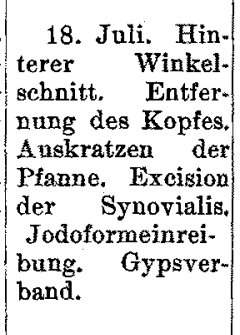 \\
\hline
\end{tabular}


Ueber die Enderfolge der operativen Behandlung bei Coxitis tuberculosa. 61

\begin{tabular}{|c|c|c|c|}
\hline $\begin{array}{l}\text { Wund- } \\
\text { behandlung }\end{array}$ & $\begin{array}{l}\text { Path. anatomischer } \\
\text { Befund }\end{array}$ & Entlassungsstatus & Endresultat \\
\hline $\begin{array}{l}\text { Nabt, Drai- } \\
\text { nage. } 29 . J \text { uli. } \\
\text { Entfernung d. } \\
\text { Gypsverband. } \\
\text { Wunde p. pr. } \\
\text { verheilt. Be- } \\
\text { wegungen. } \\
\text { 3. Angust. } \\
\text { Kleiner Ab- } \\
\text { scess in der } \\
\text { Wunde. }\end{array}$ & $\begin{array}{l}\text { "Diffuse fungöse } \\
\text { Massen im Gelenk; } \\
\text { ein Käseherd mit } \\
\text { kleinem Sequester im } \\
\text { oberen Umfang der } \\
\text { Pfanne, bis durch den } \\
\text { Knoch. perforirend." }\end{array}$ & $\begin{array}{l}\text { 8. Aug. Patient ist } \\
\text { sehr wohl, geht ohne: } \\
\text { Beschwerden, unter } \\
\text { geringem Hinken, mit } \\
\text { Krücke; A bscess voll- } \\
\text { ständig verheilt. Soll } \\
\text { sich wegen Aufnahme } \\
\text { eines Funetionsstatus } \\
\text { wieder zeigen. }\end{array}$ & $\begin{array}{l}\text { Januar 1902. Allgerneinbefinden gut. } \\
\text { Keine anderweitigen tuberculösen Sym- } \\
\text { ptome. Geht mit Stoek hinkend bis } 1 / 2 \\
\text { Stunde. Keine Schmerzen, keine Fistel. } \\
\text { Hatte 2mal starke Fisteleiterungen, die } \\
\text { aach einer Badecur in Schinznach aus- } \\
\text { heilten. Ab und zu auch seitdem geringe } \\
\text { Fisteleiterung. }\end{array}$ \\
\hline $\begin{array}{l}\text { 14. Juli } \\
\text { Schöne Prima. }\end{array}$ & $\begin{array}{l}\text { "Knorpel nament- } \\
\text { lich in der Pfanne } \\
\text { theilweise zerstört, } \\
\text { dicke, glatte, mit } \\
\text { grauen Tuberkeln be- } \\
\text { setzte Granulations- } \\
\text { verdickung der Syno- } \\
\text { vialis, Kopf nicht } \\
\text { verändert." }\end{array}$ & $\begin{array}{l}\text { 1. Aug. 1896. Narbe } \\
\text { schön lineär, keine } \\
\text { Sehwellung noch } \\
\text { Druekempfindlich- } \\
\text { keit; Patient beginnt } \\
\text { Bewegungen im Hüft- } \\
\text { gelenk zu machen. } \\
\text { Kann gut aufsitzen. } \\
\text { Extension empfohlen. }\end{array}$ & $\begin{array}{l}\text { Januar } 1902 \text { Allgemeinbefinden gut. } \\
\text { Keine Tbc. Geht hinkend mit Stock. } \\
\text { Keine Schmerzen. Nachoperation am } \\
\text { 24. November 1901. Nach mündlicher } \\
\text { Mittheilung von Dr. A, Kocher war vor } \\
\text { der Operation das Bein in leichter Ad- } \\
\text { ductionsstellung. Verkürzung } 5 \text { cm. Flexi- } \\
\text { on bis } 40^{\circ} \text {, Abd. R. unmöglich. Fisteln } \\
\text { am Trochanter major. Bei der Operation } \\
\text { fand sich ein Herd in der Pfanne. Hei- } \\
\text { lungsverlanf normal. Jetzt ohne Fisteln. }\end{array}$ \\
\hline
\end{tabular}

Naht m. Drai-

Diffuse fungöse 16. August. Narbe

Januar 1902. Allgemeinbefinden gut. nage. 1. Aug. Arthritis mit Ab-lineär. Keine Sehwel- Keine Tbo. Allgemeinerscheinungen; BeSchöne Prima. hebung des Knorpels|lung noch Infiltration. wegungen sehr beschränkt. Kann nur und tiefer Ausdeh. Soll noch einige Zeit mit einer Krücke gehen bis $1 / 4$ Stunde. nung in der Pfanne Gypsverband tragen, Ohne Beschäftigung. Sehmerzen im Knie. obne Sequester." dann vorsichtig mit 2 Fisteln, mit reiehlicher Eiterabsonderung. Uebungen anfangen. 


\begin{tabular}{|c|c|c|c|c|c|c|c|c|c|}
\hline Name, Alter & 焉 & 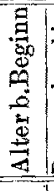 & 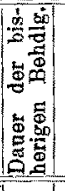 & 密 & $\sum_{E}^{E}$ & $\underset{\infty}{\infty}$ & $\begin{array}{l}\text { Anamnesti- } \\
\text { sche Daten }\end{array}$ & $\begin{array}{c}\text { Status beim } \\
\text { Eintritt }\end{array}$ & Therapie \\
\hline $\begin{array}{l}\text { 33. M. . }, y, \\
\text { Francois, } \\
141 / 2 \text { J., } \\
\text { Pruntrut. }\end{array}$ & $\begin{array}{c}19.0 \mathrm{et} . \\
1897 . \\
8 . \text { Febr. } \\
1898 . \\
3 . \text { Juni } \\
1898 . \\
30 . \\
\text { Juni } \\
1898 .\end{array}$ & $9 J$ & $\left|\begin{array}{c}51 / 2 \\
\mathrm{~J}\end{array}\right|$ & - & Fall. & I. & $\begin{array}{l}\text { Vor 5 Jahren, } \\
\text { n. einem Fall } \\
\text { v. Reck, Hin- } \\
\text { ken u.Schmer- } \\
\text { zen. Extension } \\
\text { Apparat, Bes- } \\
\text { serung. Vor } \\
\text { 10 Monaten } \\
\text { schwellung a. } \\
\text { Hütgelenk. } \\
\text { Juni Incision } \\
\text { eines Absces- } \\
\text { ses. Seither } \\
\text { profuseEiterg. } \\
\text { 3. Juni 1898. } \\
\text { Nach d.Opera- } \\
\text { tion konnte } \\
\text { Pat. sehr gut } \\
\text { gehen. Vor } 1 / 2 \\
\text { Monaten ent- } \\
\text { stand } 1 \text { kleiner } \\
\text { Abscess unter } \\
\text { d. Operations- } \\
\text { wunde.Konnte } \\
\text { trotzdem gnt } \\
\text { gehen. NaobIn- } \\
\text { cision desselb. } \\
\text { bleibt Fistel- } \\
\text { eiterg. zurück. }\end{array}$ & 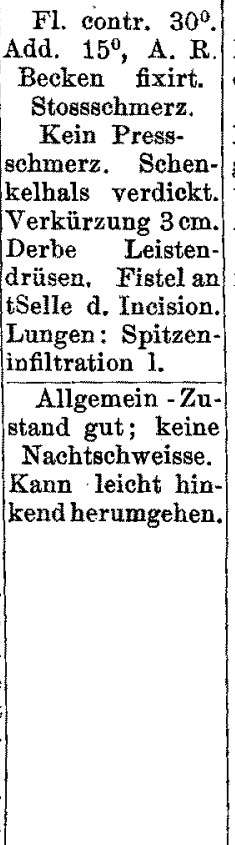 & $\begin{array}{l}\text { 27. Octbr. 1897. } \\
\text { Nach Ausräumen } \\
\text { der Fistel Winkel- } \\
\text { sehnitt naoh } \\
\text { Kocher. Abtra- } \\
\text { gung des Kopfes } \\
\text { u. Troch. majors. } \\
\text { Ausräumen der } \\
\text { Pfanne. Tampo- } \\
\text { nade mit Jodo- } \\
\text { formgaze. Kopf } \\
\text { soll in einer zwei- } \\
\text { ten Sitzung repo- } \\
\text { nirt werden. } \\
\text { 25. Juni 1898. } \\
\text { Gründliches Aus- } \\
\text { răumen der Fistel. }\end{array}$ \\
\hline $\begin{array}{l}\text { 34. Kissling, } \\
\text { Karoline,14J., } \\
\text { Hägendorf. }\end{array}$ & $\begin{array}{c}\text { 2. Nov. } \\
1897 . \\
15 . \\
\text { Febr. } \\
1898 .\end{array}$ & $\begin{array}{l}11 \\
J\end{array}$ & $3 \pi$ & 0 & - & $\mathbf{R}_{*}$ & $\begin{array}{l}\text { Anfang m. hef- } \\
\text { tigen Sehmer- } \\
\text { zen, dann } \\
\text { Nachlassen } \\
\text { derselben. Seit } \\
\text { 1/2 Jahr stetige } \\
\text { Versehlimme- } \\
\text { rung. Exten- } \\
\text { aion d. } 7 \text { Wo- } \\
\text { chen, Besserg. } \\
\text { Neues Auf- } \\
\text { treten der } \\
\text { Schmerzen. } \\
\text { Extension d. } \\
5 \text { Wochen. } \\
\text { Keine wesent- } \\
\text { liche Besserg. } \\
\text { Konnte nur } \\
\text { auf Krücken } \\
\text { gehen. }\end{array}$ & $\begin{array}{l}\text { F1. } 70^{\circ} \text { a. Add. } \\
35^{\circ} \text { contr. Stoss- } \\
\text { schmerz nichtaus- } \\
\text { gesprochen, star- } \\
\text { ker Pressschmerz. } \\
\text { Mit Ausnahme d. } \\
\text { A. R., alle Bewe- } \\
\text { gungen behindert. } \\
\text { Verdíckung am } \\
\text { Femurhalse. Kein } \\
\text { Knacken oder Rei- } \\
\text { ben bei Bewegung } \\
\text { fühlbar. Lungen } \\
\text { normal. Kein Ei- } \\
\text { weiss; derbe Drü- } \\
\text { sen am Halse. }\end{array}$ & $\begin{array}{l}25 . \text { Novbr.1897. } \\
\text { Hinterer Winkel- } \\
\text { schnitt. Kopf } \\
\text { bloss abgekratzt. } \\
\text { Pfanne ausge- } \\
\text { räumt. Jodoform } \\
\text { eingerieben. Te- } \\
\text { notomie d. Addue } \\
\text { toren u. der Mus. } \\
\text { keln an d. Sp. a. } \\
\text { sup. Extension. }\end{array}$ \\
\hline
\end{tabular}




\begin{tabular}{|c|c|c|c|}
\hline $\begin{array}{l}\text { Wund- } \\
\text { behandlung }\end{array}$ & $\begin{array}{l}\text { Path. anatomischer } \\
\text { Befund }\end{array}$ & Entlassungsstatus & Endresultat \\
\hline
\end{tabular}

Tamponade, „Coxarthritis tuber- 8.Febr.1898. Beide Secundärnaht, culosa mitstarkerVer-Beine in normaler Keine Tbc Bewegung gut 10. Nov. 1897. kürzung in Folge zu Strecklage. Fistel gut hinkend, 1-2 Stunden lang. Vor $11 / 2$ PrimaHeilung Grunde Gehens d. vernarbt. Verkürzung Jahren, 2\% Jahren nach der Operation, Extension. Kopfwölbung u. sehr $5 \mathrm{~cm}$. Fl. $20^{\circ}$, R. nor- öffneten sich 2 Fisteln, ohne Schmerzen bedeutender Pfannen- mal, Abd. u. Add. be- (eine auf der Innen-, die andere an der ausweitung m. dicken schränkt. Keine Aussenseite des Oberschenkels), die seither käsigen Massen im Schmerzhaftigkeit. Gelenk; Abscess hin- $\frac{\text { 1. Juli } 1898 .}{\text {. }}$ ter und über dem/Fisteleiterung gering. Schenkelhals herïber $\mathrm{Zur}$ Nacheur nach nach der Vorderfläche Schinznach gesandt. des Schenkels. Sequester in d. Pfanue."

Naht, Drain, Knochen fungös erJodoform. mêche. 13.Dec. Theil abgehoben. PrimaHeilung 8. Januar. Uebungen im Gelenk. fast immer eitern.

N.-U. 10. Februar 1902. Fl. contr. $75^{\circ}$, Add. $15^{\circ}$. Bewegungen: Fl. bis $90^{\circ}$, E. bis 75. Add., Abd, sehr beschränkt. E. R, A. R. $=0$. Sp. a. 8. - M. E. $74-86(12 \mathrm{~cm})$, Tr. m. - M. E. $74-81$ (7 cm). Trochanter $3 \mathrm{~cm}$ über RoserNélaton. : Sohlenabstand $11 \mathrm{~cm}$. Atrophie $39-32(7 \mathrm{~cm}), 27-24 \quad(3 \mathrm{~cm})$. Magerer, aber gesund aussehender Mann. Gang auf den Zehen, stark hinkend. Mit hohem Schuh z. gut. Lungen normal. Keine Drüsen. Röntgenaufnahme. Spondylitis; ohne Senkungsabscesse.
12. Februar 1898. (Klin. Vorstellung.) Kind hat active Bewegungen im Hüftgelenk, Fl. $\left(20-30^{\circ}\right)$. E. bis zur Geraden. Trochanter gleich hoch wie auf der gesunden seite. Sitzt mit etwas Kyphose der Lendenwirbelsäule. Verkürzung 3 cm. Am 15. Febr. entlassen.
Januar 1902. Allgemeinbefinden gut. Keine Tbc. Geht hinkend ohne Unterstützung bis $1 / 2$ Stunde. Keine Schmerzen, keine Fisteln.

10. Februar 1902. N.-U. Im J. 1898. Gypsbett, dann Corsett. Jetzt keine Schmerzen. Gibbus rom 7.-9. Dorsalwirbel. Geheilt. Nur Schwäche im Rücken.

FI. contr. $45^{\circ}$, Add. $15^{\circ}$. Bewegung: Fl. bis $75^{\circ}$, E. bis $45^{\circ}$, mit Lordosenbildung bis zur Geraden ausgleichbar. Add. norm. Abd. $=0$. E. R. norm. A. R. $1 / 2$ d. norm. Knie in Valgusstellung $\left(20^{\circ}\right.$ ).

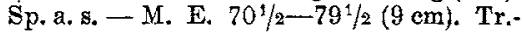
M. E. $72^{1 / 2}-74^{1 / 2}(2 \mathrm{~cm})$. Tr. $6 \mathrm{~cm}$ über Roser-Nélaton. Extreme passive Bewegungen schmerzhaft. Atrophie: $44 \frac{1}{2}$ bis $\left.36^{1 / 2} \mathrm{~cm}\right), 26^{1 / 2}-24^{1 / 2}$ (2 cm). Gang auf den Zehen, nicht stark hinkend. Mit $6 \mathrm{~cm}$ Erhöhung im Schuh kaum merkbar hinkend. Röntgenaufnahme. 


\begin{tabular}{|c|c|c|c|c|c|c|c|c|c|}
\hline Name, Alter & 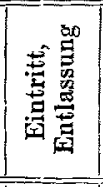 & 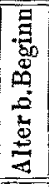 & $\mid \begin{array}{l}0 \\
0 \\
0 \\
0\end{array}$ & 滵 & 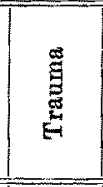 & $\stackrel{D}{+\infty}$ & $\begin{array}{l}\text { Anamnesti- } \\
\text { sche Daten }\end{array}$ & $\begin{array}{c}\text { Status beim } \\
\text { Eintritt }\end{array}$ & Therapie \\
\hline $\begin{array}{l}\text { 35. Widmer, } \\
\text { Johann, } \\
\text { Steffisburg, } \\
16 \text { Jahre. }\end{array}$ & $\mid \begin{array}{c}\text { 4. Juni } \\
1897 . \\
15 . \\
\text { Jan. } \\
1898 .\end{array}$ & $\frac{12}{J}$ & $\begin{array}{l}4 \\
J\end{array}$ & - & $\begin{array}{c}\text { Fall } \\
\text { aut die } \\
\text { Hứfte. }\end{array}$ & L. & $\begin{array}{l}\text { Fiel vor } 4 \text { Jah- } \\
\text { ren von } 5 \mathrm{~m} \\
\text { auf die Hüfte. } \\
\text { Hinken. Nach } \\
1 \text { Monat ent- } \\
\text { leert sich ein } \\
\text { Abscess, der } \\
\text { nach } 2 \text { Mona- } \\
\text { ten verheilt. } \\
\text { Sehmerzen } \\
1 / 2 \text { Jahr lang. } \\
\text { Hinken nabm } \\
\text { immer zu. }\end{array}$ & $\begin{array}{l}\text { Fl. } 90^{\circ} \text {, totale } \\
\text { Ankylose i. Hüft- } \\
\text { gelenk. Keine } \\
\text { Schmerzen. In } \\
\text { Narkose sind Be- } \\
\text { wegungen nach } \\
\text { allen Seiten mög } \\
\text { lich, aber be- } \\
\text { schränkt. Kein Fi } \\
\text { weiss Lungen nor- } \\
\text { mal. }\end{array}$ & $\begin{array}{l}\text { 6. Decbr. } 1897 . \\
\text { Hinterer Winkel. } \\
\text { schnitt. Kopf und } \\
\text { Troch. major ent- } \\
\text { fernt. Pfanne } \\
\text { etwas vertieft. Te } \\
\text { notomie des Sar } \\
\text { torius u. d. Addue- } \\
\text { toren. Jodoform. } \\
\text { einreibung. Ex. } \\
\text { tension. }\end{array}$ \\
\hline $\begin{array}{c}\text { 36. J ..e, } \\
\text { Charles, } \\
\text { Fribourg, } \\
10 \text { Jahre. }\end{array}$ & $\begin{array}{c}\text { 3. Dec. } \\
1897 . \\
\text { 7. Jan. } \\
1898 .\end{array}$ & 9 & $\frac{1}{J}$ & - & - & L. & $\begin{array}{l}\text { Schmerzen u. } \\
\text { Steifgkeit im } \\
\text { Gelenk, nach } \\
\text { Bötheln Hin- } \\
\text { ken. Nach } \\
\text { Fall Vermeh- } \\
\text { rung der } \\
\text { Schmerzen. } \\
\text { Bettruhe, Ex- } \\
\text { tension. Nach } \\
\text { Weglassender- } \\
\text { selben fängt d. } \\
\text { Sehwellung } \\
\text { an. }\end{array}$ & $\begin{array}{l}\text { Normale Stel- } \\
\text { lung bei Verkür- } \\
\text { zung des Beines. } \\
\text { Trochanter und } \\
\text { schenkelhals ver- } \\
\text { dickt.Abd. u. Add. } \\
\text { nieht ausführbar, } \\
\text { sonst beschränkte } \\
\text { Beweglichkeit. } \\
\text { Keine Abscesse. } \\
\text { Lungen normal. } \\
\text { Kein Eiweiss.Drü- } \\
\text { sen in der Fossa } \\
\text { liaca. }\end{array}$ & $\begin{array}{l}\text { 11. Decbr.1897. } \\
\text { Hinterer Winkel- } \\
\text { schnitt. Knorpel } \\
\text { u. oberflächliche } \\
\text { Knochenschichte } \\
\text { entfernt. Kapsel- } \\
\text { wand exeidirt, Ge- } \\
\text { fässe abgedreht } \\
\text { Tiefe Catgutnähte. } \\
\text { Jodoformeinrei. } \\
\text { bung. Extension. }\end{array}$ \\
\hline $\begin{array}{l}\text { 37. Bessire, } \\
\text { Jules, } \\
\text { Péry, } \\
\text { 16 Jahre. }\end{array}$ & $\begin{array}{c}24 . \\
\text { Jan. } \\
1898 . \\
30 . \text { Mai } \\
1898 .\end{array}$ & $\begin{array}{l}8 \\
J\end{array}$ & $\begin{array}{l}8 \\
\text { J. }\end{array}$ & - & $\longrightarrow$ & R. & $\begin{array}{l}\text { Nach Masern } \\
\text { soll sich vor } \\
8 \text { Jahren ein } \\
\text { Abscess gebil- } \\
\text { det haben. } \\
\text { Nach Monaten } \\
\text { traten Schmer- } \\
\text { zen im Hüt- } \\
\text { gelenk auf. } \\
\text { Abscess der } \\
\text { spontan auf- } \\
\text { brach u. } 1 \text { Jahr } \\
\text { zur Heilung } \\
\text { branehte. Hin- } \\
\text { ken seit der } \\
\text { Zeit. Vor } 3 \\
\text { Wochenneuer- } \\
\text { dings Schmer- } \\
\text { zen. }\end{array}$ & $\begin{array}{l}\text { Fl. contr. } 40^{\circ} \\
\text { Add. 150. Bewe- } \\
\text { gungen minimal. } \\
\text { Trochanter } 7 \mathrm{~cm} \\
\text { uber Roser-Néla- } \\
\text { ton; Verkürzung } \\
8 \mathrm{~cm} \text {. Kein Druck- } \\
\text { und Stossschmerz. } \\
\text { KeinEiweiss.Lun- } \\
\text { gen normal. Drü- } \\
\text { sen in inguine. }\end{array}$ & $\begin{array}{l}\text { 28. Febr, } 1898 . \\
\text { Winkelschnitt } \\
\text { nach Kocher. Te- } \\
\text { notomie des Sar. } \\
\text { torius. Trochan- } \\
\text { ter abgetragen. } \\
\text { Aus dem Adam- } \\
\text { schen Bogen Kopt } \\
\text { gebildet. Gyps. } \\
\text { verband. }\end{array}$ \\
\hline
\end{tabular}


Ueber die Enderfolge der operativen Behandlung bei Coxitis tuberculosa. 65

\begin{tabular}{|c|c|c|c|}
\hline $\begin{array}{l}\text { Wund- } \\
\text { behandlung }\end{array}$ & $\begin{array}{l}\text { Path. anatomischer } \\
\text { Befund }\end{array}$ & Entlassungsstatus & Endresultat \\
\hline $\begin{array}{l}\text { Naht mit } \\
\text { Drain. Gefässe } \\
\text { abgedreht. }\end{array}$ & $\begin{array}{l}\text { "Der Kopf zum } \\
\text { Theil granulös zer- } \\
\text { stört. Käsige Granu- } \\
\text { lationen, besonders } \\
\text { in der Epiphysen- } \\
\text { linie. Pfanne sehr er- } \\
\text { weitert, doch normal. } \\
\text { Nirgends ein Eiter- } \\
\text { herd." }\end{array}$ & $\begin{array}{l}\text { Entlassen am 12.Fe- } \\
\text { bruar 1898. } \\
\text { fehlt. }\end{array}$ & 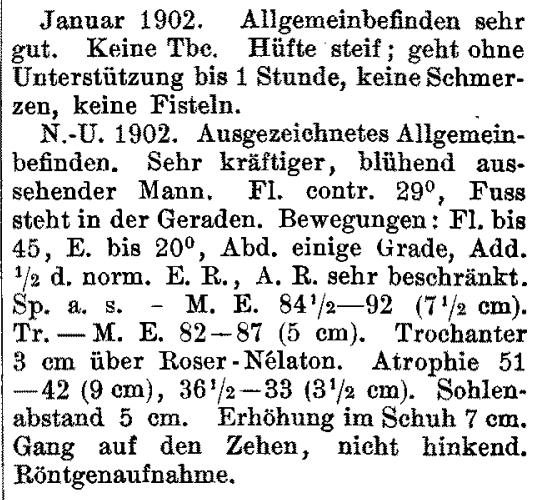 \\
\hline
\end{tabular}

Naht mit

Drainage und Jodoformmêche.

Naht mit Drainage.
Kapsel a.d.Innen-

Am 7. Januar entwand mit tbe. Gra-lassen, Status fehlt. nulationen bedeckt.

Am Halse ein francgrosser, muldenförmiger Defect, mit Granulationen; am Knorpel bläuliche Verfärbung. Knorpel abgehoben. Grosser Herd in der Pfanne, der nach innen perforirt."

Kopf fehlt voll- Am 30. Mai 1898 kommen, nur der entlassen. Status fehlt. Adam'sche Bogen erhalten.
Januar 1902. Allgemeinbefinden gut. Keine Tbc. Gelenk fixirt; liegt zu Bett. Keine Schmerzen. Fisteln. Gesund bis vor $1 \mathrm{Jahr}$; unter starken Sehmerzen bildete sich ein Abscess, der indicirt wurde.

N.-U. 29. Januar 1902. 1 Fistel vorne am Schenkelhals, 1 in der Narbe, 1 an der Crista ilei. Bewegungen: Fl., R. sehr beschränkt, Abd. $=0$, Add. contr. $15^{\circ}$. Spin. a. s. - M. E. 70-77 (7 cm). Tr. M. E. $7072(2 \mathrm{~cm})$. Troch. $5 \mathrm{~cm}$ über Roser - Nélaton. Sohlenabstand $8 \mathrm{~cm}$. Atrophie: $1 \mathrm{~cm}$ Differenz; beide Beine durch $1 \mathrm{Jahr}$ langes Liegen abgemagert. Beide Kniee, Füsse versteift. Lunge normal. Keine Drüsen.

Februar 1902. Allgemeinbefinden gut. Keine allgemeinen Erscheinungen tuberculöser Natur. Geht stark hinkend mit Stock, unter Schmerzen. Keine Beschäftigung. Ab und zu Schmerzen, Fistel an der Hüfte. 


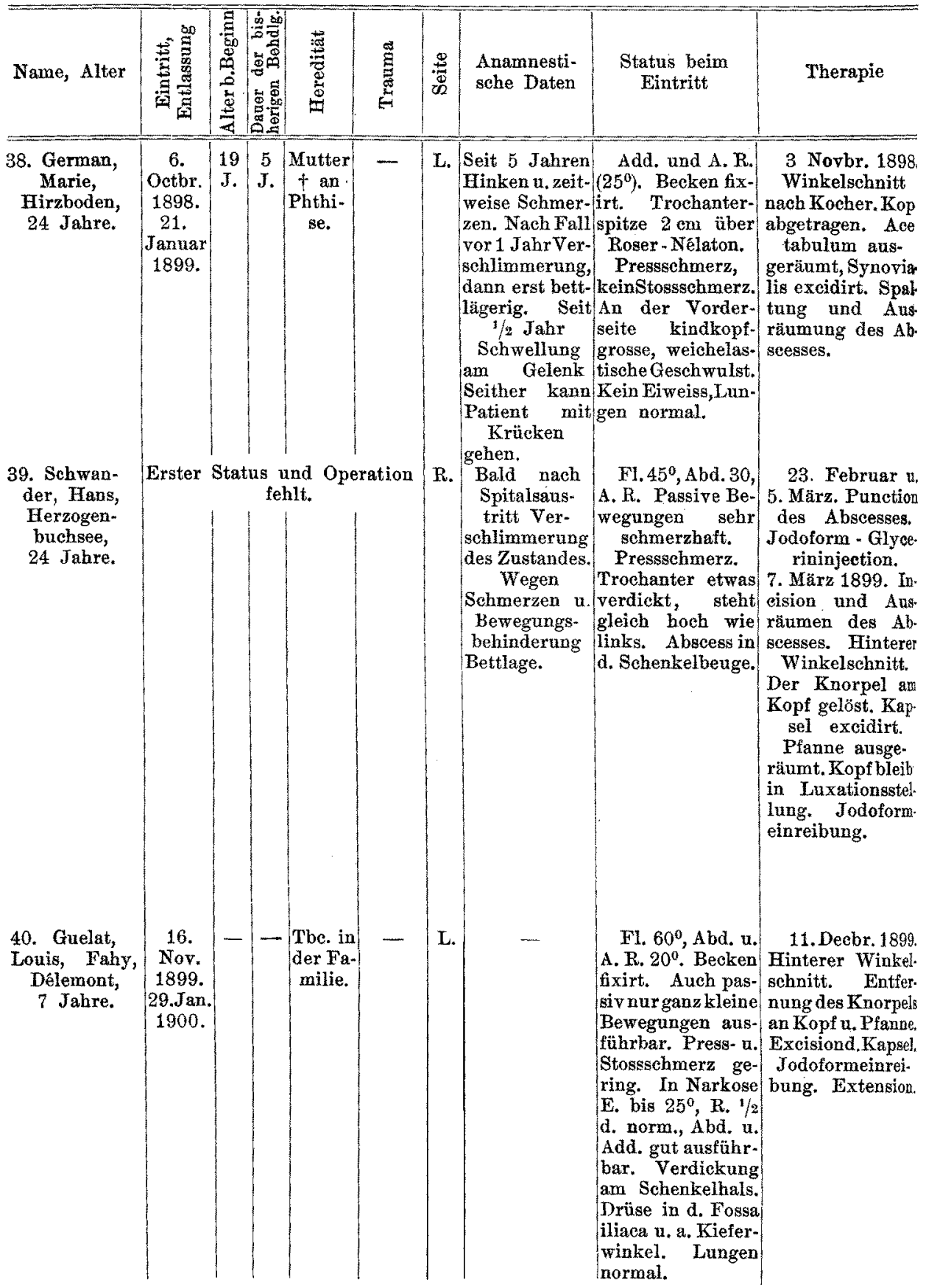


Ueber die Enderfolge der operativen Behandlung bei Coxitis tuberculosa. 67

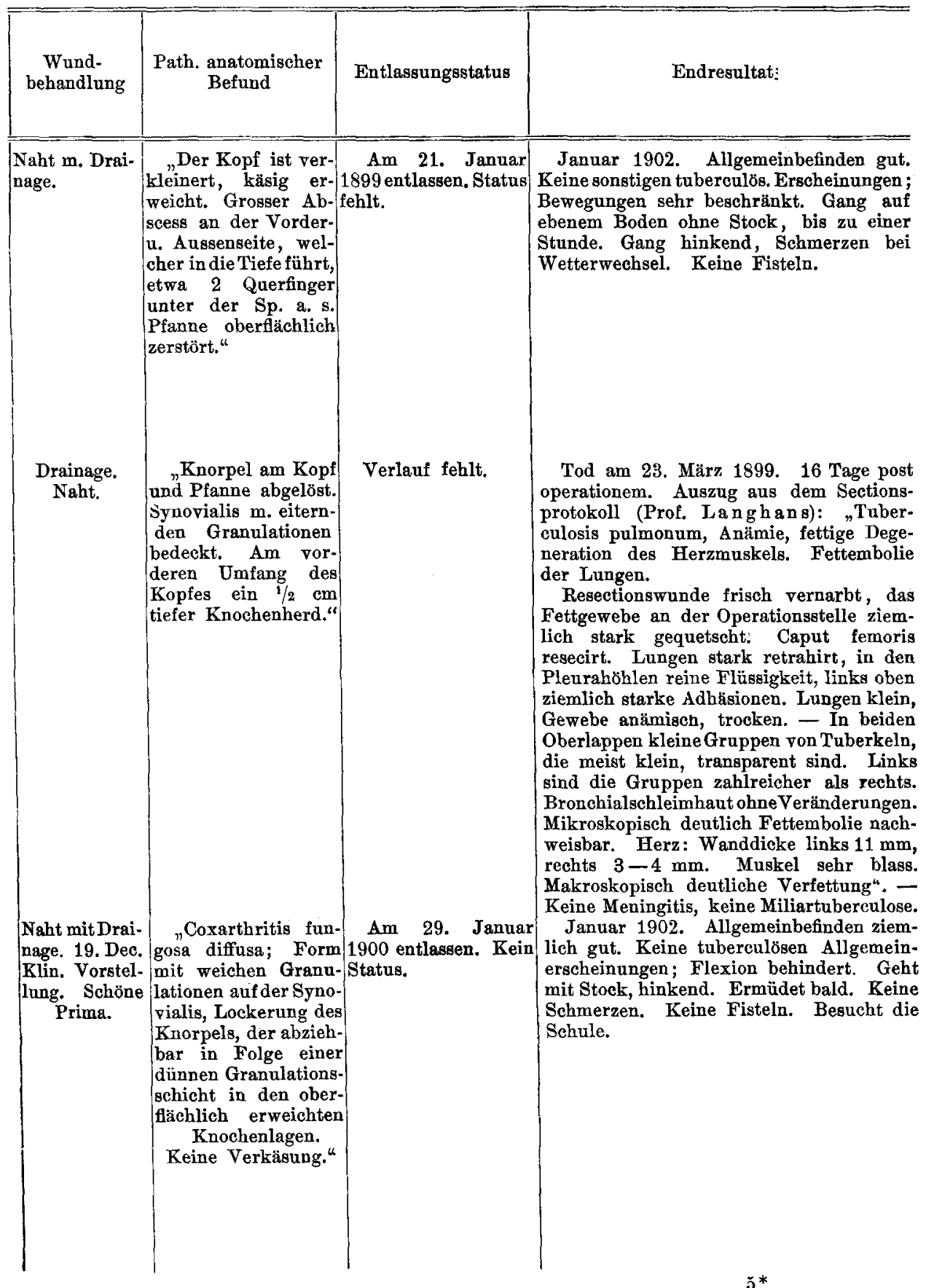




\begin{tabular}{|c|c|c|c|c|c|c|c|c|c|}
\hline Name, Alter & 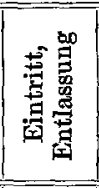 & 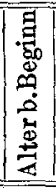 & 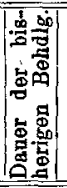 & 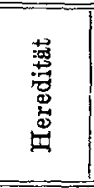 & 莺 & 焉 & $\begin{array}{l}\text { Anamnesti- } \\
\text { sche Daten }\end{array}$ & $\begin{array}{l}\text { Status beim } \\
\text { Eintritt }\end{array}$ & Therapie \\
\hline $\begin{array}{l}\text { 41. Buri, } \\
\text { Lieseli, Ebuit } \\
\text { b.Saanen, 10J. }\end{array}$ & $\begin{array}{c}19 . \\
\text { Novbr. } \\
1899 . \\
24 . \\
\text { Febr. } \\
1900 .\end{array}$ & $9 \mathrm{~J}$ & $1 \mathbf{J}$ & - & - & L. & $\begin{array}{l}\text { „Erst unter } \\
\text { Flexions- } \\
\text { krämpfen, } \\
\text { dann Hinken } \\
\text { und Knie- } \\
\text { schmerzen, zu- } \\
\text { letzt Hüft- } \\
\text { schmerzen, } \\
\text { auftretende } \\
\text { Coxitis." }\end{array}$ & $\begin{array}{l}\text { Fl. } 60^{\circ}, \text { Add. } 45^{\circ} . \\
\text { Kleinere Be- } \\
\text { wegungen glatt, } \\
\text { grössere schmerz- } \\
\text { haft. Fl. activ } 30^{\circ} \text {, } \\
\text { passiv } 90^{\circ}, \text { E.pas- } \\
\text { siv } 45^{\circ} \text {. E. R. } 90^{\circ} \text {. } \\
\text { A. R. } 45^{\circ} \text {. Bei E. } \\
\text { R.fühltman hinter } \\
\text { dem Trochanter } \\
\text { deutlich den Kopf, } \\
\text { den man auf } 2 \mathrm{~cm} \\
\text { auf und ab sehie- } \\
\text { ben kann. Ver- } \\
\text { kürzung } 21 / 2 \mathrm{~cm} . \\
\text { Trochanter ca. } 4 \\
\text { cm über der Spina- } \\
\text { linie. Grosser Ab- } \\
\text { scess hinter dem } \\
\text { Trochanter.Press- } \\
\text { schmerz. Kein Ei- } \\
\text { weiss, Lungen } \\
\text { normal. }\end{array}$ & $\begin{array}{l}\text { 16. Deebr. 1899. } \\
\text { Eröffnung u. Aus- } \\
\text { räumen des Ab- } \\
\text { scesses. Winkel- } \\
\text { schnitt n. Kocher. } \\
\text { Der Kopf brieht } \\
\text { ab, wird mit dem } \\
\text { Finger herausge- } \\
\text { boben. Pfanneaus- } \\
\text { geräumt, aus dem } \\
\text { Hals ein Kopf ge- } \\
\text { schnitten, Tro- } \\
\text { chanter abgetra- } \\
\text { gen. Synovialis } \\
\text { excidirt. Kopf in } \\
\text { die infracotyloide } \\
\text { Grube reponirt. } \\
\text { Extension. } \\
\end{array}$ \\
\hline $\begin{array}{l}\text { 42. Allenbach, } \\
\text { Rudolf, } \\
\text { Wengi bei } \\
\text { Frutigen } 29 \mathrm{~J} \text {. }\end{array}$ & $\begin{array}{c}13 . \\
\text { Decbr. } \\
1899 . \\
15 . \\
\text { März } \\
1900 .\end{array}$ & $\begin{array}{l}26 \\
1 / 2 \\
\mathrm{~J}\end{array}$ & $21 / 2$ & $\begin{array}{l}\text { Vater } \\
+ \text { an } \\
\text { Phtyse }\end{array}$ & - & L. & \begin{tabular}{|} 
Vor2 $1 / 2$ Jahren \\
Schmerzen im \\
Knie, dann \\
Hinken, Lag \\
dann dureh \\
2 Jahre im \\
Bette. Soll \\
schon vorher \\
schwindsüch- \\
tigk gewesen \\
sein. Viel Aus- \\
wurf, ab u. zu \\
blutig tingirt.
\end{tabular} & $\begin{array}{l}\text { In Streckstel- } \\
\text { lung, A. R. } 45^{\circ} \mathrm{u} . \\
\text { Add. 15-200. } \\
\text { Spitze d. Troch. } \\
\text { i. d. horiz. Spina- } \\
\text { linje. Verkürzung } \\
\text { 5cm. Becken fxirt. } \\
\text { In Narkose Fl.40 } \\
\text { E.bis zur Geraden. } \\
\text { Nach aussen und } \\
\text { vor der Spina der } \\
\text { Kopf zu fühlen. } \\
\text { Senkungsabscess } \\
\text { bis Mitte d. Ober- } \\
\text { schenkels. Syno- } \\
\text { vitis adhaesiva im } \\
\text { Knie, Fussgelenk } \\
\text { beiderseits und } \\
\text { Hüfte R. Spitzen- } \\
\text { infiltration, Bron- } \\
\text { chialathmen. Kein } \\
\text { Eiweiss. }\end{array}$ & $\begin{array}{l}\text { 12. Jan. } 1900 . \\
\text { Incision des Ab- } \\
\text { scesses. Ausräu- } \\
\text { men desselben. } \\
\text { Hinterer Winkel- } \\
\text { schnitt. Abtragen } \\
\text { des Kopfes, sodass } \\
\text { nur d. Adam'sche } \\
\text { Bogen stehen } \\
\text { bleibt. Ausräu- } \\
\text { men der Pfanne. } \\
\text { Kapsel excidirt. } \\
\text { Jodoformeinrei- } \\
\text { bung. }\end{array}$ \\
\hline
\end{tabular}


Ueber die Enderfolge der operativen Behandlung bei Coxitis tuberculosa. 69

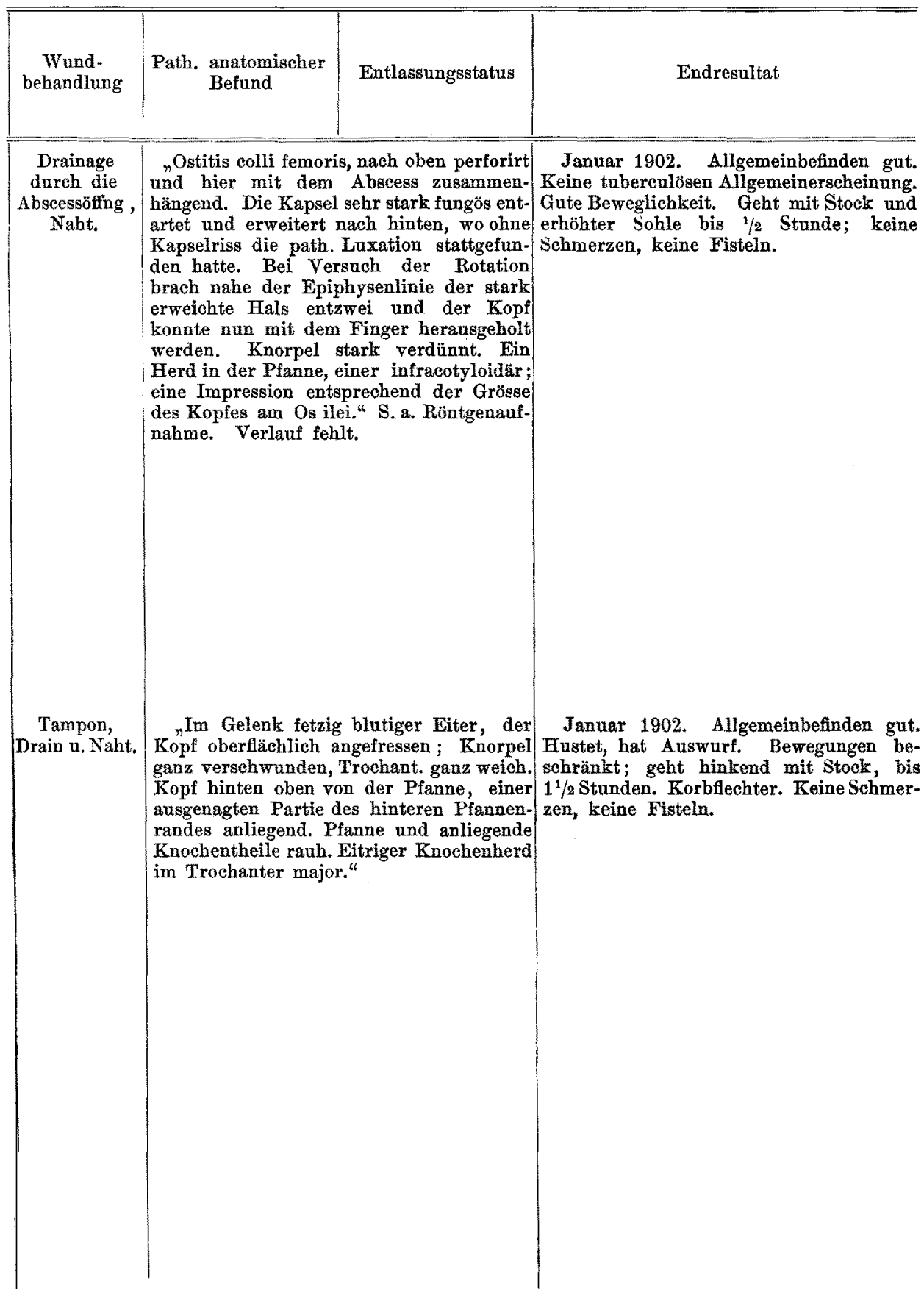




\begin{tabular}{|c|c|c|c|c|c|c|c|c|c|}
\hline Name, Alter & 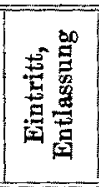 & 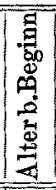 & 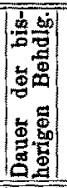 & 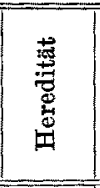 & $\stackrel{\Xi}{E}$ & 蛋 & $\begin{array}{l}\text { Anamnesti- } \\
\text { sche Daten }\end{array}$ & $\begin{array}{c}\text { Status beim } \\
\text { Eintritt }\end{array}$ & Therapie \\
\hline $\begin{array}{c}\text { 43. Fedier, } \\
\text { Emma, } \\
\text { Göschenen, } \\
6 \mathrm{~J} .\end{array}$ & $\begin{array}{c}25 . \\
\text { März } \\
1900 . \\
19 . \\
\text { Septbr. } \\
1900 .\end{array}$ & $2 \mathrm{~J}$. & $4 \mathrm{~J}$ & - & - & L. & $\begin{array}{l}\text { Vor 4 Jahren } \\
\text { fing das Kind } \\
\text { zu hinken an; } \\
\text { wurde durah } \\
\text { Monate mit } \\
\text { Gypsverbän- } \\
\text { den behandelt. } \\
\text { Im Herbst } \\
\text { 1899. Entlas- } \\
\text { sung aus dem } \\
\text { Spital Iuzern. } \\
\text { Bald wieder } \\
\text { Hinken. }\end{array}$ & $\begin{array}{l}\text { Schmerzen beim } \\
\text { Gehen. Fl, 90, } \\
\text { Add. 200, leichte } \\
\text { A.R. Becken ganz } \\
\text { fixirt. Verkürzung } \\
\text { 2 cm. Trochanter, } \\
\text { Schenkelhals ver- } \\
\text { dickt. In Narkose: } \\
\text { E. bis } 20^{\circ}, \text { Abd. u. } \\
\text { Add. bis } 2 / 3 \text { der } \\
\text { norm. A, R. und } \\
\text { E. R. bis } 1 / 2 \text {. Fl. } \\
\text { bis norm. Lungen } \\
\text { normal. Kein Ei- } \\
\text { weiss. Submaxil. } \\
\text { lardrüsen. }\end{array}$ & $\begin{array}{l}\text { Bis 22. Jull } \\
\text { 1900. Conservativ } \\
\text { behandelt. Exten } \\
\text { sion, Jodoform. } \\
\text { injectionen. } \\
\text { 23. Juli. Winkel. } \\
\text { schnitt. Excision } \\
\text { von Kopf u. Sy- } \\
\text { novialis. Ausrä̀- } \\
\text { men der Pfanne } \\
\text { Gypsverband und } \\
\text { Extension. }\end{array}$ \\
\hline $\begin{array}{c}\text { 44. Schneider, } \\
\text { Hermann, } \\
\text { Diesbach, } 9 \mathrm{~J} .\end{array}$ & $\begin{array}{c}15 . \\
\text { Octbr. } \\
1900 . \\
9 . \text { Mai } \\
1901 .\end{array}$ & $9 \mathrm{~J}$. & M. & $\begin{array}{l}\text { Tbc. in } \\
\text { der Fa- } \\
\text { milie. } \\
\text { Vater } \\
\text { Phty- } \\
\text { siker. }\end{array}$ & - & $\mathrm{R}$. & $\begin{array}{l}\text { Vor } 3 \text { Monaten } \\
\text { Hinken, bald } \\
\text { darauf heftige } \\
\text { Sehmerzen bis } \\
\text { ins Knie- } \\
\text { gelenk. }\end{array}$ & $\begin{array}{l}\text { F1. } 40^{\circ}, \text { A. R. } \\
\text { Abd. Vorderseite } \\
\text { des Gelenkes ver- } \\
\text { dickt. Bewegun- } \\
\text { gen: activ = } 0 \\
\text { passiv sehr be- } \\
\text { schränkt. In Nar- } \\
\text { kose allseitig sehr } \\
\text { ergiebige Bewe- } \\
\text { gungen. } 2 \text { Drüsen } \\
\text { in d. Fossa iliaca } \\
\text { int. Stoss- und } \\
\text { Pressschmerz. } \\
\text { Lungen normal. } \\
\text { Kein Eiweiss. }\end{array}$ & $\begin{array}{l}\text { Bis 25. Januar } \\
\text { 1901. Cons. Be- } \\
\text { bandlung. Keine } \\
\text { Besserung. Am } \\
\text { 25. Jan. Hinterer } \\
\text { Winkelschnitt. } \\
\text { Abtragung des } \\
\text { Kopfes bis z. Epi- } \\
\text { physenlinie. Ans } \\
\text { räumen d. Pfanne } \\
\text { Kapselexcision. } \\
\text { Kopf i. Luxations } \\
\text { stellung belassen. }\end{array}$ \\
\hline
\end{tabular}

Anmerkung zu den Tabellen: Aus Raumersparniss waren Abkürzungen bei den Tabellen nothwendig. Die wichtigsten derselben sind:
Fl. Flexion.
E. R. = Einwärts-Rotation.
E. = Extension.
A. R. $=$ Auswärts-Rotation.
Abd. = Abduction.
Sp.s. = Spina anterior superior.
Add. $=$ Adduction.
Tr. m. = Trochanter major.
R. Rotation.
M. E. = Malleolus externus.

In den Abschnitten "Status beim Eintritt" uad "Endresultat" beziehen sich diese Bezeichnungen in erster Linie auf die Contracturstellung. Wo sie auf Bewegungen gemeint sind, ist dies besonders bemerkt. Bezüglich der Winkelmaasse und Atrophie siehe Fussnote auf Seite 25. Bei den Längenmaassen sind die absoluten Zahlen angegeben. In Parenthese ist die Differenz bemerkt. In der Rubrik "Path. anatomischer Befund" sind die mit Anführungszeichen versehenen Notizen von Prof. K ocher eigenhändig geschrieben. Bei den Fällen, wo eine Nachoperation nöthig war, sind die Daten der ersten und zweiten Operation durch einen horizontalen Strich geschieden. 
Ueber die Enderfolge der operativen Behandlung bei Coxitis tuberculosa. 71

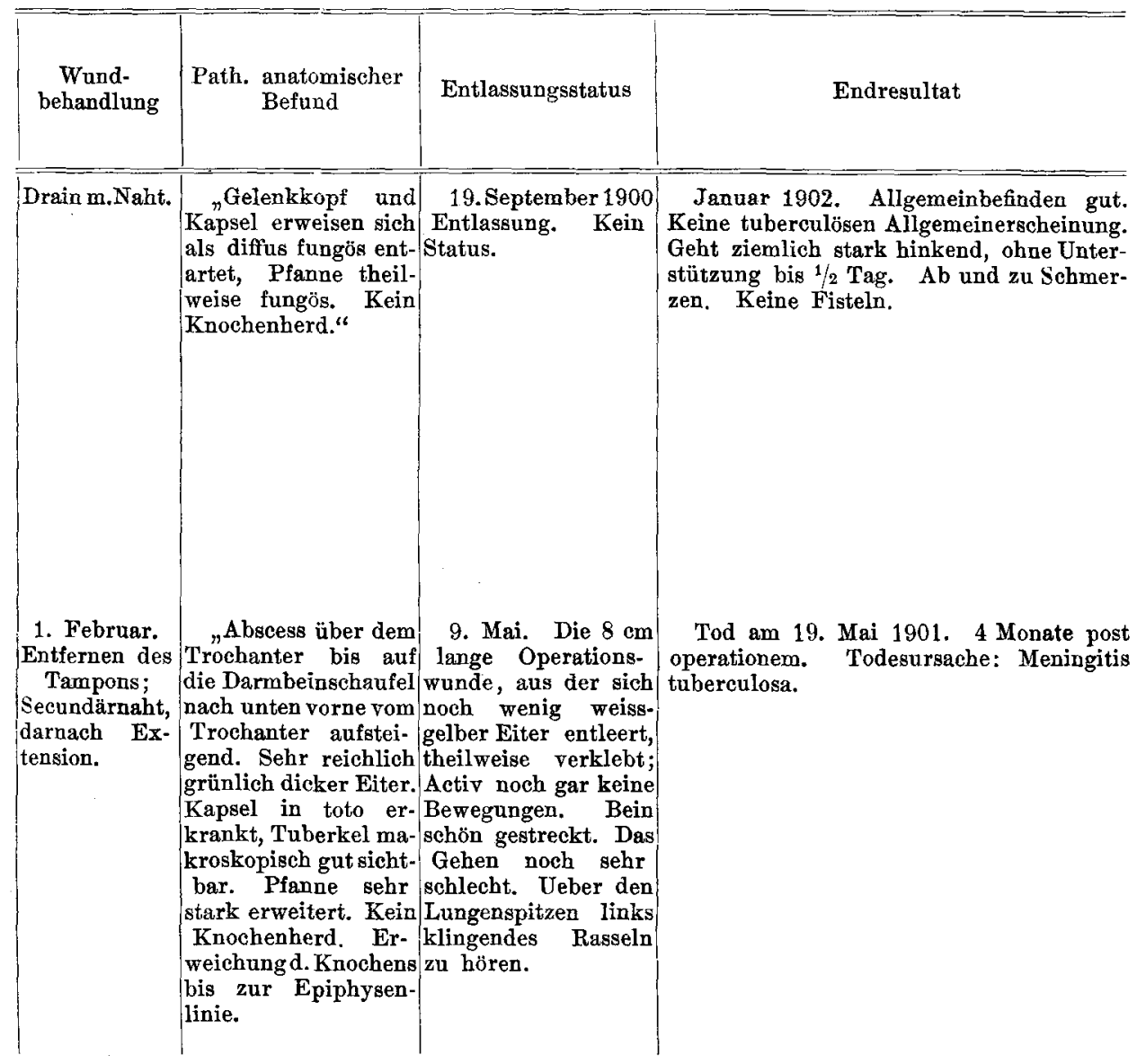

\section{'Tafelerklärung. ${ }^{1}$ )}

\section{Tafel I.}

Fig. 1. (Fall E. Wittwer S. 15.) Starke Rareficirung des Knochens bis unter den Trochanter minor. Bloss der Adam'sche Bogen ist noch von der Knochenstructur sichtbar. Die Epiphysenlinie ist ganz verwischt, während sie links gut sichtbar ist. Die Knochenatrophie erstreckt sich auch auf die ganze Beckenhälfte.

1) Die Erklärungen zu den Photogrammen sind nach den Originalabzügen geschrieben. Durch das Reproductionsverfahren sind oft die wichtigsten Details zum Theile ganz verwischt (s. Fig. 6), so dass ich gezwungen bin, an die Phantasie der Leser zu appelliren, ein bei naturwissenschaftlichen Arbeiten höchst unliebsamer Factor. Alle, die heiklige Roentgenbilder reproduciren liessen, werden die Mangelhaftigkeit der Tafeln verzeihen und mit etwas Phantasie und der beigegebenen Erklärung die Mängel ergänzen, die das Reproductionsverfahren gesetzt. 
Fig. 2 u. 3. (Fall H. Schneider Nr. 41.) Aehnlich wie Fig. 1, nur dass die Atrophie der Knochen mehr fleckenweise auftritt. Die Ansatzstelle des Lig. teres deutlich rareficirt (auf den Originalplatten). Die Contouren des Kopfes und der Epiphysenlinie verschwommen.

Fig. 4. (Fall E. Schäffli.) Exquisit schönes Bild von circumseripten Knochenherden am oberen und hinteren Pfannenrande. Ausser leichter Atrophie um das Lig. teres am Schenkelknochen kaum nennenswerthe Rareficirung.

Fig. 5. (Fall L. Buri Nr. 41. S. 16.) Hochgradige Destructionsprocesse an der Pfanne und dem Kopftheile des Schenkelknochens. Nebst sehr hochgradiger Atrophie der kranken Beckenhälfte ist der Kopf bis zur Epiphysenlinie verschwunden; der Stumpf zeigt ausgezackte, verschwommene Contouren. Sehr ausgeprägte Pfannenwanderung resp. Luxation.

Fig. 6. (Fall R. Allenbach Nr. 42.) Aehnlich wie Fig. 5. Bei der Reproduction ganz verunglückt.

\section{Tafel II.}

Röntgenbilder nach Resection.

Fig. 7. (Fall Z . . . r Nr. 20. S. 27.) Schenkelhals fast gänzlich verschwunden. An Stelle desselben breite Callusmassen. Knochenstructur gleich der gesunden Seite. Keine Knochenatrophie.

Fig. 8. (Fall Widmer Nr. 35.) Aehnlich wie Fig. 8. In der Höhe des 'Troch. minor, an der Aussenseite des Knochens eine spitze Exostose. Keine Atrophie des Schenkelknochens nachweisbar. Bloss die entsprechende Beckenhälfte ist kleiner als die gesunde.

Fig. 9. (Fall A. Vermeille Nr. 23.) Halstheil des Schenkelknochens gut erhaiten, Gelenkspalt sichtbar. Nicht unbeträchtliche Atrophie des Knochens.

Fig. 10. (Fall K. Kissling Nr. 34.) Kopf und Halstheil sind ganz verschwunden. Die Stelle des Troch. min. steht der Pfanne gegenüber. Der Troch. major ist am Becken hinaufgeglitten. Gute Pseudarthrose (v. S. 28). Kaum nennenswerthe Atrophie des Knochens.

Fig. 11. (Fall F. M . . . y Nr. 33.) Hochgradige Knochenatrophie, sowohl des Femur als des Beckens. Der Stumpf des Schenkelhalses steht am oberen Pfannenrande.

Fig. 12. (Fall $\Lambda$. Wodtli Nr. 15.) Aehnlich wie Fig. 12, bloss steht der Femurstumpf etwas höher am Becken. Trotz der missglückten Reproduction ist die starke Atrophie des Femurs deutlich sichtbar.

\section{Literaturverzeichniss.}

Zehnder, Hans, Beitrag zur Coxitisbehandlung. Inaug.-Diss. Bern 1882.

Guinand, Paul, Beitrag zur Coxitisbehandlung. Inaug.-Diss. Lausanne 1891.

Albrecht, Ueber den Ausgang der fungösen Gelenkentzündung und die Bedeutung der Gelenkresection bei solchen. Deutsche Zeitschr. f. Chir. Ba. 29. 1884.

A lexandrow (Moskau), Ueber operative Behandlung tuberculöser Erkrankungen des Hüft- und Kniegelenks bei Kindern. Ref. Centralbl. f. Chir. Bd. 28. 1891. 
Ueber die Enderfolge der operativen Behandlung bei Coxitis tuberculosa. 73

Baehr, Ueber Endresultate der IIüftgelenkresectionen. Deutsche Zeitschr. $f$. Chir. Bd. 30.

Barker, Arthur, The after history of 41 cases treated by operation for destructive hip joint disease. I Lancet 1900. Mai 26.

Binder, Die conservative Behandlung der Coxitis und ihre Resultate, insbesondere die conservative Behandlung mittels portativer Apparate. Zeitschr. f. orth. Chir. Bd. 7. Heft 2.

Bru ns, Ueber die A usgänge der tuberculösen Coxitis bei conservativer Behandlung. Arch. f. kl. Chir. Bd. 48. 1894.

Calot, La résection de la hanche dans la coxalgie. Presse méd. 1900. Ref. in Centralbl. f. Chir. 1900.

Caumont, Ueber Behandlung chronischer Gelenkentzündungen an der unteren Extremität. Deutsche Zeitschr. f. Chir. Bd. 20.

Cornet, Die Tuberculose. Nothnagels Spec. Path. und Ther. Bd. 14. III.

Dollinger, Sebészeti módszerek. Budapest 1901 (ung.).

Droba, Die Tuberculose der Knochen und Gelenke. Przeglad lekaríki 1899. No. 36-38. Ref. Centralbl. f. Chir. 1900.

Gerulanos, Die Tuberculose der Gelenke und Wirbelsäule. Festschr. d. St. Hedwig-Krankenhauses zu Berlin. Ref. Centralbl. f. Chir. 1896.

Heinecke, Die chirurgische Bekämpfung der Tuberculose in Knochen und Gelenken. Penzoldt-Stinzing. Bd. 5.

$\mathrm{Ha} \mathrm{as,} \mathrm{Ueber} \mathrm{Endresultate} \mathrm{der} \mathrm{Hüftgelenkresectionen.} \mathrm{Inaug.-Diss.} \mathrm{Würzburg} 1892$.

Henle, Die Behandlung der tubercnlösen Gelenkerkrankungen und der kalten Abscesse. Bruns Beiträge. Bd. 20.

H offa, Die ambulante Behandlung der tuberculösen Iüftgelenkentzündung mittels portativer Apparate.

Hof a , Artikel "Coxitis" im Handbuch der praktischen Chirnrgie. Bd. 4.

H üter, Klinik der Gelenkkrankheiten. 187т. 2. Aufl.

Kocher, Operationslehre. 4. Aufl. Jena. 1902.

König, Die Tuberculose der Knochen und Gelenke. 1884.

König, Die moderne Behandlung der Gelenktuberculose. Langenbecks Arch. Bd. 24. 1892.

König, Die Bedeutung des Röntgenbildes für die operative Behandlung der tuberculösen Coxitis. Deutsche Zeitschr. f. Chir. Bd. 47.

König, Lehrbuch der Chirurgic. 1900.

König, Die spec. Tuberculose der Knochen und Gelenke. I. Das Kniegelenk.

Kirmisson, Des luxations soudaines au cours de la coxalgie. Révue d'orthopédie. 1899.

Krause, Die Tuberculose der Knochen und Gelenke. (Deutache Chirurgie.)

I udl off, Die Behandlung der tuberculösen Coxitis. Arch. f. klin. Chir. Bd. 63.

Ménard (Berck sur Mer.) Arthrotomie de la hanche et curettage intégral dans la coxalgie compliquée d'un abscés rebelle à la méthode des injections. Bull. et. mém. d. la soc. d. chir. Tome 23.

Marsch, Zur Therapie der Coxitis tuberculosa. Inaug.-Diss. Marburg.

Mumelthey, Beitrag zur Behandlung der Coxitis. Inaug.-Diss. Kiel 1895.

Neuber, Zur Behandlung der Knochen- und Gelenktuberkulose. Archivf. klin. Chirurgie. Bd. 49.

Payr, Weitere Beiträge zur Kenntniss und Erklärung des fettembolischen Todes u. s. w. Zeitschrift f. orthop. Chirurgie. 1900. 
74 I. Maxninger, Ueb. d. Enderfolge d. operat. Behandlg. b. Coxitis tubereulosa.

Pedolin, Die functionellen Resultate der conservirenden und operativen Behandlung der tuberculösen Coxitis im Kniegelenk. Inaug.-Dissertation. Zürich 1895.

Riedel, Die operative Behandung tuberculöser Gelenke. S.-A. des korr. Bl. d. allg. A.-V. von Tübingen 1888.

Riedel, Die Häufigkeit der Sequester bei der Tuberculose der grossen Gelenke, nebst Bemerkungen über die Behandlung der Gelenktuberculose. Centralbl. f. Chir. 1893. Heft 7 .

Rincheval, Leber operative Behandlung der Coxitis. Archiv für klinische Chirurgie. Bd. 50.

Sasse, Die conservative Behandlung der tuberculösen Coxitis und deren Resultate. Arch. f. kl. Chir. 1895.

Schmid-M onnard, Ueber den Zeitpunkt für Bestimmung endgültiger Resultate der Resection tuberculös erkrankter Gelenke. Centralbl. f. Chir. 1889. S. 945.

Schmidt, Friedrich, Leber den Verlauf der Hüftgelenkentzündung bei nicht operativer Behandlung. Inaug.-Diss. Erlangen.

Sendler, Therapeutische Bestrebungen auf dem Gebiete der Gelenktuberculose. Festschrift zur Feier des 50 jührigen Bestehens der med. Gesellschaft zu. Magdeburg 1898.

Sprengel, Zur operativen Nachbehandlung alter Hüftresectionen. Festschrift der Braunschweiger Aerzte zur 69. Vers. d. Naturf. u. Aerzte 1898.

Thal, Ein Beitrag zur Chirurgie der Hüft- und Kniegelenktubereulose. Inaug.Diss. Dorpat 1890.

Th a us ing, Endresultate der conservativen Therapie bei tuberculöser Hüftgelenkentzündung. Archiv f. klin. Chirurgie. Bd. 42.

Wagner, Ueber die Ausgänge der tuberculösen Coxitis bei conservativer Behandlung. Bruns' Beiträge. Bd. 13. 1895.

W ahlländer, Ueber die Verallgemeinernng der Tuberculose nach chirurgischen Eingriffen. Inaug.-Diss. Berlin 1893.

Wolff, Beiträge zur Resection der tuberculösen Gelenke. Deutsche Zeitschrift f. Chirurgie. Bd. 45 .

Nachtrag:

König, Die specielle Tuberculose der Knochen und Gelenke, Das Hüftgelenk. Berlin 1902. 